\title{
3 Martyrium: Sterben für Gott als Glaubenszeugnis
}

Als ,Sterben für Gott‘ in heidnischer Umgebung stellt das Martyrium nicht nur den Ursprung und das bleibende Leitbild christlicher Heiligkeit dar, sondern ebenso ein wesentliches Grundmodell der Aushandlung des religiösen Gegensatzes zum Heidentum. Denn der Heiligenkult entwickelt sich aus der spontanen Verehrung einzelner, die in heidnischer Umgebung für ihren christlichen Glauben den Tod erleiden. ${ }^{1}$ Dabei meint der Begriff $\mu \alpha ́$ ptus im Kontext des neuen Testaments noch ganz unspezifisch den ,Zeugen“ im Wort, der seinen Glauben an den auferstandenen Christus lebt und bekennt. Dafür nimmt er allerdings Leid und Verfolgung auf sich. Erst später, unter dem Eindruck der Christenverfolgungen des 2. und 3. Jahrhunderts, wird das Martyrium zum terminus technicus für das ,Blutzeugnis“, das bald als „Höchstform der Christusnachfolge“2 gilt, die im Moment des Todes mit der himmlischen Herrlichkeit belohnt wird, weshalb sich der Märtyrer in besonderem Maße für die Rolle des Fürsprechers vor Gott eignet.

Der Gedanke des Martyriums bestimmt aber die christlichen Vorstellungen und Modelle von Heiligkeit auch dann noch, als das konkrete Sterben für Gott so längst nicht mehr möglich ist. Schon vor dem Ende der Christenverfolgungen werden auch solche Glaubenszeugen verehrt, die ihren Glauben unter Todesdrohung bekennen, ohne dafür hingerichtet zu werden. Der Typus des Bekennerheiligen, lateinisch confessor, wird spätestens dann immer wichtiger, als mit der Etablierung des Christentums zur herrschenden und Mehrheitsreligion neue Leitbilder erforderlich werden, weil das tatsächliche Martyrium nun kaum noch zu erreichen ist und andererseits kein Grundproblem christlicher Existenz mehr darstellt: Die Lebenshingabe des Märtyrers wird abgelöst durch das heiligmäßige Leben des Bekenners als eines ,Märtyrers dem Willen nach'. ${ }^{3}$

Dazu kommt mit dem Asketen schließlich noch ein weiterer Heiligentypus, der ebenfalls schon vor der Konstantinischen Wende und zunächst vor allem in der Ostkirche breite Verehrung genießt, von dort aus aber auch im Westen weite Verbreitung findet und geeignet ist, den Gedanken des Martyriums noch weiter zu spiritualisieren, dergestalt, dass auch die asketische ,Abtötung` des Leibes als konsequente Chris-

1 Vgl. insgesamt zum Zusammenhang der Entwicklung des Märtyrerbegriffs mit den Anfängen der Heiligenverehrung und der Märtyrerliteratur Susanne Hausammann: Alte Kirche. Zur Geschichte und Theologie in den ersten vier Jahrhunderten, Bd. 2: Verfolgungs- und Wendezeit der Kirche. Gemeindeleben in der Zeit der Christenverfolgungen und Konstantinische Wende. Neukirchen-Vluyn 2001, Kap. 3, S. 19-58. Zur Entwicklung der Märtyrerlegende vgl. auch meinen Beitrag: Von der Märtyrerlegende zum kirchengeschichtlichen Exempel. Die Transformation legendarischen Erzählens im nachreformatorischen Meistergesang: In: Zeitschrift für deutsche Philologie 136, 1 (2017), S. 1-20, hier S. 4-6.

2 Vgl. Angenendt, Heilige und Reliquien, S. 36.

3 Vgl. ebd., S. 55.

Ә OpenAccess. ( 2021 Felix Prautzsch, publiziert von De Gruyter. (cc) BY Dieses Werk ist lizenziert unter der Creative Commons Attribution 4.0 International Lizenz. https://doi.org/10.1515/9783110664720-004 
tusnachfolge und höchste Stufe christlichen Lebens verstanden wird. ${ }^{4}$ Dieses ,unblutige Martyrium' der Askese steht aber mit dem tatsächlichen in einem engen Zusammenhang; gerade mit Blick auf die in der Legenda aurea überlieferten Märtyrerlegenden lässt sich vereinfacht formulieren: „Die Askese fungiert als Vorbereitung des Martyriums, das Martyrium wiederum als prolongierte Askese. ${ }^{* 5}$ Das aber ist nicht nur in einer zeitlichen Abfolge $\mathrm{zu}$ verstehen, denn inhaltlich gehen beide als Ausdrucksformen der imitatio Christi ineinander über, sodass die „rigoristische Askese als eine Form des Martyriums [...], andererseits das Martyrium als Spielart einer radikalen Askese" ${ }^{\text {66 }}$ erscheint.

Die Herausbildung und Entwicklung der verschiedenen Heiligkeitsmodelle ist daher insgesamt weniger als historische und hierarchisierende Linie einer Ablösung der Märtyrer durch Bekenner und Asketen, sowie später noch andere Rollenentwürfe wie die der heiligen Ordensgründer, Missionare und Herrscher, zu sehen. ${ }^{7}$ Sie stellt sich vielmehr als metaphorisierende Entfaltung des Begriffs und der Idee des Martyriums dar, die in unterschiedlichen Kontexten je verschiedene Konjekturen und Konkretisierungen erfahren. Das gilt gerade hinsichtlich der vielfältigen religiösen Praktiken der Askese und Buße in der mittelalterlichen Frömmigkeit oder, weit weniger breitenwirksam, in der Mission in heidnischen Gebieten, die die Möglichkeit des ,Blutzeugnisses' in Kauf nimmt oder als Weg zur Heiligkeit gar bewusst sucht. Von Anfang an stehen dabei verschiedene Konstruktionen des Martyriums nebeneinander.

Wenn trotz der neuen und sich diversifizierenden Heiligkeitsmodelle die Verehrung der frühchristlichen Märtyrer ungebrochen fortwirkt, dann mag sich das zumindest zum Teil auch ganz pragmatisch damit erklären lassen, dass sie im Gegensatz zu den klerikalen Heiligen des Mittelalters größtenteils Laien sind und daher den entsprechenden Ständen besondere Rezeptionspotentiale bieten mochten. ${ }^{8}$ Ihre anhaltende breite und intensive Wirkung erklärt sich aber wohl auch daraus, dass es sich bei den frühchristlichen Martyrien um so etwas wie die ,Gründungsmythen' der Kirche handelt, die ihre identitätsstiftende Wirkung weiterhin behalten oder gerade dann entfalten können, wenn die äußere Überwindung des Heidentums nur mehr erinnert und als immer wieder neu zu vollziehende conversio des Gläubigen zu Gott nach innen

\footnotetext{
4 Vgl. ebd.

5 Ulrich Ernst: Der Körper des Asketen. Zur Theatralik von ,Heiligkeit‘ in legendarischen Texten von der Spätantike bis zur Frühen Neuzeit. In: Körperinszenierungen in mittelalterlicher Literatur. Kolloquium am Zentrum für Interdisziplinäre Forschung der Universität Bielefeld (18. bis 20. März 1999). Hrsg. von Klaus Ridder. Berlin 2002 (Körper, Zeichen, Kultur. 11), S. 275-307, hier S. 293. Das Martyrium erweist sich dabei oftmals nicht bloß als passives Erleiden von Gewalt durch andere, sondern wird als „Fortsetzung der Askese mit anderen Mittel“ funktionalisiert und bewusst gesucht, vgl. ebd.

6 Ebd. S. 276.

7 Auch wenn die sich verändernde Situation des Christentums von der verfolgten Minderheit hin zur staatstragenden Kirche und kulturell maßgeblichen Institution fraglos andere funktionale Ansprüche an den Heiligenkult mit sich bringt.
}

8 Vgl. Dittmeyer, Gewalt und Heil, S. 48. 
gewendet und spiritualisiert werden kann. ${ }^{9}$ Denn als konkrete Vorbilder, ob hinsichtlich ihrer Heiligkeit oder der Form der Auseinandersetzung mit den Heiden, müssten sie in einer christlichen Mehrheitsgesellschaft ansonsten erst einmal funktionslos sein: Abgesehen von einigen Missionaren des frühen Mittelalters, die an den nördlichen und östlichen Grenzen der europäischen Christenheit den germanischen oder prußischen Heiden den christlichen Glauben predigen und dabei den Tod finden, ${ }^{10}$ gewinnt der Märtyrertod in der Verkündigung erst im 13. Jahrhundert wieder eine konkrete und breitere Bedeutung. Im Zuge der franziskanischen Neubelebung der Heidenmission außerhalb der Grenzen der christianitas, in islamischen Herrschaftsgebieten, wird das Martyrium auf neue Weise zu einer tatsächlichen Option christlicher Existenz in der Konfrontation mit dem Heidentum und damit zum Heiligkeitsmodell.

Da sich die mittelalterlichen Märtyrerlegenden in den frühchristlichen Märtyrerdiskurs einschreiben, wird es mir hier zunächst darum gehen, die Herausbildung der Idee des Martyriums im frühen Christentum darzustellen, und zwar in seiner zweifachen Dimension als Grundmodell christlicher Heiligkeit wie als Form der Aushandlung des religiösen Gegensatzes zum Heidentum. Schon die ersten christlichen ,Märtyrerakten' sind nicht als bloße Tatsachenberichte zu verstehen, sondern immer schon eine Deutung des Geschehens aus christlicher Sicht und damit eine Form narrativer Identitätsbildung, bei der der Tod unter heidnischer Verfolgung als ein Sterben für Gott zum Glaubenszeugnis erklärt wird. Das Martyrium lässt sich dabei als eine ,Praxis der Differenz ${ }^{111}$ beschreiben, die das religiös Eigene befördert, indem sie es in scharfem Kontrast zum religiös Fremden setzt. Gleichzeitig stellt es aber eine ,Praxis der Entdifferenzierung', weil der Märtyrer in seinem Sterben alle irdischen Kategorien überschreitet und die Menge der Gläubigen ebenso überragt wie die der Heiden. Das ,Zeugnis‘ des Märtyrers in Wort und Tat zielt dabei auch auf die Bekehrung der Heiden, und hierin liegt, zumindest in der christlichen Fiktion, die missionarische Wirkung des Martyriums, die wohl erst einmal eine apologetische oder kerygmatisch-erbauliche Funktion hat, das Märtyrertum andererseits immer wieder zum Modell für die Heidenmission macht.

Im zweiten Schritt werde ich daher untersuchen, wie die narrativen Muster des Martyriums in den mittelalterlichen Märtyrerlegenden tradiert werden und welche Rezeptionspotentiale sie dort entfalten, wo eine Verfolgungssituation nicht mehr gegeben ist und das Zeugnis des Märtyrers auf den christlichen Binnendiskurs zielt. Angesichts der zahlreichen im Mittelalter tradierten Märtyrerlegenden, wie sie dann auch in der Legenda aurea und dem Passional einen Großteil des Legendenbestandes

9 Vgl. dazu noch gesondert unten in Kap. 5.1 conversio - Religionswechsel und Bekehrung. 10 So Bonifatius ( 754 oder 755) oder Adalbert von Prag († 977) und Brun von Querfurt († 1009). 11 Begriff nach Hans Reinhard Seeliger: ,,Das Geheimnis der Einfachheit“. Bild und Rolle des Märtyrers in den Konflikten zwischen Christentum und römischer Staatsgewalt. In: Die Anfänge des Christentums. Hrsg. von Friedrich Wilhelm Graf, Klaus Wiegandt. Frankfurt 2009, S. 339-372, hier S. 360. 
ausmachen, ist mein Vorgehen notwendigerweise ein exemplarisches. Ich greife dabei zwei Beispiele für weibliches Märtyrertum heraus, das schon in der frühchristlichen Literatur eine charakteristische Zuspitzung des Märtyrerschemas über den Geschlechterdiskurs darstellte. ${ }^{12}$ Als eine der vier virgines capitales gehört Margareta zu den populärsten Heiligengestalten des lateinischen Mittelalters und wird als Helferin in Kindbettsnöten besonders von Frauen verehrt. Daher findet sich ihre Legende nicht nur in den großen Legendaren, sondern seit dem 12. Jahrhundert auch in eigenständigen volkssprachigen Versionen, die ich hier als spezifische Vermittlungsformen in den Blick nehme. ${ }^{13}$ Katharina, deren Verehrung sich im 13. Jahrhundert durch die Berührung der Kreuzfahrer und Pilger mit ihrem Grabeskult am Sinai intensiviert, zählt ebenfalls zu den vier ,vorzüglichen“ oder ,Hauptjungfrauen“ und gilt nach der Gottesmutter gar als die ranghöchste Heilige. Weil sie in einem Glaubensdisput die besten heidnischen Philosophen überwindet, gilt sie als Schutzheilige der Redner und findet an den Universitäten besondere Verehrung. ${ }^{14}$

Der heilige Franziskus (1181/82-1226) bietet demgegenüber das Beispiel einer historischen Figur des frühen 13. Jahrhunderts, die sich in ihrer spezifischen religiösen Lebensform in die narrativen Muster des Martyriums einschreibt und die damit selbst wieder zum konkreten Vorbild und verehrten Heiligen wird. ${ }^{15}$ In seiner Bedeutung für das kirchliche Selbstbild, die religiöse Praxis wie auch die ,volkstümliche‘ Frömmigkeit ist Franziskus eine der zentralen Heiligengestalten des lateinischen Hochmittelalters. Im Kontext der religiösen Auseinandersetzungen des mittelalterlichen Christentums mit dem Heidentum bietet sie ein religiöses Leitbild, das das Märtyrerideal als konkrete Option in der Mission aktualisiert und damit gegenüber seiner Spiritualisierung in der Askese wieder ,rekonkretisiert'. In den verschiedenen Bearbeitungen der Orientreise des Heiligen und seiner Predigt vor dem Sultan lässt sich dabei nachvollziehen, welche Potentiale der Zusammenhang von Heilszeugnis und Selbstheiligung, vom Wunsch des Heiligen nach Bekehrung der Heiden und seiner Sehnsucht nach dem Märtyrertod, mit Blick auf die Aushandlung des religiösen Gegensatzes wie die christliche Identitätsbildung entfaltet.

12 Vgl. Helen Rhee: Early Christian Literature. Christ and Culture in the Second and Third Centuries. London/New York 2005 (Routledge Early Church Monographs), S. 192.

13 Vgl. Werner Williams-Krapp: Art. Margareta von Antiochien. In: ${ }^{2}$ VL 5 (1985), Sp. 1239-1247, hier Sp. 1240.

14 Vgl. Peter Assion: Art. Katharina von Alexandrien. In: ${ }^{2}$ VL 4 (1983), Sp. 1055-1073, hier Sp. 1055; Ekkart Sauser: Art. Katharina von Alexandrien. In: BBKL 3 (1992), Sp. 1213-1217; Hans Reinhard Seeliger: Art. Katharina von Alexandrien. In: ${ }^{3}$ LThK 5 (1996), Sp. 1330 -1331. Beide Märtyrerinnen gehören schließlich zu den vierzehn Nothelfern, deren feste Reihung sich allerdings erst im 14. Jahrhundert herausbildet.

15 Wie Tolan, Saint Francis and the Sultan 2009, S. 62, mit Bezug auf Jacques Le Goff: Saint Louis. Paris 1996 bemerkt, lesen die Heiligen selbst Hagiographie und nutzen sie als Inspiration: „When their biographers use these topoi to describe their deeds, is this because they wish to attribute to them words and deeds considered obligatory in a work of hagiography? Or do the future saints themselves model their words and behaviour on the lives of their saintly predecessors?“ 


\section{1 martyrium - passives Leiden und aktives Glaubenszeugnis}

\subsubsection{Die Herausbildung des christlichen Märtyrerbegriffs}

Im Kontext des Neuen Testaments bezeichnen der Begriff $\mu$ óptuৎ und die gesamte davon abgeleitete Terminologie das Glaubenszeugnis im Wort. Ein „charakteristisches Merkmal der christlichen Botschaft“ liegt dabei darin, „daß sowohl die Verkündigung Jesu wie die Predigt der an ihn Glaubenden Zeugnis genannt wird“. ${ }^{16}$ Besonders die Apostel als Zeugen der Verkündigung Christi sowie seiner Auferstehung sind dazu berufen, den Glauben in der ganzen Welt zu bezeugen. Wenn dabei das Erleiden von Verfolgung oder gar das Sterben für den Glauben noch nicht mit dem Begriff des Martyriums bezeichnet werden, so heißt das gleichwohl nicht, dass diese Phänomene unbekannt gewesen wären.

In der jüdischen Tradition finden sich Vorläufer dafür vor allem in den ersten beiden Makkabäerbüchern, die auf unterschiedliche Weise den Unabhängigkeitskampf der Juden gegen die Fremdherrschaft der Seleukiden (167-142 v. Chr.) schildern: Das Erste Buch der Makkabäer berichtet vom Tod zahlreicher Juden, die angesichts des gewaltsamen Versuchs einer kulturellen Einigung des Seleukidenreiches im griechischen Kult lieber in den Tod gehen als ihre religiöse Identität preiszugeben, was zu harter Verfolgung und schließlich zum Aufstand führt. Das Zweite Buch der Makkabäer hingegen erzählt vom greisen Schriftgelehrten Eleasar (2 Makk 6, 18-31) und einer Mutter mit sieben Söhnen (2 Makk 7), die allesamt einen grausamen Tod erleiden, weil sie es ablehnen Schweinefleisch zu essen und sich dem heidnischen Gesetz $\mathrm{zu}$ beugen. Das Motiv eines Sterbens für den Glauben bestimmte daher auch die Wahrnehmung und Darstellung der Verfolgung Christi und seiner Jünger:

Zur Zeit Jesu war das Faktum des Martyriums und dessen literarische Ausgestaltung in Palästina präsent und virulent, zumal es die Vorstellung gab, alle Propheten Israels seien eines gewaltsamen Todes gestorben. Jesus selbst konnte Ablehnung als Prophetengeschick verstehen; zumindest haben so frühe Anhänger den Tod Jesu und eigene Verfolgungserfahrungen interpretiert. $^{17}$

Ein spezifisch christliches Märtyrertum in der Nachfolge Christi erzählt in der zweiten Hälfte des 1. Jahrhunderts die Apostelgeschichte, auch wenn sich die entsprechende Terminologie dort noch nicht findet: Stephanus, Diakon der Jerusalemer Urgemeinde, vollbringt mit göttlicher Kraft prodigia et signa magna in populo (Apg 6, 8) ${ }^{18}$ und als einige der Juden im Streit, wie es heißt, seiner sapientiae et Spiritui qui loquebatur

16 Norbert Brox: Zeuge und Märtyrer. Untersuchungen zur frühchristlichen Zeugnis-Terminologie. München 1961 (Studien zum Alten und Neuen Testament. 5), S. 106.

17 Theofried Baumeister: Märtyrer und Martyriumsverständnis im frühen Christentum. Ursprünge eines geschichtsmächtigen Leitbildes. In: Wissenschaft und Weisheit 67 (2004), S. 179-190, hier S. 186. 18 „Stephanus aber, voll Gnade und Kraft, tat Wunder und große Zeichen unter dem Volk.“ 
(Apg 6, 10) ${ }^{19}$ nichts entgegensetzen können, bezichtigen sie ihn gegen Mose und Gott gelästert zu haben. Seiner göttlichen Begnadung, die auch äußerlich sichtbar wird, wenn die im Hohen Rat Versammelten viderunt faciem eius tamquam faciem angeli (Apg 6, 15), ${ }^{20}$ steht dabei die ungerechtfertigte und boshafte Anklage der ,Ungläubigen“ gegenüber. Diese hetzen das Volk, die Ältesten und die Schriftgelehrten gegen ihn auf, doch hält Stephanus vor dem Rat eine Rede, in denen er seinen Anklägern ihren eignen Unglauben vorhält, in dem sie sich wie ihre Väter dem Heiligen Geist verschlössen. Das steigert die Wut der Juden: audientes autem haec dissecabantur cordibus suis, et stridebant dentibus in eum (Apg 7, 54), ${ }^{21}$ doch erweist sich gerade in diesem Moment die Erwählung des Stephanus, der den Himmel über sich offen sieht und dort Gott erblickt: cum autem esset plenus Spiritu Sancto, intendens in cælum vidit gloriam Dei, et Iesum stantem a dextris Dei (Apg 7, 55). ${ }^{22}$ Die Gottesunmittelbarkeit wird aber nicht nur vom Erzähler postuliert, sondern auf der Figurenebene inszeniert als Vision, angesichts derer Stephanus ruft: ecce video caelos apertos, et Filium hominis stantem a dextris Dei (Apg 7, 56). ${ }^{23}$ Das setzt sich fort in der Hinrichtungsszene, wenn er sich Gott anbefiehlt und ihn um Vergebung für seine Verfolger bittet, während er gesteinigt wird: et lapidabant Stephanum invocantem et dicentem, Domine Iesu suscipe spiritum meum, positis autem genibus clamavit voce magna, Domine ne statuas illis hoc peccatum, et cum hoc dixisset obdormivit (Apg 7, 58-59). ${ }^{24}$

Als ,Erzmärtyrer' gibt Stephanus damit das Modell eines christlichen Sterbens für Gott, dem auch die Apostel folgen, die bald allesamt als Märtyrer gelten, wenngleich die Apostelgeschichte nur bei einigen von ihnen von einem gewaltsamen Tod zu berichten weiß. Zeitgleich mit den ersten Märtyrerberichten entstehen ab der Mitte des 2. Jahrhunderts die apokryphen Apostelakten, die von den Missionsreisen, den Wundertaten und der Verkündigung sowie schließlich der Verfolgung und dem Märtyrertod der fünf wichtigsten Apostel (Andreas, Johannes, Paulus, Petrus, Thomas) erzählen. $^{25}$

Angesichts der heidnischen Ablehnung der Glaubenszeugen und unter dem Eindruck der Christenverfolgung der ersten Jahrhunderte erfährt das Martyrium also

19 „Doch sie vermochten nicht zu widerstehen der Weisheit und dem Geist, in dem er redete.“

20 „Und alle, die im Rat saßen, blickten auf ihn und sahen sein Angesicht wie eines Engels Angesicht."

21 „Als sie das hörten, ging’s ihnen durchs Herz und sie knirschten mit den Zähnen über ihn.“

22 „Er aber, voll Heiligen Geistes, sah auf zum Himmel und sah die Herrlichkeit Gottes und Jesus stehen zur Rechten Gottes.“

23 „Siehe, ich sehe den Himmel offen und den Menschensohn zur Rechten Gottes stehen.“

24 ,[U]nd sie steinigten Stephanus; der rief den Herrn an und sprach: Herr Jesus, nimm meinen Geist auf! Er fiel auf die Knie und schrie laut: Herr, rechne ihnen diese Sünde nicht an! Und als er das gesagt hatte, verschied er.“

25 Zur liturgischen Verehrung der Apostel als Märtyrer vgl. Els Rose: From Eyewitnesses to Blood Witnesses. The Cult of the Apostles in the Early Medieval West. In: Vom Blutzeugen zum Glaubenszeugen? Formen und Vorstellungen des christlichen Martyriums im Wandel. Hrsg. von Gordon Blennemann, Klaus Herbers. Stuttgart 2014 (Beiträge zur Hagiographie. 14), S. 57-70. 
seine feste Prägung als Leiden von Verfolgung und Sterben für den Glauben. Die Entwicklung des narrativen Musters in der Märtyrerliteratur geht dabei einher mit der Herausbildung einer Theologie des Martyriums: Das Martyrium des Glaubenszeugen wird mit dem Leiden und Tod Christi parallelisiert und als Höchstform der imitatio Christi stilisiert, es meint also nicht nur ein Sterben für, sondern wie Christus. ${ }^{26} \mathrm{Im}$ Tod erreicht der Märtyrer seine Vollendung und die volle Gemeinschaft mit Gott, das Sterben für den Glauben in der Nachfolge Christi wird zur höchsten Form der Lebensheiligung.

Die Forschung hat immer wieder versucht, in den frühchristlichen Schriften eine „allmähliche Bedeutungsverschiebung der Zeugnisterminologie in Richtung auf ihre martyrologische Verwendung im Sinn des terminus technicus Märtyrer“27 zu belegen. Es lässt sich aber unterscheiden zwischen

einerseits dem Motivzusammenhang eines Wortzeugnisses in gefährlicher Situation bis hin zu einem gewaltsamen Tod sowie eines gelegentlichen Tatzeugnisses durch Leiden und andererseits der direkten Benennung des Sterbens durch Termini des Zeugnisses. ${ }^{28}$

Die christliche Vorstellung des Martyriums erklärt sich folglich nicht aus einem semantischen Wandel vom Wortzeugnis zum Tatzeugnis, sondern aus der Deutung des in der Ablehnung und Verfolgung erlittenen Todes als eine Form des Glaubenszeugnisses, das die Mitte der christlichen Botschaft ausmacht:

Die ursprüngliche Bedeutung des Titels mártys wäre demnach, dass der standhafte Christ im extremen Konfliktfall sein mündliches Bekenntnis auf der Ebene der Taten, also aktiv verwirklicht, so dass der erlittene Tod selbst zum Zeugnis wird, auch wenn es von Außenstehenden nicht verstanden wird. Im Titel mártys und in der martyrologischen Zeugnisbegrifflichkeit insgesamt drückt sich also konzentriert die christliche Uminterpretation und Sinngebung eines grausamen Geschehens aus, in die natürlich auch die Thematisierung von Gnade und Erlösung gehört. ${ }^{29}$

Dieser martyrologische Gebrauch der Zeugnisterminologie findet sich zuerst überliefert im Martyrium des Polykarp, das bald nach dem Tod des Bischofs von Smyrna im Jahr 155 oder 156 entstanden ist. Dieser erste außerbiblische Märtyrerbericht macht das Martyrium „zum Thema einer eigenen Schrift [...], die den Anfang einer sehr bald verbreiteten und ausgebildeten Literaturgattung im Christentum darstellt“. ${ }^{30}$ Die technische Verwendung des Märtyrerbegriffs erscheint hier bereits voll entwickelt:

26 Vgl. Maarten Taveirne: Das Martyrium als imitatio Christi. Die literarische Gestaltung der spätantiken Märtyrerakten und -passionen nach der Passion Christi. In: Zeitschrift für antikes Christentum 18 (2014), S. 167-203, hier S. 169.

27 Baumeister, Märtyrer und Martyriumsverständnis im frühen Christentum, S. 181.

28 Ebd., S. 182.

29 Ebd., S. 182-183. Vgl. ausführlicher dazu in Baumeisters umfassender Darstellung, die den Überlegungen seiner Aufsätze zugrundeliegt: Die Anfänge der Theologie des Martyriums. Münster 1980 (Münsterische Beiträge zur Theologie des Martyriums. 45).

30 Brox, Zeuge und Märtyrer, S. 227. 


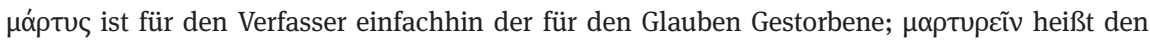
Märtyrertod erleiden, und $\mu \alpha \rho \tau$ тí $\alpha$ beziehungsweise $\mu \alpha \rho$ túpıov ist das Martyrium, das heißt der Vorgang des Leidens und Sterbens, das um des Festhaltens am Glauben willen ertragen wird. ${ }^{31}$

Dass diese Terminologie in ihrer Verwendung keine Erklärung erfährt, lässt darauf schließen, dass der Autor sie als schon geläufig voraussetzen kann. ${ }^{32}$ Gleichzeitig ist das Martyrium des Polykarp das erste schriftliche Zeugnis für den christlichen Märtyrerkult, denn es heißt, die Gemeinde von Smyrna versammele sich am Tag seines Totengedächtnisses „in Jubel und Freude“ am Grab Polykarps und zwar „zum Gedächtnis derer, die zuvor den Kampf bestanden haben, und zur Übung und Vorbereitung für die, denen dies bevorsteht“ (MartPol 18, 3). Die Märtyrerverehrung ist demnach nicht als eine Steigerung des allgemein üblichen rituellen Totengedenkens und Fortsetzung des griechischen Heroenkultes zu verstehen, ${ }^{33}$ sondern als spezifisch christliche Prägung.

Im Martyrium des Polykarp zeigt sich also insgesamt der enge Zusammenhang der Entstehung des Märtyrerkultes mit der Herausbildung einer Theologie des Martyriums sowie der entsprechenden literarischen Darstellung von Martyrien. Schon die Briefform lässt dabei auf ein „Rezeptionsinteresse mit paränetisch-kerygmatischer Intention“ ${ }^{34}$ schließen und macht damit deutlich, dass es sich nicht um einen bloßen Bericht handelt, sondern um eine Deutung des Geschehens mit dem Anspruch auf Vorbildlichkeit und lehrhafte Unterweisung. Dieser Funktionszusammenhang wird schon im Eingang entworfen, wenn sich die christliche Gemeinde von Smyrna an diejenige von Philomelion wendet, aber auch an alle anderen „Gemeinden der heiligen und katholischen Kirche an jedem Ort“ (MartPol, Präskript a). Der Tod ihres Bischofs Polykarp ist dabei Anlass und Exempel für das eigentliche Briefthema, nämlich die Nachahmung Christi und das geduldige Leiden in der Verfolgung gemäß dem Evangelium und zum Wohl und Heil der Nächsten:

Wir haben euch aufgeschrieben, Brüder, das, was sich mit den Märtyrern und dem seligen Polykarp zugetragen hat, der, indem er ihr durch sein Zeugnis gleichsam ein Siegel aufgedrückt hat, der Verfolgung ein Ende gesetzt hat. Denn fast alles, was vorging, geschah, damit der Herr uns von oben das dem Evangelium gemäße Martyrium zeige. Denn er wartete, um ausgeliefert zu werden, wie auch der Herr, damit auch wir seine Nachahmer würden, indem wir nicht nur unser eigenes Geschick, sondern auch das der Nächsten im Auge haben. Denn es ist das Wesen wahrer und

31 Ebd.

32 Theofried Baumeister: Genese und Entfaltung der altkirchlichen Theologie des Martyriums. Bern 1991 (Traditio christiana. 8), S. 75, Anm. 2.

33 Vgl. Theofried Baumeister: Die Entstehung der Heiligenverehrung in der Alten Kirche. In: Ders: Martyrium, Hagiographie und Heiligenverehrung im Christlichen Altertum. Rom 2009 (Römische Quartalschrift für christliche Altertumskunde und Kirchengeschichte. Supplementband. 61), S. 233-250; ebenso Ders: Die Entstehung der Märtyrerverehrung. In: Ebd., S. 260-268.

34 Das Martyrium des Polykarp. Übersetzt und erklärt von Gerd Buschmann. Göttingen 1998 (Kommentar zu den Apostolischen Vätern. 6), S. 68. 
starker Liebe, nicht nur sich selbst retten zu wollen, sondern auch alle seine Brüder. (MartPol 1, $1-2)$

Offenkundig geht es dabei um eine Normierung des Martyriums, die auf die christliche Gemeinschaft bezogen ist. Entsprechend widmet sich der erste Teil des Briefes zunächst allgemein dem „Vorbild der edlen Märtyrer Christi““35 unter dem verheißenden wie normativen Leitspruch: „Selig und edelmütig also sind alle Martyrien, die gemäß dem Willen Gottes geschehen sind.“ (MartPol 2, 1 a) Erstmals ist dabei von Märtyrern

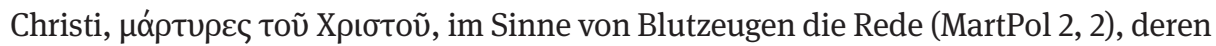
motivischer Kern die Standhaftigkeit im Sterben für den Glauben ist, die mit dem ewigen Leben belohnt wird, das alle irdischen Qualen nichtig erscheinen lässt: „Sie richteten ihren Sinn auf die Gnade Christi und verachteten die irdischen Foltern: während einer einzigen Stunde erkauften sie das ewige Leben. Kalt waren ihnen das Feuer der entmenschten Folterknechte.“ (MartPol 2, 3 a)

Worin dabei das dem Willen Gottes und dem Evangelium Gemäße besteht, wird aber vor allem im Exempel zweier Nebenfiguren deutlich: ${ }^{36}$ Germanikos lässt sich durch die Überredungsversuche des heidnischen Prokonsuls nicht von seinem Bekenntnis als Christ abbringen, wird ad bestias verurteilt, zieht in der Arena das wilde Tier zu sich heran um schneller zu sterben und gilt damit als Vorbild an Standhaftigkeit und Bekennermut (MartPol 3). Seine Gegenfigur ist der Phrygier Quintos, der sein Martyrium durch Selbstanzeige als Christ provoziert und auch andere Christen dazu verleitet, angesichts der wilden Tiere aber in Angst gerät und dem Zureden des Prokonsuls nachgibt und das heidnisches Opfer leistet (MartPol 4).

In diesen beiden Exempelfiguren wird ein Problem verhandelt, das sich schon an die Worte von der Selbstverleugnung und Nachfolge bis in den Tod anschließt, die Christus im Evangelium selbst zu seinen Jüngern spricht: qui enim voluerit animam suam salvam facere perdet eam, qui autem perdiderit animam suam propter me inveniet eam (Mt 16, 25). ${ }^{37}$ Denn auch wenn der Akzent in den neutestamentlichen Schriften insgesamt auf dem freudigen Leiden und nicht auf dem Sterben für Gott liegt, „lassen diese Texte die Frage offen, ob die Imitatio-Motivation zur Bereitschaft, möglicherweise gar zu mehr, zum Nacheifern des Märtyrertums einlädt“, oder ob im Gegenteil letztere Haltung gerade problematisiert werden soll. ${ }^{38}$ Angesichts der anzunehmen-

35 So die thematische Überschrift bei Buschmann, vgl. ebd.

36 Vgl. die Inhaltszusammenfassung bei Theofried Baumeister: Der Rekurs auf die Bibel als Mittel zur Darstellung heiliger Geschichte. In: Ders: Martyrium, Hagiographie und Heiligenverehrung im Christlichen Altertum. Rom 2009 (Römische Quartalschrift für christliche Altertumskunde und Kirchengeschichte. Supplementband. 61), S. 217-230, hier S. 219.

37 „Denn wer sein Leben erhalten will, der wird's verlieren; wer aber sein Leben verliert um meinetwillen, der wird's finden.“

38 Boudewijn Dehandschutter: Leben und/oder Sterben für Gott bei Ignatius und Polykarp. In: Martyriumsvorstellungen in Antike und Mittelalter. Leben oder sterben für Gott? Hrsg. von dems. Leiden [u. a.] 2012 (Arbeiten zur Geschichte des antiken Judentums und des Urchristentums. 80), S. 191-202, hier S. 195. 
den Abfassungszeit der Evangelien zwischen 70 und 120 ist davon auszugehen, dass sie dem „Verhältnis von Nachfolge und Martyrium [...] nicht nur in proskriptiver, sondern auch in deskriptiver Weise begegnen“ und „auf narrativem Wege Strategien der Bewältigung von Verfolgung und damit von Besitz-, Status- und Lebensverlust“ anbieten. ${ }^{39}$ Unter dem Eindruck der Parusieverzögerung mag der Gedanke der Nachfolge bis in den Tod dann an Schärfe verlieren, sodass sich der pragmatische Gehalt der Evangelien insgesamt nicht auf eine Aufforderung zum Sterben für und wie Christus engführen lässt. ${ }^{40}$ Letztlich bleiben aber beide Lesarten möglich und auch in der frühchristlichen Praxis dürften die Bereitschaft zum oder das Verlangen nach dem Martyrium wohl immer wieder dicht beieinandergelegen haben.

In diesem Spannungsfeld verhandelt das Martyrium des Polykarp das Problem des Drängens zum Martyrium, das als die christliche Gemeinde gefährdender Heilsegoismus und Versuchung Gottes abgelehnt wird. Denn niemand kann sich sicher sein, ob er in den Martern standhalten und damit das Heil gewinnen wird, das auch dem Märtyrer letztlich nur im unverfügbaren Gnadenhandeln Gottes zuteilwird. Das Martyrium ist folglich als von Gott bestimmtes Geschick anzunehmen, wo es unausweichlich wird, aber nicht zu suchen, ganz so wie es sich im Vorbild Polykarps verkörpert findet, der wartet und ausweicht, bis er der Verfolgung nicht mehr entgehen kann: „Die Evangeliumsthematik dient einmal der Apologie des Polykarp, zum anderen ist sie antienthusiastische Normierung eines vorsichtig-mutigen Martyriumsverhaltens, für das verbindlich geworben wird.“41

Auf dieser Grundlage schildert der zweite und längere Teil des Briefs ausführlich „Polykarps evangeliumsgemäßes Martyrium““42: Zweimal entzieht sich der greise Bischof auf Drängen seiner Gemeinde durch Flucht der Festnahme, beim dritten Mal aber lehnt er diese Möglichkeit ab, damit Gottes Wille an ihm geschehe, denn eine Vision hatte ihm offenbart, dass er lebendig verbrannt werden müsse. Sanftmütig und gastfreundlich empfängt er seine Häscher, die ihm auf dem Weg zum Gericht zureden, den Kaiser als Herrn anzuerkennen und zu opfern, um sich zu retten (MartPol 8, 1-3). Doch widersteht Polykarp dieser Versuchung und wird darin durch eine wunderbare Himmelstimme bestärkt, die auch seine Glaubensgeschwister vernehmen: „Als aber Polykarp in das Stadion hineinging, ertönte eine Stimme aus dem Himmel: ,Sei mutig, Polykarp, und tapfer wie ein Mann!‘ Niemand sah zwar den Redenden, die Stimme

39 Sebastian Fuhrmann: Leben verlieren und Leben finden. Nachfolge und Martyrium in den Evangelien. In: Martyriumsvorstellungen in Antike und Mittelalter. Leben oder sterben für Gott? Hrsg. von dems. Leiden [u. a.] 2012 (Arbeiten zur Geschichte des antiken Judentums und des Urchristentums. 80), S. $167-189$, hier S. 167.

40 Vgl. ebd., S. $183-184$.

41 Theofried Baumeister: Die Norm des evangeliumgemäßen Blutzeugnisses. Das Martyrium Polycarpi als vorsichtige Exhortatio ad Martyrium. In: Stimuli. Exegese und ihre Hermeneutik in Antike und Christentum. Festschrift für Ernst Dassmann. Hrsg. von Georg Schölligen, Clemens Scholten. Münster 1996 (Jahrbuch für Antike und Christentum. Ergänzungsband. 23), S. 122-128, hier S. 128.

42 So wiederum die thematische Überschrift bei Buschmann, Das Martyrium des Polykarp 1998. 
jedoch hörten diejenigen von den Unsrigen, die anwesend waren.“ (MartPol 9, $1 \mathrm{a}-\mathrm{b}$ ) Der Prokonsul, der ihn verhört, versucht ihn mit dem Hinweis auf sein hohes Alter zu überreden, seinen Glauben zu verleugnen und Christus zu verfluchen, er aber weist das gerade mit Blick auf sein Alter rhetorisch geschickt ab: „,Sechsundachtzig Jahre diene ich ihm, und er hat mir kein Unrecht zugefügt; wie kann ich da meinen König verfluchen, der mich gerettet hat?،“ (MartPol 9, 3 b)

Der zweiten Aufforderung des heidnischen Statthalters, das Kaiseropfer zu leisten, hält Polykarp das formelhafte Bekenntnis als Christ und zum Namen Christi entgegen, das im Rahmen des heidnischen Gerichtsverfahrens sein Todesurteil bedeutet: „Wenn du der trügerischen Meinung bist, daß ich schwöre beim Glück des Kaisers, wie du sagst, dann tust du so, als wüßtest du nicht, wer ich bin; höre mein freimütiges Bekenntnis: Ich bin ein Christ.“ (MartPol 10, 1 b) Die konfrontative Zuspitzung des Verhörs ist zugleich eine Herausforderung des aus christlicher Sicht heidnischen Unglaubens. So verknüpft Polykarp sein Bekenntnis mit dem Appell: „,Wenn du aber die Sache des Christentums kennenlernen willst, so gib mir einen Tag und höre zu. ““ (MartPol 10,1 b) Die Aufforderung des Prokonsuls, er möge statt seiner das Volk überzeugen, wehrt Polykarp hingegen mit der Erklärung ab:

,Dich zwar habe ich einer Erklärung für würdig gehalten; denn man hat uns gelehrt, den von Gott eingesetzten Obrigkeiten und Gewalten die angemessene Ehre zu erweisen, wenn sie uns nicht schädigt. Jene aber halte ich nicht für wert, mich ihnen gegenüber zu verteidigen. ' (MartPol 10, 2 b)

In dieser Nuancierung wird auch der eigentliche Anlass für das christliche Martyrium deutlich: Das Kaiseropfer ist zwar wie der heidnische Polytheismus insgesamt eine Frage äußerlicher Kulterfüllung, verbindet aber als Staatskult den religiösen Bereich untrennbar mit den öffentlichen Interessen des römischen Gemeinwesens, das in der Ausdehnung des Reiches darin seine Einheit und Identität stiftende Mitte sucht. Seine Ablehnung muss aus dieser Sicht als töricht und gefährlich zugleich erscheinen, weil es den Frieden mit den Göttern und damit das gesellschaftliche Wohl gefährdet. Der exklusive und alle Lebensbereiche umfassende Anspruch des christlichen Monotheismus aber lässt keine andere Option zu, wenn es um die Frage religiöser Autorität geht. Das meint allerdings nicht die Ablehnung des Kaisers und des römischen Staates als solchen, sondern nur insofern ersterer eine Verehrung beansprucht, die nur Gott zukommen kann. Den Maßstab dafür gibt die Formel reddite ergo quae sunt Caesaris Caesari, et quae Dei sunt Deo (Lk 20, 25). ${ }^{43}$ Der äußere Anlass für die staatliche Verfolgung ist denn auch nicht der christliche Glaube an sich, sondern die Ablehnung des Kaiseropfers. In den christlichen Märtyrerberichten wird sie zum Fanal einer religiösen Konfrontation auf Leben und Tod, die eine endgültige Scheidung von Glaube und Unglaube, aber eben auch die von Heiligkeit und allen weltlichen Ansprüchen bedeutet.

43 „So gebt dem Kaiser, was des Kaisers ist, und Gott, was Gottes ist!“ 
Diese Konfrontation auf eine finale Scheidung hin gestaltet das Martyrium des Polykarp dramatisch aus: Angesichts der Erfolglosigkeit seines Mahnens bleibt dem Prokonsul nur die blanke Drohung mit den wilden Tieren und schließlich mit dem Feuertod. Doch Polykarp lässt sich davon nicht beeindrucken, wendet die Drohungen vielmehr gegen den heidnischen Verfolger selbst, indem er ihm die ewigen Qualen vor Augen stellt, die alle irdischen Strafen übersteigen und entwerten: „,Du drohst mit einem Feuer, das nur eine Stunde brennt und nach kurzem erlischt; denn du kennst nicht das Feuer des zukünftigen Gerichtes und der ewigen Strafe, das für die Gottlosen aufbewahrt ist. Aber warum zögerst du? Hole herbei, was du willst!““ (MartPol 11, 2 b) Der Glaubensmut des Bischofs steht dabei in anschaulichem Kontrast zur Verwunderung und dem Entsetzen des heidnischen Statthalters:

Während er dieses und anderes mehr sagte, wurde er voll Mut und Freude und sein Angesicht war erfüllt von Gnade, so daß er nicht nur nicht die Fassung verlor, eingeschüchtert von dem gegen ihn Gesagten, sondern im Gegenteil der Prokonsul außer sich geriet, seinen Herold in die Mitte des Stadions schickte und verkünden ließ: ,Polykarp hat sich dreimal als Christ bekannt.” (MartPol 12, $1 \mathrm{a}-\mathrm{b})$

Der Angeklagte geht als der eigentliche Sieger aus dem öffentlichen Tribunal hervor, während sein Ankläger und Versucher angesichts der todesverachtenden Unbeirrbarkeit des vermeintlich Unterlegenen seine Sicherheit verliert. Als die Menge der anwesenden Heiden und Juden „mit unbändiger Wut und lauter Stimme“ (MartPol 12, 2-3) den Tod des Christen durch Verbrennen bei lebendigem Leibe fordert, legt dieser bereitwillig seine Oberkleider ab und lehnt es heldenhaft ab, sich annageln $\mathrm{zu}$ lassen: „,Laßt mich so; denn der, der mir die Kraft gibt, das Feuer zu ertragen, wird mir auch die Kraft geben, ohne eure Sicherheit auf Grund der Nägel unbeweglich auf dem Scheiterhaufen auszuharren. “ (MartPol 13, 3 b) Mit der Thematisierung der Nägel wird Polykarps Tod auf dem Scheiterhaufen mit dem Kreuzestod Christi parallelisiert, wobei die Differenz zwischen Christus und seinem Märtyrer gewahrt bleibt, wenn letzterer schließlich ,nur“ festgebunden wird; andererseits wird damit sein heroisches Leiden herausgestellt, das er mit Gottes Beistand besteht. ${ }^{44}$

Die sakramentale, das Heil vergegenwärtigende und heilsvermittelnde Dimension des Sterbens für Gott unterstreicht das mit liturgischen Anspielungen auf die Eucharistie durchsetzte Gebet des Heiligen auf dem Scheiterhaufen, wenn er sich an Gott wendet mit den Worten: „,[I]ch dankopfere dir, daß du mich dieses Tages und dieser Stunde gewürdigt hast, teilzunehmen in der Zahl der Märtyrer an dem Kelch deines Christus zur Auferstehung ins ewige Leben von Seele und Leib Unvergänglichkeit heiligen Geistes“ (MartPol 14, 2 a). Wie schon in der Erzählung vom Martyrium des Stephanus ist sich auch hier der Glaubenszeuge im Moment seiner Hinrichtung seiner Gottesunmittelbarkeit gewiss. Die Verbrennung, die doch eigentlich zur vollständigen physischen Vernichtung Polykarps führen soll, gerät denn auch zum zumindest für die 
umstehenden Gläubigen sinnlich erfahrbaren Wunder, das die heidnische Ermächtigung eindrucksvoll konterkariert:

Denn das Feuer nahm die Form einer Wölbung an, wie ein vom Wind aufgeblähtes Schiffssegel, und umhüllte ringsherum (schützend) den Leib des Märtyrers. Er befand sich mittendrin, nicht wie Fleisch, das brät, sondern wie Brot, das gebacken wird, oder wie Gold und Silber, das im Schmelzofen gereinigt wird. Auch empfanden wir einen solchen Wohlgeruch wie von duftendem Weihrauch oder von irgendeinem anderen der kostbaren Rauchwerke. (MartPol 15, 2 a-c)

Als es nicht gelingt, seinen Leib zu verbrennen, fordert die Menge schließlich, er solle mit dem Dolch getötet werden, doch auch diese letztlich erfolgreiche Form der Hinrichtung wird zum allen wahrnehmbaren Zeichen der Heiligkeit Polykarps und der grundlegenden Scheidung von Heidentum und Christentum: „Und als er [= der Vollstrecker, F.P.] dies tat, kam eine solche Menge Blut hervor, daß das Feuer verlosch und die ganze Menge sich verwunderte, welch ein Unterschied zwischen den Ungläubigen und den Auserwählten besteht.“ (MartPol 16, 1 b)

Trotz dieser sakramentalen Überhöhung des exemplarischen Sterbens Polykarps zum sichtbaren Zeichen göttlichen Wirkens in seinem Heiligen besteht der Anspruch des Briefes aber nicht darin, ein bloßes admirabile zu geben, das aus der Entfernung des einfachen Gläubigen nur andächtig verehrt werden kann. Vielmehr soll er offenbar kerygmatisch-erbaulich „ein theologisch begründetes Vorbild zur Nachahmung schaffen“ ${ }^{45}$, wenn es im auf den Tod des Heiligen folgenden Abschnitt heißt: „,[D]ie Märtyrer aber lieben wird in angemessener Weise als Jünger und Nachahmer des Herrn wegen der unüberbietbaren Zuneigung zu ihrem König und Lehrer; wenn doch auch wir deren Teilhaber und Mitjünger würden!“ (MartPol 17, 3) So wie Christus das Vorbild des Märtyrers ist, soll dieser in einer Traditionskette der Nachahmung wiederum zum Vorbild für die Christen werden. ${ }^{46}$ Die liturgische Formel des Briefschlusses betont dann noch einmal die Vorbildhaftigkeit Polykarps in seinem evangeliumsgemäßen Martyrium als Sieg über den heidnischen Unglauben und verbindet dabei das Motiv des Sterbens für Gott als Form der Lebensheiligung mit dem des Glaubenszeugnisses, dessen zeichenhafte Funktion identitätsstiftend nach innen gerichtet ist, zur Erbauung der Kirche:

Durch seine Standhaftigkeit besiegte er den ungerechten Herrscher und empfing so den Kranz der Unsterblichkeit; zusammen mit den Aposteln und allen Gerechten verherrlicht er voller Jubel Gott, den Vater, den Allmächtigen, und preist unseren Herrn Jesus Christus, den Retter unserer Seelen und den Lenker unserer Körper, den Hirten der katholischen Kirche auf dem ganzen Erdkreis. (MartPol 19, 2 a-b)

45 Gerd Buschmann: Martyrium Polycarpi. Eine formkritische Studie. Ein Beitrag zur Frage nach der Entstehung der Gattung Märtyrerakte. Berlin und New York 1994 (Beihefte zur Zeitschrift für die neutestamentliche Wissenschaft und die Kunde der älteren Kirche. 70), S. 322.

46 Vgl. ebd., S. 324 


\subsubsection{Das Martyrium als Praxis der Differenz}

Im narrativen Muster des Martyriums werden zwei entgegengesetzte Machtansprüche miteinander konfrontiert; entweder den Kaiser gottgleich zu verehren und die heidnischen Götter anzuerkennen - oder dies im Namen des christlichen Glaubens zurückzuweisen und dafür den Tod zu erleiden. Auf kategoriale Weise scheiden sich im öffentlichen Bekenntnis des Märtyrers und seinem Eintreten dafür bis in den Tod wahr und falsch, Glaube und Unglaube, Heil und Verdammnis. Insofern ist das Martyrium mehr als ein passives Erleiden von Verfolgung, vielmehr hat es zugleich den Charakter einer aktiven Konfrontation, die das Offenbarwerden des religiösen Gegensatzes bewusst herbeiführt, damit sich die Wahrheit und Überlegenheit des christlichen Glaubens erweisen möge.

Darin kommt ein Zeugnisbegriff zum Tragen, der mit der Vorstellung der Gegenwart Christi verbunden ist: Wie Heiligkeit im christlichen Verständnis generell als Nachfolge Christi und ,Zeugnis‘ gedacht wird, so ist der narrative wie inhaltliche Kern des Martyriums, das macht gerade das ,evangeliumsgemäße‘ Beispiel Polykarps deutlich, nicht die heldenhafte Lebenshingabe als solche, sondern die bedingungslose Nachfolge, bei der Christus sich im Märtyrer noch einmal abbildet und gegenwärtig wird. ${ }^{47}$,Zeuge‘ ist der Märtyrer also nicht, weil er leidet, sondern weil er mit seinem Leben und Sterben vom Heil in Christus kündet, und das nicht einfach im Sinne eine Überzeugung oder Lehre, die weiterzugeben ist, sondern heilspräsentisch gedacht:

Dabei besteht das Zeugnisgeben wesentlich darin, daß die Wirklichkeit der Tatsache in die Gegenwart zurückgeholt wird. Zeugnis ist Anamnese. So tritt im Zeugnis von Christus, welches der Märtyrer gibt, die Heilstat Gottes, seine Wahrheit und Wirkmacht ins Präsens: das Zeugnis hat heilsschaffende Macht. ${ }^{48}$

Das beschreibt zwar erst einmal die christliche Binnenperspektive, in der das Martyrium als Heilszeichen für die Gläubigen und zur inneren Bestärkung gedeutet, die Verfolgung „zu einem Stück der heilvermittelnden Nachfolge Jesu“49 wird. Wenn sich aber im Narrativ des Martyriums der Glauben in seiner Wahrheit und Kraft als objektive Tatsache erweisen soll, braucht es dafür gerade eine nichtchristliche Umgebung und zwar nicht nur, weil das Sterben für Gott notwendigerweise eine Verfolgungssituation voraussetzt, sondern weil es nicht zuletzt erzähllogisch einer textinternen Öffentlichkeit bedarf, die sich in Ablehnung und Annahme der christlichen Botschaft zu diesem Heilszeichen verhält. Das Zeugnis des Glaubenszeugen im Martyrium muss in seiner missionarischen Wirksamkeit selbst bezeugt werden, damit

47 Vgl. Beinert, Die Heiligen in der Reflexion der Kirche, S. 52.

48 Ebd.

49 Suso Karl Frank: Zur altkirchlichen Missionsgeschichte. In: Franziskanische Studien 66 (1984), S. 3-18, hier S. 5. 
es seine heilsgeschichtliche Relevanz entfalten und tatsächlich heilsvergewissernd wirken kann.

Dazu kommt, dass das Christentum in seinem Selbstverständnis gegenüber den Ungläubigen, wie es sich im Missionsbefehl verdichtet, grundlegend auf Verkündigung und Ausbreitung des Glaubens hin angelegt ist. ${ }^{50}$ Der lateinische Begriff missio meint dabei erst einmal nicht mehr als eine Sendung, allerdings wird deren Inhalt im Bericht der Evangelien mit Taufe und Unterweisung im Glauben deutlich benannt: euntes ergo docete omnes gentes, baptizantes eos in nomine Patris et Filii et Spiritus Sancti, docentes eos servare omnia quaecumque mandavi vobis, und in der Erfüllung dieser Aufgabe sagt Christus den Aposteln seine Gegenwart zu: et ecce ego vobiscum sum omnibus diebus usque ad consummationem saeculi (Mt 28, 19-20). ${ }^{51}$ In den letzten Worten des Auferstandenen vor der Himmelfahrt werden dieser Auftrag und seine Verheißung in der Zeugnisterminologie formuliert, denn mit der Kraft des Heiligen Geistes werden die Apostel den Glauben an Christus bezeugen: accipietis virtutem supervenientis Spiritus Sancti in vos, et eritis mihi testes in Hierusalem et in omni Iudaea et Samaria, et usque ad ultimum terrae (Apg 1, 8). ${ }^{52}$ Die engsten Jünger sind demnach

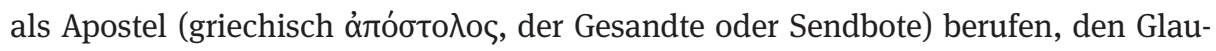
ben in der ganzen Welt zu verkündigen, weil sie selbst Zeugen der Verkündigung Christi und seiner Auferstehung waren, wie es bei der Nachwahl des zwölften Apostels heißt: oportet ergo ex his viris qui nobiscum congregati sunt, in omni tempore quo intravit et exivit inter nos Dominus Iesus, incipiens a baptismate Iohannis usque in diem qua adsumptus est a nobis, testem resurrectionis eius nobiscum fieri unum ex istis (Apg 1, 21-22). ${ }^{53}$

Das Glaubenszeugnis wird in neutestamentlicher Zeit also nicht als etwas Herausgehobenes verstanden, sondern als grundlegender Aspekt christlicher Lebensweise: „Offensichtlich galt die ganze Existenz der Christen als Zeugnis, wobei - von der Wortverkündigung abgesehen - das beispielhafte Leben der Gemeinde missionarisch wirkte. ${ }^{\text {"54 }}$ Darin hat man in der Forschung denn auch immer wieder den Grund

50 Als „Nachfolge Christi in der ständigen Vergegenwärtigung der Glaubensstiftung“ wird die Apostelaussendung zu einer ,Schlüsselszene für die Christenheit‘, die in Predigt und geistlichem Spiel rituell vergegenwärtigt wird und die mittelalterliche Literatur und Kunst durchzieht. Verena Linseis: Aussendung - Mission - Migration. Zur Szene der Apostelaussendung im Geistlichen Spiel. In: PBB 134, 4 (2012), S. 512-539, hier S. 513.

51 „Darum gehet hin und machet zu Jüngern alle Völker: Taufet sie auf den Namen des Vaters und des Sohnes und des Heiligen Geistes und lehret sie halten alles, was ich euch befohlen habe. Und siehe, ich bin bei euch alle Tage bis an der Welt Ende.“

52 „[A]ber ihr werdet die Kraft des Heiligen Geistes empfangen, der auf euch kommen wird, und werdet meine Zeugen sein in Jerusalem und in ganz Judäa und Samarien und bis an das Ende der Erde."

53 „So muss nun einer von diesen Männern, die bei uns gewesen sind die ganze Zeit über, als der Herr Jesus unter uns ein- und ausgegangen ist - von der Taufe des Johannes an bis zu dem Tag, an dem er von uns genommen wurde -, mit uns Zeuge seiner Auferstehung werden.“

54 Otto Betz: Art. Mission III. Neues Testament. In: TRE 23 (1994), S. 23-31, hier S. 30. 
für die erfolgreiche Ausbreitung des christlichen Glaubens gesehen: „Die Stoßkraft der kirchlichen Mission lag in der Weitergabe der Botschaft von Mund zu Mund, in der Einheit von Wort und Tat, in dem das Leben auch in den alltäglichen Bezügen einfordernden, totalen Anspruch der Botschaft Jesu. "55 Der vollkommene Einsatz im Glaubenszeugnis habe aber unter den Bedingungen heidnischer Ablehnung und Verfolgung zwangsläufig zum Martyrium führen müssen, sodass es immer schon mit der Mission verbunden gewesen sei, beides wesentlich zueinander gehöre und ineinander übergehe, wodurch „die christliche Verkündigung von selbst ein eigentümliches Gewicht und einen einzigartigen Ernst" gewonnen habe, so die idealisierende Darstellung bei Hans von Campenhausen. ${ }^{56}$ Wenn er aber die „Zeit der ältesten Kirche“ beschreibt als die „einer Christenheit, die die Mission und das Martyrium in seltener, ursprünglicher Gleichzeitigkeit wirklich geübt und erfahren hat" ${ }^{* 57}$, und dabei zudem festhalten zu können glaubt, dass „[d]ie missionarische Ausrichtung der Kirche [...] das Martyrium davor [bewahrt], sich als Selbstzweck zu verstehen" ${ }^{68}$, folgt er darin der kirchlichen Selbstinszenierung.

Tatsächlich erweist sich gerade am Martyriumsdiskurs, wie wenig selbstverständlich diese Gleichzeitigkeit und wie sehr sie letztlich das Ergebnis christlicher Selbstbeschreibung ist. Diese zielt auf den exklusiven Anspruch des Christentums, der eine, mit Assmann, ,lebenswendende Entscheidung fordert, denn unter den Bedingungen der Verfolgungen erscheint das Zeugnis genau als eine solche, nicht nur allgemein existenziell, sondern in einer physischen Konkretisierung. Für die Christen hält das Martyrium, „dieses In-der-Entscheidung-Stehen“ aktuell, es stellt ihnen „dieses Moment der innerchristlichen Gefährdung“ vor Augen, wonach sich auch der Gläubige seines Heils niemals sicher sein kann: „Nur die Märtyrer sind der Zweideutigkeit des Lebens für immer entnommen“59, denn sie haben die endgültige conversio vollzogen und sind in die Transzendenz eingegangen. Nach außen soll das Martyrium hingegen wirken ,als eine furchtbare Drohung für die Welt der Verfolger, die das Blut des Zeugen vergossen haben“60, wobei diese Drohung in erster Linie eine symbolische ist, die vor allem der Inszenierung der ,lebenswendenden Entscheidung und der finalen Unterscheidung von Glaube und Unglaube dient.

Die christliche Vorstellung des Martyriums ist daher schon in ihren Ursprüngen nicht als neutrale Tatsachenbeschreibung zu verstehen: ,,Am Anfang der christlichen Märtyrerliteratur stehen - wie am Anfang der Evangelien - nicht ,wertfreie‘ Ge-

55 Gülzow, Reichert, Art. Mission, S. 33.

56 Hans von Campenhausen: Das Martyrium in der Mission. In: Kirchengeschichte als Missionsgeschichte, Bd. 1: Die Alte Kirche. Hrsg. von Heinzgünter Frohnes, Uwe W. Knorr. München 1974, S. 71-85, Zitat S. 73.

57 Ebd., S. 70.

58 Ebd., S. 73.

59 Beide Zitate ebd., S. 76.

60 Ebd. 
schichtstatsachen, sondern steht tendenziöse kerygmatische Erbauungsliteratur.“61 Als solche ist sie aber ein Element der christlichen Identitätsbildung gegenüber der herrschenden griechisch-römischen Mehrheitsgesellschaft des 2. und 3. Jahrhunderts. Neben den Apologien dieser Zeit, die einem systematischen und diskursiven Ansatz folgen und bemüht sind die Inhalte der neuen Religion in Übereinstimmung mit und als erfüllende Fortführung der überkommenen heidnischen Philosophie darzustellen, erweisen sich die Märtyrerschriften als eine Form narrativer Identitätsstiftung und Selbstvergewisserung, die gerade die Erfahrung religiöser Konfrontation in Ablehnung und Verfolgung bearbeitet. ${ }^{62}$ Die Vorstellung des Martyriums als Glaubenszeugnis im Sterben für Gott bietet hierbei nicht nur eine kompensatorische Gegenerzählung, sondern ermöglicht gar eine triumphale Umkehrung, wenn sie die Hinrichtung zu einem Machterweis des Christentums in eschatologischer Dimension macht: „The martyrs not only resist the Roman temporal power but also place themselves in a higher tribunal than their earthly persecutors by pronouncing God's eschatological judgement upon the persecutors.“63

Aus diesem konfrontativen Charakter erklärt sich der aktiv kämpferische Grundzug, der sich in der Verwendung militärischer Metaphorik in der Darstellung des Martyriums niederschlägt und den Märtyrer in seinem Leiden als einen ,Streiter Gottes zeigt. Die Grundlage der militia-Christi-Metaphorik findet sich schon im Neuen Testament, wenn der spirituelle Weg jedes Gläubigen als Kampf beschrieben wird: labora sicut bonus miles Christi Iesu, heißt es in 2 Tim 2, 3. ${ }^{64}$ Der auf Sieg und Überwindung des Heidentums angelegte konfrontative Charakter erklärt auch die starke Schematisierung und den hohen Grad der Stilisierung, wenn im Martyrium, mit deutlich vernehmbaren literarästhetischen Urteil der älteren Forschung, ,hartnäckige fanatische Verfolgte einem ebenso hartnäckigen fanatischen Verfolger gegenüber[stehen]“. ${ }^{65}$ Denn die „Erzähllogik der Martyrienberichte, die auf der Opposition zwischen dem Glauben der Christen und den Götter(opfer)n der Heiden beruhte“, verlangt das standhafte und geradezu hartnäckige Bekenntnis des Christen wie die gnadenlose Bestrafung durch die Vertreter der heidnischen römischen Obrigkeit. ${ }^{66}$

\footnotetext{
61 Buschmann, Das Martyrium des Polykarp, S. 251.

62 Vgl. Rhee, Early Christian Literature, S. 1-2.

63 Ebd., S. 186.

64 „Leide mit als ein guter Streiter Christi Jesu.“ Zur militia Christi vgl. weiter unten noch ausführlich in Kap. 4.2.1 Die Verchristlichung des Rittertums.

65 Erich Auerbach: Mimesis. Dargestellte Wirklichkeit in der abendländischen Literatur. 8. Aufl. Bern/ Stuttgart 1988, S. 22.

66 Peter Gemeinhardt: Märtyrer und Martyriumsdeutungen von der Antike bis zur Reformation. In: ZKG 120 (2009), S. 289-322, hier S. 293. Es ist demnach eine Fehlinterpretation, das dualistische Weltbild von Gut und Böse, das sich in den mittelalterlichen Märtyrerlegenden, hier speziell der Legenda aurea, „in hartem Schwarzweißkontrast“ niederschlägt, als Ergebnis einer Befreiung vom „Realitätsbezug“ und daher als „irreale“ Schematisierung verstehen zu wollen, so beispielsweise bei Ferdinand Barth: Legenden als Lehrdichtung. Beobachtungen zu den Märtyrerlegenden in der Legenda aurea. In: Europäische Lehrdichtung. Festschrift für Walter Naumann zum 70. Geburtstag. Hrsg. von
} 
Auch die lange Zeit in der Forschung übliche Unterscheidung in authentische und daher als historische Quellen verlässliche ,Märtyrerakten“ und im Nachhinein verfasste, fiktive ,Märtyrerpassionen“ verkennt daher, dass es schon in der frühchristlichen Märtyrerliteratur immer um die narrative Inszenierung und Deutung eines Geschehens geht. ${ }^{67}$ Dabei ist weniger das ,Was ${ }^{6}$ des Inhalts, sondern das ,Wie ${ }^{6}$ der Darstellung aufschlussreich:

Die Einsicht, daß es das von der historischen Kritik so lange gesuchte originale Martyrer-Aktenstück überhaupt nicht gibt, daß vielmehr auch die bescheidenste Passio, sobald sie aufgezeichnet wird, Literatur ist, befreit uns von den hermeneutischen Problemen von Texten, die nur Niederschlag der Wirklichkeit und nicht mehr sein wollen, und ermöglicht die Frage nach dem Ausdruckswillen, der hinter der Überlieferungsform eines Martyriums im ,Aktenstil', in der ,Protokollform', steht. ${ }^{68}$

So erweist sich gerade die Protokollform als bewusste literarische Inszenierung, denn sie suggeriert eine realistische Nähe zum Geschehen, indem sie sich den Anschein einer knappen und vertrauenswürdigen Aufzeichnung des tatsächlichen Verhörs unmittelbar während seines Verlaufs gibt. Dabei ist unübersehbar, dass die Konfrontation des Märtyrers mit dem heidnischen Statthalter in den scharfen Wechselreden hochgradig stilisiert und exemplarisch ist. Das gesamte Geschehen scheint auf den religiösen Gegensatz hin konzentriert und liefert dabei die entsprechende Wertung gleich mit. Die vermeintliche Authentizität zielt darauf, beim Rezipienten über Unmittelbarkeitseffekte religiöse Wirkung zu erzielen, indem die Distanz zwischen dem Augenzeugen, als der sich der Erzähler inszeniert, und dem im gläubigen Mitvollzug vereinten Publikum aufgehoben scheint.

Wenn es also in der Märtyrerliteratur nie um die ,bloße' Darstellung eines Märtyrertodes geht, sondern am Ende immer schon um Martyrologie, ${ }^{69}$ so ist diese Deutung umgekehrt aber nicht zu trennen von ihrer narrativen Vermittlung. Erst in der deutenden Darstellung einer Hinrichtung als Martyrium wird diese überhaupt zu einem solchen und damit zu einem sinnhaften Geschehen: martyres non facit poena, sed

Hans Gerd Rötzer, Herbert Walz. Darmstadt 1981, S. 61-73, S. 68. Der Dualismus ist vielmehr von Anfang an konstitutiv für die Märtyrerlegende.

67 Die Begriffsbildung und damit die gesamte Fragestellung ist ohnehin eine anachronistische, denn der Begriff acta martyrum geht auf eine Anthologie des ausgehenden 17. Jahrhunderts zurück, in frühchristlicher Zeit findet er sich sehr selten, die Märtyrerberichte werden als passiones oder gesta martyrum bezeichnet. Vgl. François Dolbeau: Art. Märtyrerakten (acta martyrum). In: LexMA 6 (1993), Sp. 352-353, hier S. 352.

68 Walter Berschin: Biographie und Epochenstil im lateinischen Mittelalter, Bd. 1: Von der Passio Perpetuae zu den Dialogi Gregor des Großen. Stuttgart 1986, S. 41.

69 Vgl. Ekkehard Mühlenberg: The Martyr's Death and its Literary Presentation. In: Historica, theologica et philosophica, critica et philologica. Papers presented at the Twelfth International Conference on Patristic Studies. Hrsg. von Elizabeth Anne Livingstone. Leuven 1997 (Studia patristica. 29), S. $85-93$, hier S. 93. 
caus $a,{ }^{70}$ so die einflussreiche Formel bei Augustinus, der zufolge nicht das Faktum der Hinrichtung den Märtyrer ausmacht, sondern Grund und Anlass des Sterbens, was letztlich sowohl die persönliche Handlungsmotivation des Sterbenden meint als auch die kollektive Deutungsleistung im Erinnern und Erzählen von ihm. ${ }^{71}$ Der diskursive Charakter des Martyriums betrifft aber nicht nur die Deutung des Sterbens in den Christenverfolgungen, sondern des religiösen Gegensatzes insgesamt: „[T]he memory work done by early Christians on the historical experience of persecution and martyrdom was a form of culture making, whereby Christian identity was indelibly marked by the collective memory of the religious suffering of others"; das Märtyrertum ist also das Ergebnis einer Interpretationsleistung und bietet einen Verständnisrahmen „for interpreting a wide array of historical encounters between Christians and the dominant imperial culture“. ${ }^{72}$

Die Märtyrer bilden daher einen Kristallisationspunkt kollektiver religiöser Identitätsbildung in der Verfolgungszeit und darüber hinaus in ihrer Erinnerung im kulturellen Gedächtnis als der Gründungszeit der Kirche: „Einzelne in Extremsituationen exemplifizieren das Ideal christlicher Lebenshingabe und dienen den Vielen zur Orientierung und zur Entlastung. “73 Der oft konstatierte kompensatorische Charakter der Heiligenverehrung ist mithin schon im Märtyrerkult der frühen Kirche angelegt, mehr noch: gerade er ist ein Ursprung des Heiligenkultes, wenn die Märtyrer helfen sollen, mit dem Abfall von Christen in Verfolgungssituationen umzugehen, indem sie nicht nur ihre, sondern auch fremde Sünden sühnen. ${ }^{74}$ Das idealisierte Bild einer glühenden Bereitschaft zum und mitunter gar eines aktiven Strebens nach dem Martyrium, wie es die Märtyrerliteratur zeichnet, steht folglich in Diskrepanz zur historischen Situation:

Es läßt sich kaum bestreiten, daß das Verhalten jener Männer und Frauen, die ihr eigenes Martyrium beförderten, konsequent war, wenn man die Bewertung des Märtyrertodes in den meisten einschlägigen Schriften betrachtet. Dennoch stellte es nicht den Normalfall dar. Die große Masse der Christen, die in den Verfolgungen durchhielten, drängte sich nicht zum Tod. ${ }^{75}$

70 Enarratio in psalmum XXXIV, Sermo II, 13. Aurelius Augustinus: Enarrationes in psalmos I-L. Turnholt 1990 (Corpus christanorum. Series Latina. 38/Aurelii Augustini Opera. 10, 1).

71 Vgl. dazu auch Peter Gemeinhardt: Non poena sed causa facit martyrem. Blut- und Lebenszeugnis in der Alten Kirche: Sache, Kontext und Rezeption. In: Vom Blutzeugen zum Glaubenszeugen? Formen und Vorstellungen des christlichen Martyriums im Wandel. Hrsg. von Gordon Blennemann, Klaus Herbers. Stuttgart 2014 (Beiträge zur Hagiographie. 14), S. 23-39.

72 Elizabeth A. Castelli: Martyrdom and Memory. Early Christian Culture Making. New York 2004 (Gender, Theory, and Religion), S. 4 und 6.

73 Gemeinhardt, Märtyrer und Martyriumsdeutungen, S. 322.

74 Vgl. ebd., S. 303.

75 Dorothea Wendebourg: Das Martyrium in der Alten Kirche als ethisches Problem. In: ZKG 98 (1987), S. $295-320$, S. 305. 
Insofern lässt sich die Normierung des Martyriums und die Einhegung eines Martyriumsenthusiasmus, wie ihn zur Entstehungszeit des Martyriums des Polykarp die endzeitlich-prophetische Bewegung des Montanismus als rigoristische Gegenposition zu einer zunehmenden Verweltlichung der Großkirche propagierte, als Teil komplexer innerkirchlicher Deutungsprozesse und Legitimationsstrategien verstehen. Die Argumentation der kirchlichen Autoritäten bleibt dabei insgesamt uneindeutig: Zwar lehnen sie das Drängen zum Martyrium ab, legitimieren sowohl die Flucht als auch das Ausharren im Verborgenen und wählen selbst diese Wege, andererseits stammen solche Stellungnahmen von denselben führenden Kreisen wie die Schriften, die den Märtyrertod als erstrebenswertes Ziel und Leitbild idealisieren und propagieren. ${ }^{76}$ Das wird man aber weniger als Doppelmoral verurteilen, denn als Beleg für die schwierige und durchaus widersprüchliche Identitätsbildung nehmen können, die das Problem der Ablehnung und Verfolgungen deutend auffangen muss, andererseits Wege einer Etablierung der Kirche innerhalb einer heidnischen Umgebung sucht - und damit das grundlegende Problem der christlichen Existenz in der ,Welt' bearbeitet: ganz konkret als Gegensatz zwischen Christen und Heiden, der auch im Martyrium als ein dynamischer und zu überwindender gedacht wird, zugleich aber auch schon spiritualisiert in der Frage nach dem persönlichen Heil jedes einzelnen Gläubigen, dessen er sich auf Erden nie sicher sein kann. ${ }^{77}$

Bereits die frühchristliche Märtyrerliteratur ist also immer eine rückblickende Deutung, die kaum die deutlich vielschichtigeren historischen Situationen widerspiegelt, nicht nur hinsichtlich der im Narrativ des Martyriums unausweichlich scheinenden Konfrontation im Verhältnis von Christentum und Heidentum, das im Gegenteil verschiedene Formen der Koexistenz zwischen pragmatischer Duldung und aktiver Auseinandersetzung erlebt hat. Eine Diskrepanz besteht dabei vor allem zum tatsächlichen Ausmaß der Christenverfolgungen bis zur Konstantinischen Wende, die in den Martyrien ja als durchgängige Grundbedingung erscheinen. Entgegen dieser Engführung gab es bis zur Mitte des 3. Jahrhunderts nur lokal und zeitlich eng begrenzte Verfolgungen, erst unter Kaiser Decius kam es 250-251 zu einer systematischen und umfassenden staatlichen Verfolgung, die auf eine Vernichtung des Christentums als solches zielte, fortgesetzt durch die Verfolgungen unter Kaiser Valerian 257-259 und schließlich noch einmal unter Kaiser Diokletian und seinen Nachfolgern

76 Vgl. ebd., S. 306-307.

77 Vgl. dazu oben in Kap. 2.2.1 Heidentum als dynamischer Gegenbegriff. Ein ganz anderes Problem, dem die doppelwertige Normierung des Martyriums und seine Einhegung in das kirchliche Leben begegnet, ist die der Eigendynamik der Verehrung einzelner religiöser Charismatiker, die mit aufgrund der ihnen zugeschriebenen Heilsunmittelbarkeit zur Konkurrenz für die ,Amtskirche“ werden konnten, wie sich in den Auseinandersetzungen um die Vollmacht von Bekennern und Märtyrern zur Sündenvergebung zeigt. Vgl. Franz Dünzl: Bekenner und Märtyrer. Heroen des Volkes - ein Problem für das Amt? In: Volksglaube im antiken Christentum. Hrsg. von Heike Grieser, Theofried Baumeister. Darmstadt 2009, S. 504-524. 
303-311. ${ }^{78}$ Die Zahl der Märtyrer dürfte daher tatsächlich deutlich geringer sein, als in späterer Wahrnehmung und bis weit in die Neuzeit immer wieder konstatiert worden ist. Dennoch wird man die Christenverfolgungen der Antike nicht zum Mythos erklären können, ${ }^{79}$ zumindest nicht in dem negativen Sinn einer kompletten und bewusst täuschenden Erfindung, sondern allenfalls im positiven eines Diskurses, der historisches Geschehen und seine Deutung umfasst, also vor allem Wahrnehmungen und Inszenierungen widerspiegelt. Denn das Selbstbild der frühen Kirche ist zweifellos das einer verfolgten Minderheit. ${ }^{80}$

Ein anderes Missverständnis betrifft die missionarische Wirksamkeit, die der angenommenen Martyriumsbereitschaft der vielen Christen in den blutigen Verfolgungen zugeschrieben wurde und die Tertullian zu belegen scheint, wenn er in seinem im Jahr 197 entstandenen Apologeticum an die heidnischen Verfolger gerichtet formuliert: Nec quicquam tamen proficit exquisitior quaeque crudelitas uestra: illecebra est magis sectae. Etiam plures efficimur, quoties metimur a uobis; semen est sanguis Christianorum! (Apologeticum 50, 13) ${ }^{81}$ Dabei ist aber der Kontext zu beachten, in dem der Gedanke vom Blut der Christen als Same der Kirche bei Tertullian erscheint, nämlich nicht oder weniger zur selbstvergewissernden Ermutigung oder Tröstung der Christen, sondern als Verteidigung nach außen, denn Tertullian propagiert hier nicht das Martyrium als Mittel zur Erlangung des Heils oder Mission der Heiden, sondern argumentiert rhetorisch geschickt, es läge letztlich im Interesse des römischen Staates selbst, nicht durch weitere Verfolgung das Christentum noch zu bestärken. ${ }^{82}$

Und auch wenn die Formel tatsächlich als Bestärkung der verfolgten Christen verstanden worden sein sollte, ${ }^{83}$ so bleibt sie dabei Teil einer Inszenierung von Macht und Ohnmacht, die die tatsächlichen Verhältnisse in der christlichen Gegenerzählung des Martyriums umkehrt. Die Martyrien dürften hingegen insgesamt eine eher zwie-

78 Vgl. Jutta Tloka: Märtyrer. In: Arbeitsbuch Religion und Geschichte. Das Christentum im interkulturellen Gedächtnis, Bd. 1. Hrsg. von Harry Noormann. Stuttgart 2009, S. 61-82, hier S. 64-66. Zu „Phasen und Formen der Konfliktgeschichte zwischen Staat und Christen“ vgl. Seeliger, „Das Geheimnis der Einfachheit“, S. 340-352.

79 So wie jüngst Candida Moss: The Myth of Persecution. How Early Christians Invented a Story of Martyrdom. New York 2013. Für sie ist ,the idea of the persecuted church [...] almost entirely the invention of the fourth century and later“ (ebd. S. 245).

80 So in kritischem Bezug auf die vorgenannte These Andreas Merkt: Verfolgung und Martyrium im frühen Christentum. Mythos, Historie, Theologie. In: Sterben für Gott - Töten für Gott? Religion, Martyrium und Gewalt. Hrsg. von Jan-Heiner Tück. Freiburg i. Br. 2015, S. 192-206, hier S. 205.

81 „Und doch richtet jede noch so erlesene Grausamkeit von euch überhaupt nichts aus: Sie ist eher ein Lockmittel für unsere Gemeinschaft. Wir werden noch zahlreicher, sooft wir von euch niedergemäht werden: Ein Same ist das Blut der Christen!“ Tertullian: Apologeticum. Verteidigung des christlichen Glaubens. Eingeleitet und übersetzt von Tobias Georges. Freiburg i. Br. 2015 (Fontes Christiani. 62), S. 294 und 295.

82 Vgl. Campenhausen, Das Martyrium in der Mission, S. 79.

83 Wofür Tertullians bekannte Sympathie für den Montanismus ebenso sprechen könnte wie die katechetisch-apologetische Tendenz seines Werkes insgesamt, in der er 202 während der Severianischen Verfolgung auch eine Trostschrift Ad martyras verfasst. 
spältige Wirkung gehabt haben: Mochten die Konsequenz und Standhaftigkeit der Märtyrer mitunter Bewunderung hervorrufen, dürften sie sich andererseits aus heidnischer Sicht immer wieder auch als törichter oder gar gefährlicher Fanatismus dargestellt haben. So erkennt Mark Aurel in seinen Selbstbetrachtungen $(11,3)$ wohl die Todesbereitschaft der Christen an, sieht sie aber „aus reinem Widerspruchsgeist“ hervorgehen. ${ }^{84}$

Diese Verkürzungen und Vereindeutigungen mindern aber keinesfalls den funktionalen Wert der Märtyrerberichte, sondern spiegeln eben genau die entsprechenden Bedürfnisse und Anforderungen an eine identitätsstiftende Deutung der Verfolgungssituation. Als wesentliches Element narrativer Selbstvergewisserung kommt das Martyrium aber gerade auch in der weiteren Expansion des Christentums nach der Konstantinischen Wende zum Tragen:

Der christliche Märtyrerakt wurde so zu einem Vorbild, das offenbar vor allem bei der Glaubensmobilisierung und -rekrutierung helfen sollte, auch dann, als die religiöse Verfolgung der Christen bereits abgenommen hatte. Im Christentum wurde die geistige Überlegenheit des Märtyrers gegenüber seinen Verfolgern, die nun in der Rückschau als Verlierer der Geschichte zu gelten hatten, als Sieg aufgefasst, worauf bald das Symbol der Märtyrerkrone hinweisen sollte. So wurde - wohl bei der späteren Konstruktion der Märtyrerfiguren - ihre ursprüngliche Ohnmacht als Verfolgte in ein Symbol kirchlicher Macht umgemünzt. ${ }^{85}$

Wenn schon in der Genese des Märtyrerkultes einerseits Narrativ und Theologie des Martyriums, andererseits Verehrung und religiöse Lebenspraxis eng miteinander verwoben sind, so gilt das zumal im Blick auf die große Menge der bis ins Mittelalter tradierten und immer wieder neu erzählten Märtyrerlegenden. Denn die frühchristlichen Märtyrerberichte bieten nicht nur eine selbstvergewissernde Deutung, sondern entwerfen gleichzeitig ein Leitbild, das als solches schon in der Verfolgungszeit rezipiert und umgesetzt wird. Der Märtyrer braucht die literarische Darstellung des Martyriums insofern in doppelter Weise: Er orientiert sich an ihr und schreibt sich selbst wiederum neu in sie ein. ${ }^{86}$ Tatsächliches Geschehen und Deutung, faktische

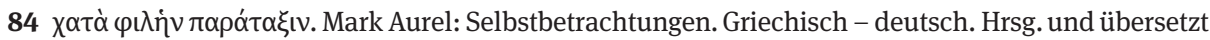
von Rainer Nickel. 2. Aufl. Mannheim 2010 (Sammlung Tusculum), S. 274 und 275.

85 Joseph Croitou: Der Märtyrer als Waffe. Zur Funktion des Selbstmordattentäters als Märtyrer. In: Tinte und Blut. Politik, Erotik und Poetik des Martyriums. Hrsg. von Andreas Kraß, Thomas Frank. Frankfurt a. M. 2008, S. 59-71, hier S. 62-63. Eine historische Fallstudie zum vielfältigen Potential der Märtyrerverehrung für die christliche Identitätsbildung nach der Verfolgungszeit bietet Johan Leemans: Flexible Heiligkeit. Der Beitrag der Märtyrer zur Identitätskonstitution christlicher Gemeinden im griechischen Osten im 4. Jahrhundert. In: Heilige, Heiliges und Heiligkeit in spätantiken Religionskulturen. Hrsg. von Peter Gemeinhardt, Katharina Heyden. Berlin/Boston 2012 (Religionsgeschichtliche Versuche und Vorarbeiten. 61), S. 205-230.

86 Das lässt sich zuspitzen auf die Frage, „ob der vom Märtyrer praktizierte Lebensentwurf ohne die Acta möglich war: die Rezeption des Leitbildes erfolgte jedenfalls nicht nur in den verfolgungsfreien Zeiten der Spätantike“. Walter Ameling: Vorwort. In: Märtyrer und Märtyrerakten. Hrsg. von dems. Stuttgart 2002 (Altertumswissenschaftliches Kolloquium. 6), S. 7-12, hier S. 8. 
Historizität und literarische Gestaltung gehen beim Martyrium also immer schon ineinander über, denn gerade als gedeutetes und gestaltetes historisches beziehungsweise als historisch angenommenes Geschehen kann es handlungsmotivierend wie handlungsleitend wirken:

Das Martyrium, das uns die Märtyrerviten vor Augen führen, ist denn auch nicht einfach ein geschichtliches Ereignis, das über den Märtyrer hereinbricht und ihn zum Zeugen werden lässt. Im Gegenteil, es ist ein literarisches, ein rituelles und liturgisches Ereignis, dessen Eintreffen vorbereitet, kalkuliert und inszeniert wird. Das Martyrium ist immer Geschichte und Legende des Martyriums. Es ist pädagogisches Beispiel, das zur Nachahmung anleitet. ${ }^{87}$

Die Deutung und Inszenierung betrifft nun aber nicht nur die Heiligkeit des Protagonisten, sondern auch die Aushandlung des religiösen Gegensatzes zum Heidentum. So ist die Märtyrerliteratur nach innen gerichtet und dient internen Zwecken, indem sie „stabilisierende Identitätsfiguren“ zur Verfügung stellt, die auf der Konstruktion religiöser Alterität beruhen beziehungsweise diese überhaupt erst herstellen:

Das durch sie verkörperte Identifikationspotential kann als Aufforderung zu einer Identität begründenden ,Praxis der Differenz verstanden werden, mit der durch die Vorstellung einer in die Tiefe der Zeit zurückreichenden und aktualisierbaren faktischen oder fiktiven Kontinuität ein Selbst- oder Gruppenbild erzeugt und gesichert wird. ${ }^{88}$

Diese ,Praxis der Differenz‘ erfordert eine scharfe Grenzziehung, die über Gewalt verhandelt wird, hier in Form des Opfers, das kein individuelles ist, sondern alle Christen meint, worauf das stereotype Bekenntnis Christianus sum hinweist, wobei mitunter gar die Angabe des eigenen Namens explizit verweigert wird. ${ }^{89}$ So gesehen ist das Martyrium „die höchste und radikalste Form von passiver Intoleranz “90, weil es im Sterben für Gott eine absolute und scheinbar unüberwindbare Grenze markiert und in seiner konfrontativen Konsequenz strukturell vom Töten für Gott nicht weit entfernt scheint, zumal angesichts des Problems der aktiven Suche nach dem Martyrium. ${ }^{91}$

Entscheidend für das christliche Verständnis des Martyriums ist allerdings die spezifische Codierung von Gewalt, die eben nicht das Ausüben, sondern gerade das Erleiden von Gewalt im freiwilligen Opfer meint und damit einen anderen strukturellen Zusammenhang beschreibt: Fremd-Gewalt wird dabei zum Selbst-Opfer oder anders: zur Selbst-Gewalt, wobei beide Aspekte des Gewalthandelns in der höheren

87 Niklaus Largier: Das Theater der Askese. Gewalt, Affekt und Imagination. In: Askese und Identität in Spätantike, Mittelalter und Früher Neuzeit. Hrsg. von Werner Röcke, Julia Weitbrecht. Berlin/New York 2010 (Transformationen der Antike. 14), S. 207-221, S. 209.

88 Seeliger, ,,Das Geheimnis der Einfachheit“, S. 360.

89 Vgl. ebd., S. 361.

90 Assmann, Gottesbilder - Menschenbilder, S. 327.

91 Vgl. Tloka, Märtyrer, S. 78. 
Gewalt Gottes aufgefangen sind, die das Geschehen eigentlich bestimmt. ${ }^{92}$ Die Spirale aus Drohung und standhaftem Bekenntnis und Ergebenheit des Märtyrers in den göttlichen Willen vollzieht diesen „Dreischritt von der Fremdgewalt zur Selbstgewalt und zur Überschreitung beider in einer Instanz, welche die Bedingungen dieser Gewalten transzendiert, [...] in der Gestaltung von Figurenrede und -gegenrede“..$^{93}$ Seine integrative Funktion entfaltet der Märtyrer dabei darin, dass er mit seiner Lebenshingabe bis in den Tod imitator Christi ist, dessen Opfer gerade Gewalt überwinden soll. Denn nach René Girards ,Mimetischer Theorie“ deckt die Passion Christi den Sündenbockmechanismus auf, der in archaischen Gesellschaften die Spirale der Nachahmung und damit Ausbreitung von Gewalt, die in der Wiedergutmachung von Unrecht immer noch mehr Unrecht schafft, unterbrechen kann und im Opfer das Heilige findet. Der Tod Christi durchbricht diese Logik durch sein stellvertretendes und unschuldiges Sterben für alle Menschen ein für alle Mal und schafft das Heilige nicht mehr über die „Glorifizierung des Opfers auf der Basis der Verfolgung““.94

Die christlichen Märtyrer setzen das fort und unterscheiden sich damit von archaisch-mythischen Vorstellungen des Heiligen. Wenn sich das christliche Martyrium dennoch als geeignet erweist, eine abgrenzende Identität herzustellen, indem es das Geschehen in der Dichotomie von Gut und Böse ordnet und die Verfolger ausgrenzt, dann ist das so etwas wie seine „sakrifizielle Versuchung“, aus der sich die dann auch archaisch-mythische Züge und der ,falsche` Heroismus der Märtyrerberichte erklären. ${ }^{95}$ Das Potential der Märtyrer und ihrer Legenden für einen Umschlag in und zur Legitimation von Gewalt ist insofern nicht erst in der möglichen Umbildung von

92 Vgl. Elke Koch: Formen und Bedingungen von Sprachgewalt in Katharinenlegende und -spiel. In: Blutige Worte. Internationales und interdisziplinäres Kolloquium zum Verhältnis von Sprache und Gewalt in Mittelalter und Früher Neuzeit. Hrsg. von Jutta Eming, Claudia Jarzebowski. Göttingen 2008 (Berliner Mittelalter- und Frühneuzeitforschung. 4), S. 15-30, hier S. 20.

93 Ebd., S. 24. Auf andere Weise und im Hinblick auf die konfessionellen Auseinandersetzungen der frühen Neuzeit hat Peter Burschel den Zusammenhang von Gewaltcodierung und kollektiver Identitätsbildung im Martyrium herausgearbeitet, das „weder in Ethik noch in Theologie aufgeht, sondern als Ort verstanden werden muss, der den kulturellen Sinn heroischen Sterbens offenbart und damit auf die Bedeutung physischer Gewalt in sozialen Gemeinschaften und ihren mentalen Haushalten zurückweist. Wer nach dem Martyrium fragt, so ließe sich vor diesem Hintergrund programmatisch formulieren, fragt nach Selbst-und Weltentwürfen - und damit nach jenen normativen kulturellen Imaginationen, die man gemeinhin ,Identitäten“ nennt.“ Peter Burschel: Leiden und Leidenschaft. Zur Inszenierung christlicher Martyrien in der frühen Neuzeit. In: Martyrdom in literature. Visions of death and meaningful suffering in Europe and the Middle East from antiquity to modernity. Hrsg. von Friederike Pannewick. Wiesbaden 2004, S. 91-104, hier S. 91-92; ausführlicher in: Sterben und Unsterblichkeit. Zur Kultur des Martyriums in der frühen Neuzeit. München 2004 (Ancien Régime, Aufklärung und Revolution. 35), S. 5-6.

94 Vgl. Hüseyin I. Cicek: Martyrium zwischen Gewalt und Gewaltfreiheit. Eine Kriterologie im Blick auf Christentum, Islam und Politik. Wien 2011 (Beiträge zur mimetischen Theorie. Religion - Gewalt Kommunikation - Weltordnung. 31), S. 170, der sich dabei bezieht auf René Girard: Der Sündenbock. Benziger 1988, S. 281-286.

95 Vgl. Cicek, Martyrium zwischen Gewalt und Gewaltfreiheit, S. 169-182, Zitat S. 173. 
Soldaten-Märtyrern in Kriegsheilige zu finden, wie ich sie im folgenden Kapitel untersuchen werde, sondern offenbar bereits in der Problematik der Martyriums selbst angelegt, wenn das Leiden Christi und der Märtyrer, das doch gerade Gewaltverzicht voraussetzt, ${ }^{96}$ als Legitimation für die Verfolgung von Andersgläubigen, historisch besonders der Juden, dienen kann.

Neben der Codierung der Gewalt ist das christliche Martyriumsverständnis aber wesentlich bestimmt durch die missionarische Funktion, die dem Sterben für Gott zugeschrieben wird und es zu einem Glaubenszeugnis macht, das nicht auf die Ausgrenzung oder gar Vernichtung der Heiden zielt, sondern ihre Integration in die christliche Gemeinschaft durch Bekehrung zum ,wahren' Glauben: Der Märtyrer ist insofern immer auch schon ein Missionar. Diesen signifikanten Zusammenhang ,nutzen' nicht erst die mittelalterlichen Heiligen in der Heidenmission wie der heilige Franziskus, denn „,[d]er gemarterte Missionar stirbt für seinen Glauben und ist insofern ein klassischer christlicher Märtyrer“ “. ${ }^{97}$ Allerdings scheint er diesen Umstand in seinem Streben nach Heiligkeit und Verbreitung des christlichen Glaubens bewusst einzusetzen:

Er ist ein aktiver ,Glaubensunternehmer', der die Kluft zwischen Erfolg und Misserfolg so umdeutet, dass er in jedem Fall profitieren wird: Entweder er ,verkauft' sein Anliegen gut und sein Glaube siegt oder das Unternehmen misslingt, würde dann aber vom Martyrium gekrönt. ${ }^{98}$

Und der Erfolg liegt dann nicht nur in der persönlichen Heiligung, sondern in der Bedeutung seines Martyriums für die christliche Gemeinschaft - und womöglich für die Heiden, die sich erst angesichts seines Sterbens und den darauffolgenden Wundern bekehren. Für den Märtyrer gilt jedenfalls, was für den Heiligen allgemein gilt, nach ,innen' hinsichtlich seiner Funktion für die christliche Identitätsbildung im Heiligkeitsdiskurs wie nach ,außen' im Hinblick auf die Bekehrung der Heiden als spezifische Form der Aushandlung des religiösen Gegensatzes: ${ }^{99}$ Er ist eine „Figur der Grenze, aber auch der Grenzüberschreitung und Vermittlung“, denn er markiert mit seinem blutigen Opfer die Scheidelinien zwischen wahrem Glauben und Unglauben,

\footnotetext{
96 Hierin liegt ein Spezifikum des christlichen Martyriumsverständnisses. Während im Islam und Judentum das Wortzeugnis im Mittelpunkt steht, ist im Christentum die „Nachahmung Christi [...] die Richtlinie für ein wirkliches Zeugnis“, was ,jede Gewalttat seitens des Märtyrers“ verbietet, der sogar für seine Verfolger betet, sie nicht der göttlichen Strafe anheimgibt, sondern um ihre Erlösung bittet. Im Judentum und im Islam hingegen werden sowohl Zivilisten als auch Krieger zu Zeugen des heiligen Bundes beziehungsweise des einen Gottes, wenn sie aufgrund ihres Strebens nach der Heiligung des göttlichen Namens (Kiddush Hashem) beziehungsweise auf dem Wege Gottes (Fi sabil Allah) getötet werden. Vgl. ebd., S. 197, Zitate ebendort.

97 Thomas Frank: Märtyrer der christlichen Mission im früheren Mittelalter. In: Tinte und Blut. Politik, Erotik und Poetik des Martyriums. Hrsg. von Andreas Kraß und dems. Frankfurt a. M. 2008, S. 219-237, hier S. 220.
}

98 Ebd.

99 Vgl. dazu oben in Kap. 2.2.3 Die Dynamik der Mission. 
also sowohl zwischen Christentum und Heidentum als auch zwischen Heiligkeit und Nicht-Heiligkeit - bestätigt dabei aber nicht nur die bestehenden Differenzen, sondern ist gerade aufgrund seines Opfers als Mittler zwischen Transzendenz und Immanenz anrufbar. $^{100}$

\subsection{Das Martyrium als Glaubenszeugnis in Wort und Zeichen}

Die Konfrontation mit dem Heidentum ist die historische wie symbolische Grundbedingung des Martyriums, das aus christlicher Sicht ein Glaubenszeugnis im Sterben für Gott meint. Der Tod des Märtyrers ist dabei mehr als ein individuelles Leiden und Sterben im Streben nach persönlicher Heiligkeit, sondern ein sichtbares und vor allem erinner- und erzählbares Bekenntnis für andere; er wird selbst zum Zeugnis für den Glauben. Dieser Zeugnischarakter kann grundsätzlich alle Elemente des Märtyrernarrativs umfassen: das unerschrockene Bekenntnis des Märtyrers im öffentlichen Verhör, das ihm Gelegenheit gibt zur Verkündigung des christlichen Glaubens oder gar zum formalen Glaubensdisput mit den Heiden, seine Standhaftigkeit in den grausamen Qualen der Folter und schließlich seine Haltung im Sterben, die freilich ergänzt werden durch wundersame Bewahrung, Visionen und andere Formen göttlichen Eingreifens.

Im Zeugnis-Geben und im Zeugnis-Sein des Märtyrers, in seiner Verkündigung des Glaubens und dessen Beglaubigung mit seinem Leben und Sterben, verschränken sich die beiden grundlegenden Dimensionen des Zeugnischarakters des Martyriums: die Zeichenhaftigkeit des Geschehens, seine Performanz, und die Möglichkeiten zur diskursiven Glaubenskonfrontation, also der Vermittlung und Verhandlung von Glaubensinhalten, die es bietet. Dabei lässt sich letztere Ebene durch die erste verstärken, sodass das Martyrium insgesamt als Form des ,Glaubensdisputs“ erscheint: Das grausame Wüten des Heiden und die körperlichen Torturen auf der einen, die Standhaftigkeit des Christen und seine wundersame Bewahrung auf der anderen Seite werden im metaphorischen und doch höchst konkreten Sinn zu ,Argumenten“ der religiösen Auseinandersetzung und verlängern den verbalen Disput ins Physische, machen das Martyrium also zu einem ,Glaubensdisput mit anderen Mitteln'. Ebendiese Verschränkung von Wort und Zeichen im Glaubenszeugnis sowie die dabei dargestellte Wirkung auf die Heiden will ich im Folgenden am Beispiel der Legenden der heiligen Margareta und Katharina untersuchen, weil darin das identitätsstiftende Potential des Martyriums, als Form der Aushandlung des religiösen Gegensatzes zu den Heiden, deutlich wird.

100 Vgl. Thomas Frank: Zur Figur des christlichen Märtyrers. In: Nachleben der Religionen. Kulturwissenschaftliche Untersuchungen zur Dialektik der Säkularisierung. Hrsg. von Martin Treml, Daniel Weidner. München 2007 (Trajekte), S. 209-224, hier S. 210 u. 224, Zitat S. 210. 


\subsubsection{Die Zeichenhaftigkeit des Martyriums: Margareta}

Die Margaretenlegende, wie sie die Legenda aurea überliefert, veranschaulicht bereits in den ersten Passagen die Grundkonstellation heiliger Jungfräulichkeit und weiblichen Märtyrertums im legendarischen Erzählen: Margareta ist die Tochter eines heidnischen ,Patriarchen', der sie hasst, weil sie sich mit Erreichen der Mündigkeit taufen lässt. In ihrem 15. Lebensjahr weckt sie unfreiwillig das sexuelle Begehren eines heidnischen Mannes: Der Präfekt Olybrius entbrennt angesichts ihrer Schönheit in heftiger Liebe zu ihr und will sie um jeden Preis besitzen. Seine Diener schickt er zu ihr mit den Worten: ,Ite et eam comprehendite, ut, si libera est, eam mihi in uxorem accipiam, si ancilla, eam mihi concubinam habeam. ' (LA 1216) ${ }^{101}$ Das grundlegende Ungleichgewicht in der Machtkonstellation der Märtyrerlegende ist durch die Geschlechtsdifferenz und die damit verbundene sexuelle Konnotation noch verschärft:

Die Repräsentanten weltlicher Macht werden in einzelnen Texten zwar personalisiert, erscheinen strukturell aber als Masse von männlichen, heidnischen, mit der Souveränität des römischen Staates ausgestatteten Aggressoren, die die Christinnen zum Beischlaf, zur Ehe und zum Abfall vom Christentum zwingen wollen. ${ }^{102}$

Dieser Eindruck wird in der Margaretenlegende der Legenda aurea zusätzlich verstärkt, indem der Name des Präfekten nur zu Beginn genannt wird, im Folgenden und gerade in den Martern, die als besonders drastischer Versuch der Verfügbarmachung des weiblichen Körpers zu verstehen sind, nur die Amtsbezeichnung erscheint, wenn von ihm die Rede ist: Die personale Zeichnung der Figur tritt hinter deren Funktion und die Struktur der Erzählung zurück.

Der Versuch gewaltsamer männlicher Bemächtigung der jungen Frau ist dabei von vornherein auf eine religiöse Konfrontation hin angelegt, die auch diskursiv ihren Ausdruck findet. Denn vor den Präfekten gebracht und nach ihrer Herkunft, ihrem Namen und Glauben befragt, bekennt sich Margareta als Christin. Der Heide antwortet darauf in den Kategorien religiöser Polemik und theologischer Disputation, wie sie die Verhörszenen der Märtyrerliteratur von Anfang an bestimmen, wenn er zunächst in Anspielung auf die Bedeutung des Namens Margareta als ,Perle‘ ihren Adel und ihre Schönheit rühmt: ,Duo prima tibi recte conveniunt, quia et nobilis videris et margerita pulcherrima comprobaris', ihr dann aber im Kontrast umso heftiger ihren Glauben

101 ,,Geht hin und ergreift sie, damit ich sie, wenn sie eine Freie ist, zur Frau nehme, wenn eine Magd, zur Geliebten habe.““

102 Julia Weitbrecht: Entblößung, Scham und Heiligung in den Märtyrerinnenlegenden des Mittelalters und in Hugo von Langensteins Martina. In: Scham und Schamlosigkeit. Grenzverletzungen in Literatur und Kultur der Vormoderne. Für Werner Röcke zum 65. Geburtstag. Hrsg. von Katja Gvozdeva, Hans Rudolf Velten. Berlin/New York 2011 (Trends in medieval philology. 21), S. 330 - 350, hier S. 337. 
vorhält: ,sed tertium tibi non convenit, ut puella tam pulchra et nobilis deum habeat crucifixum‘ (LA 1216). ${ }^{103}$

Dass die hier den Heiden unterstellte Auffassung, wonach ihnen ein gemarterter und gekreuzigter Gott, mit den Worten des Apostels Paulus, als ,Torheit' erscheinen müsse, eben weil äußerer Schein und wahrer Glaube im ,Wort vom Kreuz' auseinandertreten (1 Kor 1), aus christlicher Sicht eine defizitäre ist, kann für den intendierten Rezipientenkreis der Legenda aurea als gemeinsames Glaubenswissen vorausgesetzt werden; es wird in ihrem Rahmendiskurs aber zusätzlich markiert. Denn schon die übliche der Legende vorangestellte pseudo-etymologische Namensdeutung erklärt, Margareta heiße nach einem weißen, kleinen und wundertätigen Edelstein, und bezieht das auf ihre Jungfräulichkeit, Demut und die durch sie bewirkten Wunder, also gerade auf ihre Heiligkeit.

In der Legendenhandlung wird die christliche Perspektive dann herausgearbeitet, indem Margarete den Vorwurf des Heiden gegen diesen selbst umkehrt und ihm seinerseits Verblendung vorwirft. Als er auf ihre Frage, woher er wisse, dass Christus gekreuzigt wurde, antwortet, aus den Büchern der Christen, entgegnet sie: ,Cum ibi legatur Christi poena et gloria, quae vecundia est vestra, ut unum credatis et alterum denegetis?‘ (LA 1216) ${ }^{104}$ Die folgende Verkündigung Margaretas ist zwar, der die Legendenstoffe auf das Wesentliche konzentrierenden Konzeption des Legendars entsprechend, nur stichwortartig angeführt. Ihr Inhalt aber, nämlich die Lehre, Christus habe sich freiwillig kreuzigen lassen und lebe nun in Ewigkeit, ist aber geradezu topisch für Glaubensdispute innerhalb von Märtyrerlegenden, ${ }^{105}$ zumal sie den inhaltlichen Kern des Martyriums, der im jeweiligen Märtyrer exemplarisch durchgespielt wird, vorwegnimmt: Der äußere Schein trügt, gerade in Schwachheit und Sterben erweist sich die Wahrheit des christlichen Gottes.

Margareta weckt mit dieser Verkündigung aber nur den heftigen Zorn des Präfekten, der sie in den Kerker werfen lässt, was die zunächst vom Liebesbegehren des Heiden bestimmte Begegnung der beiden spätestens hier zur Konfrontation nach dem Muster der Märtyrerlegenden codiert. Für deren narratives Schema charakteristisch

103 „,Das erste und zweite paßt gut zu dir, weil du edel scheinst und dich als die schönste Perle erweist, aber das dritte paßt nicht zu dir, daß ein so schönes und edles Mädchen einen Gekreuzigten zum Gott hat.““

104 „,Wenn man doch Christi Leiden und Verherrlichung nachlesen kann, warum seid ihr dann so verblendet, das eine zu glauben, das andere zu leugnen?““

$105 \mathrm{Vgl}$. beispielsweise die Andreaslegende der Legenda aurea, die auf die apokryphen Andreasakten zurückgeht und in deren Tradition der Frage, ob Christus zur Rettung der Menschheit freiwillig ans Kreuz gegangen sei, breiten Platz einräumt und die christliche Auffassung mit fünf Belegen aus den Evangelien belegt (LA 110 - 112). Zur Andreaslegende vgl. meinen Beitrag: Geheimnis und Offenbarung des Glaubens. Zur Konstruktion christlicher Gemeinschaft im legendarischen Erzählen. In: Geheimnis und Verborgenes im Mittelalter. Funktion, Wirkung und Spannungsfelder von okkultem Wissen, verborgenen Räumen und magischen Gegenständen. Hrsg. von Stephan Conermann, Harald Wolter von dem Knesebeck, Miriam Quiering. Berlin 2021 (Das Mittelalter. Perspektiven mediävistischer Forschung. Beihefte. 15), S. 45-64. 
sind die wiederholten und sich steigernden Versuche des Verfolgers, den Christen umzustimmen, hier nicht wie bei Polykarp mit Verweis auf das Alter, sondern die Jugend und Schönheit Margaretas. Erst tadelnd und bittend: ,Vana puella, miserere pulchritudinis tuae et deos nostros adora, ut bene tibi sit', dann zornig und ganz unverhohlen mit Folter und physischer Vernichtung drohend: ,Nisi mihi consentias, corpus tuum faciam laniari. ' (LA 1218) ${ }^{106}$ Margareta Worte setzen dem, der konfrontativen und eskalierenden Logik des Martyriums folgend, das Bekenntnis zum wahren Schöpfer entgegen, dazu die Bereitschaft und mehr noch: die Sehnsucht, für Christus zu sterben, der ,semetipsum pro me in mortem tradidit‘ (LA 1218). ${ }^{107}$

Die freudige Martyriumsbereitschaft Margaretas wird im Folgenden noch drastischer inszeniert, indem ihre Martern konkret ausgemalt werden: Tunc praefectus iussit eam in eculeum suspendi et tam crudeliter primo virgis, deinde pectinibus ferreis usque ad nudationem ossium laniari, quod sanguis de eius corpore tamquam de fonte purissimo emanavit. (LA 1218) ${ }^{108}$ Diese Torturen sollen die heidnische Überlegenheit und die christliche Ohnmacht demonstrieren, zielen zugleich aber explizit auf die Zerstörung der äußeren Schönheit der jungen Christin. Der Eindruck grausamer und ganz körperlich gemeinter Vernichtung wird zusätzlich dadurch gesteigert, dass der heidnische Präfekt selbst als unmittelbarer Veranlasser dieser Torturen genannt wird, während die anderen Umstehenden unter Tränen und mit heftigen Ausrufen das Geschick Margaretas beklagen: ,o Margareta, vere te dolemus, quia corpus tuum crudeliter lacerari conspicimus. O qualem amisisti pulchritudinem propter tuam incredulitatem. Iam nun vel saltem crede, ut vivas. ' (LA 1218) ${ }^{109}$

Doch eine solche Klage erscheint aus christlicher Sicht, wie sie die Märtyrerin stellvertretend für die christliche Rezeptionsgemeinschaft der Legende verkörpert, wiederum defizitär, weil allein in immanenten Kategorien verhaftet, die sich sub specie aeternitatis gerade in ihr Gegenteil verkehren müssen. Die nach rein weltlichen Maßstäben paradoxe Formel, die sie den Klagenden harsch entgegenhält, offenbart den höheren Sinn des Sterbens für Gott und zeugt damit von Margaretas heiligmäBigem Streben: ,O mali consiliarii, recedite et abite, haec carnis cruciato est animae salvatio.' Und den Präfekten schmäht sie siegesgewiss: ,Impudens canis, insatiabilis

106 „,Du dummes Mädchen, erbarme dich deiner Schönheit und bete unsere Götter an, damit es dir wohl ergehe.“ Und: „,Wenn du dich mir nicht fügst, lasse ich deinen Leib zerfleischen.““

107 „,Christus gab sich selbst für mich dem Tode hin, deswegen sehne ich mich danach, für Christus zu sterben.““

108 „Da ließ der Präfekt sie auf das Folterpferd spannen und so grausam zuerst mit Ruten, dann mit eisernen Kämmen bis auf die nackten Knochen zerfleischen, daß das Blut aus ihrem Körper wie aus dem reinsten Quell herausfloß.“

109 „,O Margareta, es schmerzt uns wahrlich, daß wir deinen Leib so grausam zerfleischt sehen! O welche Schönheit hast du verloren wegen deines Unglaubens, doch glaube wenigstens jetzt, damit du am Leben bleibst.““ 
leo, in carne potestatem habes, sed animam Christus servat. '(LA 1218) $)^{110}$ Was hier noch als Behauptung auf der Ebene der Figurenrede formuliert ist, im Fortgang der Handlung dann aber seine performative Evidenz finden soll, ist die dem Narrativ des Martyriums eigene „paradoxale[] Logik der Inversion von Gegensätzen“, wonach „,i]m Zeichen des Martyriums [...] Schwäche zu Stärke, Schmerz zu Lust, Niederlage zum Sieg, Tod zum Leben“ wird:

Diese Umwertungen werden über ein allegorisches Prinzip reguliert. Was in weltlicher Hinsicht negativ besetzt ist, erfährt in geistlicher Hinsicht eine positive Wendung. Diese Logik ist eine der stärksten Waffen aus dem rhetorischen Arsenal des Märtyrers, denn was immer ihm an körperlichen und seelischen Demütigungen angetan wird, kann er ihm Rahmen des religiösen Bezugssystems als erstrebenswerte Auszeichnungen umcodieren. ${ }^{111}$

Eng damit verbunden ist eine andere rhetorische Figur, nämlich die der „Überbietung durch einen höheren Wahrheitsanspruch“"112, die ebenfalls im Handlungsverlauf umgesetzt wird und damit die Kategorien des heidnischen Unglaubens wie jeder rein immanenten Weltsicht desavouiert. Der religiöse Gegensatz zum Heidentum wird eben nicht nur verbal ausgetragen, sondern im Erleiden von Folter und Tod verhandelt, in denen sich letztlich nur die Überlegenheit des christlichen Glaubens erweisen kann: haec carnis cruciato führt nicht nur paradoxerweise zu, sondern sie ist in einer Art Umschlagslogik zugleich animae salvatio, was die wundersame Bewahrung des Märtyrers und endlich seine Aufnahme in den Himmel belegen.

In dieser martyrologischen Dialektik verbinden sich erzähllogisch die äußere Zeichenhaftigkeit des Martyriums und das Streben des Märtyrers nach dem eigenen Heil, das ihn dazu treibt, die Auseinandersetzung mit den heidnischen Verfolger nicht nur zu ertragen, falls sie unausweichlich wird, sondern bewusst herauszufordern. Wo Margareta freudig das Martyrium begrüßt und das Klagen der umstehenden Heiden wie die Drohungen ihres Peinigers, diesen schmähend, zurückweist, wird manch anderer Märtyrer als noch konfrontativer dargestellt. So lässt sich das Bild, das in der Legenda aurea vom heiligen Vincentius während seiner Martern auf einem glühenden Rost gezeichnet wird, folgendermaßen herausarbeiten:

Der Heilige unterstellt das Martyrium seinem persönlichen Lebenszweck, dem Erwerb der ewigen Seligkeit, provoziert die heidnischen Gewalthaber bei oder nach Folterungen durch demonstrative Fröhlichkeit, fordert sie mit Reden heraus, treibt die Schergen zur Eile an und tut alles, um durch

110 „,O ihr schlechten Ratgeber, geht und weicht von mir, diese Folterung des Fleisches ist der Seele Erlösung.““ Und: „,Du schamloser Hund, du unersättlicher Löwe, über das Fleisch hast du Macht, doch Christus bewahrt meine Seele.““

111 Andreas Kraß: Der heilige Eros des Märtyrers. Eine höfische Georgslegende des deutschen Mittelalters. In: Tinte und Blut. Politik, Erotik und Poetik des Martyriums. Hrsg. von dems. und Thomas Frank. Frankfurt a. M. 2008, S. 143-168, hier S. 166.

112 Ebd. 
einen grausamen Tod die gloria passionis und damit zugleich das Ziel des himmlischen Lebens möglichst rasch zu erreichen. ${ }^{113}$

Die Martyriumsbereitschaft und gar -sehnsucht des Heiligen demonstriert jeweils neu die Überbietungs- und Inversionslogik, die das Martyrium aus christlicher Sicht bestimmt. Denn die möglichst brutale Vernichtung seines Körpers muss letztlich umschlagen in die Aufnahme seiner Seele in die himmlische Herrlichkeit. Der religiöse Gegensatz wird also gerade am Heiligenkörper verhandelt und dieser wird zum Medium, in dem sich die Unterlegenheit des Heidentums ebenso manifestiert wie die höhere Wahrheit des christlichen Glaubens und ganz konkret die Kraft seines Gottes.

Diese doppelte und sich gegenseitig kontrastiv verstärkende Zeichenhaftigkeit beruht auf der spezifischen Codierung von Gewalt im Martyrium, die das Erleiden von Fremd-Gewalt zum freiwilligen Selbst-Opfer erklärt und beides in der höheren Gewalt Gottes transzendent absichert. ${ }^{114}$ Das Gewalthandeln der Heiden am Märtyrer ist zunächst der Versuch, den Machtanspruch der weltlichen, heidnischen Herrschaft wiederherzustellen, indem der Christ durch Drohungen und Folter zur Umkehr, also zum Abfall vom christlichen Glauben und der ,Rückkehr` zum heidnischen genötigt werden soll. Wenn diese pragmatische Lösung des Konflikts allerdings scheitert, dienen die weiteren Martern dazu, den heidnischen Machtanspruch in einer symbolischen Ersatzhandlung physisch in den Körper des Märtyrers ,einzuschreiben', wie es der vormodernen Praxis entspricht, „dem Schuldigen seine Schuld mit Folterinstrumenten in seinen Leib einzuprägen, einerseits, um Schuld überhaupt sichtbar zu machen und andererseits, um über die Reziprozität Ordnung wiederherzustellen“. ${ }^{115}$

Es geht den heidnischen Verfolgern also vorrangig nicht um die Tötung und damit die physische Vernichtung des Märtyrers, „sondern um die Durchsetzung uneingeschränkter Herrschaft im Sinne grenzenloser Kontrolle“. ${ }^{116}$ Alle immanenten Versuche, die Verfügungsgewalt über den Glaubenszeugen wiederzugewinnen, müssen allerdings angesichts der transzendenten Macht Gottes kläglich scheitern. Das spielen die Märtyrerlegenden in immer neuen Folgen aller erdenklichen Arten von Martern und Hinrichtungsmethoden durch, denn gerade in ihrer Steigerung erweist sich die hilflose Vergeblichkeit solch weltlichen Tuns: Gott bewahrt seinen Heiligen in der

113 Vgl. Ernst, Der Körper des Asketen, S. 294.

114 Vgl. oben in Kap. 3.1.2 Das Martyrium als Praxis der Differenz, S. 109-110.

115 Franziska Hammer: Grausamkeit als Modus der Unterhaltung. Zur Funktionalisierung von Grausamkeit in den Folterszenen spätmittelalterlicher Passionsspiele und Heiligenlegenden. In: Grausamkeit und Metaphysik. Figuren der Überschreitung in der abendländischen Kultur. Hrsg. von Mirjam Schaub. Bielefeld 2009 (Edition Moderne Postmoderne), S. 118-140, hier S. 125.

116 Ebd., S. 124. Ganz ähnlich argumentiert Albrecht Schirrmeister: Folter und Heiligung in der Legenda Aurea. Frühchristliche Martern und spätmittelalterliche Körperkonzepte. In: Das Quälen des Körpers. Eine historische Anthropologie der Folter. Hrsg. von Peter Burschel, Götz Distelrath, Sven Lembke. Köln [u. a.] 2000, S. 133-149, hier S. 137-139. 
Folter und tilgt anschließend alle ihre Spuren von seinem Körper. ${ }^{117}$ Heiligung und Heiligkeit werden damit visualisiert, sie sind am Körper des Heiligen ,abzulesen', der Körper wird zum Zeichenträger:

Der weltlichen Beschriftung wirkt aber eine transzendente Macht entgegen: Auf vielfältige Weise widersetzen sich die Körper der Märtyrer dieser ,Strafliturgie‘ [...] Je nachdrücklicher sich die Heiligkeit vergegenständlichen soll, desto gewalttätiger muß geschrieben werden und desto resistenter muß der Körper die Annahme der Schriftspuren verweigern. ${ }^{118}$

Dabei vollzieht sich immer wieder die äußerliche sichtbare „Umdeutung der Zeichen durch die transzendente Macht“"119, die die innere Struktur der überbietenden Inversion verdeutlicht. Heiligkeit wird als Präsenzphänomen am Körper des oder der Heiligen auf diese Weise öffentlich sichtbar gemacht, der Prozess der Heiligung so vor einem intra- wie extradiegetischen Publikum nachvollziehbar dargestellt, das sich als Zeuge dieser Manifestation des Heils verstehen soll und an ihm teilhaben darf. ${ }^{120}$ In dieser Sichtbarwerdung und Wahrnehmbarkeit von Heiligkeit gerade am Heiligenkörper selbst liegt das besondere Potential der Märtyrerlegenden, die beiden Leitunterscheidungen von christlich-heidnisch und heilig-profan, die das legendarische Erzählen bestimmen, aber nicht deckungsgleich sein müssen, ${ }^{121}$ in Übereinstimmung zu bringen.

Dieses Potential einer zeichenhaften Aushandlung des religiösen Gegensatzes wird in der Margaretenlegende der Legenda aurea indes kaum ausgeschöpft, denn die wundersame Wiederherstellung des Heiligenkörpers wird hier nicht auserzählt, sondern vor allem der Schrecken der Zerstörungen geschildert, die es als umso erstaunlicher erscheinen lassen, dass sie, die „bis auf die nackten Knochen“ (LA 1218) zerfleischt ist und aus deren Körper das Blut in Strömen fließt, noch unerschrocken ihren Glauben bekennt. Entscheidender für das Bild der Heiligen scheint hier die innere geistliche Dimension ihres Martyriums, ihre Glaubensgewissheit, die nicht an die

117 ,„W]obei man nicht vergessen darf, daß im geltenden Rechtsbewußtsein des Mittelalters scheiternde Hinrichtungen entweder zur offiziellen Begnadigung oder zum Durchsetzen der Gnade durch die Zuschauer führen, was das Skandalon der trotz aller Vergeblichkeit wiederholten Tötungsversuche deutlich macht, das im Bewußtsein der Rezipienten entstanden sein muß“. Hans-Jürgen Bachorski, Judith Klinger: Körper-Fraktur und herrliche Marter. Zu mittelalterlichen Märtyrerlegenden. In: Körperinszenierungen in mittelalterlicher Literatur. Kolloquium am Zentrum für Interdisziplinäre Forschung der Universität Bielefeld (18. bis 20. März 1999). Hrsg. von Klaus Ridder. Berlin 2002 (Körper, Zeichen, Kultur. 11), S. 310 - 333, hier S. 315.

118 Vgl. dazu auch ebd., S. 317.

119 Ebd., S. 319.

120 Vgl. Julia Weitbrecht: Die magd nakint schowen / Ir reinen lip zerhowen. Entblößung und Heiligung in Märtyrerinnenlegenden. In: „Und sie erkannten, dass sie nackt waren.“ Nacktheit im Mittelalter. Ergebnisse einer interdisziplinären Tagung des Zentrums für Mittelalterstudien der Otto-FriedrichUniversität Bamberg, 3. und 4. November 2006. Hrsg. von Stefan Biessenecker. Bamberg 2008 (Bamberger interdisziplinäre Mittelalterstudien. 1), S. 269-288, hier S. 276-277.

121 Vgl. Hammer, Seidl, Die Ausschließlichkeit des Heiligen, S. 275. 
äußeren Zeichen der materiellen Welt gebunden ist. Denn die Haltung, die ihr mit den Entgegnungen an die Heiden und ihren Verfolger in den Mund gelegt wird, ist bestimmt von einem Leib-Seele-Dualismus, der alles Irdische in einem rein spirituellen Verständnis immer schon transzendiert und die Verfügungsgewalt der Peiniger über den Heiligenkörper damit nicht nur konterkariert, sondern völlig entwertet: Nur in carne haben die Heiden potestatem, aber Margaretas Seele dient Christus. Die Transzendenz bricht hier nicht herein in die Immanenz, um in ihr den Körper der Heiligen wundersam zu bewahren, sondern ist der eigentliche Zielpunkt, von dem her alles Immanente einen nur vorläufigen Sinn erhält.

Man wird diese Konzentration auf die geistliche Haltung der Heiligen, entgegen anderen Überlieferungen, die die körperlichen Qualen und die Heilung ihrer Wunden in den Mittelpunkt rücken, der straffenden und reduzierenden Erzählweise der Legenda aurea zuschreiben können, andererseits dem klerikal-monastischen Kontext, in dem ihre Entstehung und intendierte Rezeption zu verorten ist und in dem man sich sehr wohl des Problems bewusst war, dass übertriebene Wunderdarstellungen und allzu drastische Ausschmückungen der grausamen Martern den ,eigentlichen“ spirituellen Gehalt der Legenden überlagern und ihrer Glaubwürdigkeit abträglich sein mochten. Davon unberührt ist aber die grundlegende paradoxale Konstruktion, die die christliche Vorstellung vom Martyrium bestimmt und derzufolge gerade und mitunter obsessiv ausgebreitete Gewaltdarstellungen das Heilige sichtbar machen sollen, eben weil sie eine Transzendierung des Geschehens ermöglichen. ${ }^{122}$ Die GegenGewalt, die der Märtyrer in dieser Konstellation auszuüben vermag, liegt allein auf sprachlicher Ebene in der verbalen Konfrontation mit den Heiden oder aber der symbolischen Überwindung des Heidentums in Götzenbildern und Teufelsmanifestationen.

Letzteres hat gerade in der Margaretenlegende seinen festen Platz, denn bevor sich das Wechselspiel aus heidnischer Folter und göttlicher Bewahrung fortsetzt, um im Moment des Todes mit der Aufnahme der Heiligen in die himmlische communio sanctorum aufgelöst zu werden, wird sie zunächst in den Kerker gebracht, der auch sofort von wunderbarem Glanz erfüllt ist. Diese narrative Pause nach den ersten Foltern ermöglicht nun die Ausdeutung der äußeren Konfrontation mit dem Heidentum auf einer spirituellen Ebene und zwar in einem bildhaften Ausdruck des inneren Glaubenskampfes, den Margareta in ihrem Martyrium siegreich bestehen wird. Im Kerker betet sie zu Gott, ut inimicum, qui secum pugnat, visibiliter sibi demonstraret (LA 1218) ${ }^{123}$, erbittet also selbst die Manifestation des teuflischen Gegenspielers, der ihr und dem Legendenpublikum als eigentlicher Gegner hinter dem heidnischen Unglauben gilt. Daraufhin erscheint zuerst ein riesiger Drache, der sie verschlingen

122 Vgl. dazu Ralf Lützelschwab: Vom Blut der Märtyrer. Gewalt in der Legenda aurea. In: Blutige Worte. Internationales und interdisziplinäres Kolloquium zum Verhältnis von Sprache und Gewalt in Mittelalter und Früher Neuzeit. Hrsg. von Jutta Eming, Claudia Jarzebowski. Göttingen 2008 (Berliner Mittelalter- und Frühneuzeitforschung. 4), S. 113-128, hier S. 127.

123 „[D]aß er ihr den Widersacher, mit dem sie kämpfte, sichtbar zeige“. 
will, aber verschwindet, als sie das Kreuzzeichen macht. ${ }^{124}$ Das in einer anderen Überlieferung der Legende Berichtete, wonach der Drache sie frisst und beim Kreuzzeichen birst, damit sie unversehrt aus ihm heraussteigen kann, wird in der Legenda aurea, ein Beispiel für die vorsichtige Quellenkritik in diesem Legendar, ${ }^{125}$ als apocryphum et frivolum (LA 1218) abgelehnt.

Der Teufel erscheint Margareta schließlich in Gestalt eines Mannes, der sie von ihrem Kampf abbringen will. Das passive Leiden in der Folter durch die Heiden wird hier in einen aktiven, physischen Kampf gewendet: Sie packt ihn am Kopf, wirft ihn nieder und setzt ihren Fuß auf seinen Nacken. Ihre Jungfräulichkeit dient auch in diesem Zusammenhang zur kontrastiven Steigerung des Sieges, denn während der männlichen Jugend Stärke zugeschrieben wird, gilt die weibliche als Schwäche: Daemon autem clamabat: ,O beata Margareta, superatus sum. Si iuvenis me vinceret, non curassem. Ecce, a tenera puella superatus sum et inde plus deleo, qui pater tuus et mater amici mei fuerunt.' (LA 1220) ${ }^{126}$ Doch die Überwindung des Teufels dient nicht nur der symbolischen Ausdeutung des Martyriums als Kampf gegen das Heidentum, von dem sich Margareta in der Taufe einst selbst aktiv abgewendet hat, sondern legt dessen spirituelle Dimension offen. Denn sie zwingt den Dämon, ihr zu bekennen, dass er gekommen sei, um ihr zu raten, den Ermahnungen des Präfekten nachzugeben, und dass er die Menschen versuche, weil er selbst, so die Anspielung auf den apokryphen Höllensturz der Engel, einst das Heil verloren habe. Schließlich schickt sie ihn fort und dieser Sieg über den Teufel nimmt den Sieg gegen den heidnischen Unglauben im Martyrium vorweg, so leitet der Erzähler über: Secura igitur efficitur, quia quae principem vincerat, ministrum procul dubio superaret. (LA 1220) 127 $^{27}$

Am folgenden Tag fordert der Präfekt Margareta noch einmal auf, den heidnischen Göttern zu opfern, und als sie sich weigert, wird sie entkleidet und ihr Leib facibus ardentibus usque ad intima comburitur ita, ut cuncti mirarentur, quomodo tam tenera puella tot posset tolerare tormenta (LA 1220). ${ }^{128}$ Die Sexualisierung des weiblichen Körpers, die den Märtyrerinnenlegenden zugrundeliegt, setzt sich in der mit dem öffentlichen Entkleiden verbundenen Beschämung fort und bekommt mit der bis ins Innerste dringenden Bemächtigung noch eine weitere Konnotation immanenter Verfügbarmachung. Doch bleibt dieses Motiv hier in der Latenz, der Fokus liegt auf der von den Heiden bestaunten Leidensfähigkeit Margaretas und ihrer Bewahrung, wie sie

124 Das Drachenmotiv findet sich in Ausschmückung der Begegnung Margaretas mit dämonischen Mächten schon seit der Spätantike in ihren Legenden. Vgl. Josef J. Schmid: Art. Margareta. In: BBKL 18 (2001), Sp. 855-859., hier Sp. 857.

125 Vgl. Prautzsch, Die Wahrheit der Legende, S. 104.

126 „Der Dämon aber schrie: ,O heilige Margareta, ich bin bezwungen! Wenn mich ein Jüngling besiegte, hätte ich's noch hingenommen. Doch siehe, von einem zarten Mädchen bin ich überwunden, und das schmerzt mich um so mehr, als dein Vater und deine Mutter meine Freunde waren.““

127 „Sie fühlte sich also sicher: Da sie den Fürsten besiegt hatte, würde sie zweifellos auch den Diener bezwingen.“

128 „[B]is zuinnerst mit brennenden Fackeln versengt, so daß sich alle wunderten, wie ein so zartes Mädchen so viele Foltern ertragen könne“. 
gerade in der unmittelbar folgenden Tortur deutlich wird: Als der Heide Margareta gefesselt in ein Wasserfass legen lässt, ut ex poenarum commutatione cresceret vis doloris (LA 1220), ${ }^{129}$ erbebt die Erde und für alle sichtbar entsteigt die Jungfrau dem Wasser. Die der Weiblichkeit zugeschriebene Schwäche steigert also die für alle wahrnehmbare Exorbitanz ihrer Standhaftigkeit im Martyrium - und führt letztlich zum größtmöglichen Umschlag, nämlich der massenweisen Bekehrung von Heiden, die nun unmittelbar ihrerseits bereitwillig das Martyrium erleiden: Tunc quinque milia virorum crediderunt et pro nomine Christi capitalem sententiam acceperunt. (LA 1220) $)^{130}$

Damit verschiebt sich der strukturelle Gegensatz: Der heidnische Verfolger steht nun allein blind und unbelehrbar der Glaubenswahrheit gegenüber, die seinen eigenen Leuten offenbar geworden ist, die spätestens in ihrem Sterben für ihren neuen Glauben Teil der christlichen Rezeptionsgemeinschaft werden, die sich im zeichenhaften Zeugnis des Martyriums der Heiligen konstituiert, intra- wie extradiegetisch. Gerade um weitere Bekehrungen und damit den ,Erfolg' des Martyriums aus christlicher Sicht zu verhindern, lässt der Präfekt Margareta schließlich enthaupten, die sich vorher jedoch Zeit erbittet, um demütig für sich und ihre Verfolger zu bitten, zudem pro eius memoria agentibus et se invocantibus [...] addens, ut, quaecumque in partu periclitans se invocaret, illaesam prolem emitteret (LA 1220). ${ }^{131}$

Wenn schließlich noch eine Stimme vom Himmel ertönt, als Zeichen, so der Erzähler, dass ihre Bitte erhört sei, dann ist diese narrative Begründung der spezifischen Mittlerfunktion Margaretas unmittelbar vor ihrem Tod, der ihre endgültige Aufnahme in die himmlische Herrlichkeit markiert, ein topisches Motiv des legendarischen Erzählens, das die Legende mit der kultischen Verehrung der Heiligen post mortem verklammert und damit das Geschehen auf die extradiegetische Rezeptionsgemeinschaft hin öffnet. Eine letzte Bestätigung ihrer Heiligkeit, die noch einmal die Freiwilligkeit ihres Opfers und die Ergebenheit in die göttliche Vorsehung unterstreicht, stellen ihre Worte an den Henker dar, den sie als „Bruder“ anspricht und auffordert, das Schwert zu erheben und zuzuschlagen. Angesichts der Gnadengewissheit Margaretas scheint selbst der Gegensatz zum heidnischen Scharfrichter überwunden, für den sie nicht nur betet, sondern den sie als Werkzeug göttlichen Gnadenhandelns begrüßen kann. Die Handlung wird mit der prosaischen und ebenso glaubensgewissen Feststellung beschlossen: Qui percutiens caput eius uno ictu abstulit et sic martyrii coronam suscepit (LA 1222), ${ }^{132}$ die die Formel von der Marter des Fleisches, die das Heil

129 „[D]amit aus dem Wechsel der Qualen die Wucht des Schmerzes sich noch steigere“.

130 „Darauf wurden 5000 Männer gläubig und nahmen für den Namen Christi das Todesurteil auf sich.“

131 „[F]ür die, die ihr Andenken wahren und sie anrufen wollten, indem sie hinzufügte, daß jede Frau, die sie bei der Geburt in Nöten anrufe, ein gesundes Kind zur Welt bringe“.

132 „Dieser schlug zu und hieb ihr mit einem einzigen Hieb das Haupt ab, und so empfing sie die Märtyrerkrone.“ 
der Seele bedeute, auf Erzählerebene bekräftigt und zur verbindlichen Glaubenswahrheit erhebt.

Der zeichenhafte Charakter des Martyriums besteht also strukturell und erzähllogisch im Wechselspiel von heidnischer Verfolgung und göttlicher Bewahrung, das im Tod des Heiligen endgültig auf letztere hin aufgelöst wird, überdies aber paradigmatisch in der Glaubenshaltung des Märtyrers sowie in den Wundern, zu denen das Martyrium Anlass gibt und die es damit zugleich bestätigen. So ergänzt auch Feistner in ihrer Darstellung des Märtyrerschemas, dessen Basisnexus in der syntagmatischen Verknüpfung von Verhör, Haft und Hinrichtung liege, dass zu diesen drei Elementen und als deren Bestandteile „mit Vorliebe die Elemente Folter und Wunder beziehungsweise Bekehrung“ hinzutreten: Während die Foltern vor allem das oder die Verhöre begleiten, können „[d]ie Elemente Wunder und Bekehrung [...] sowohl Verhör als auch Haft und Hinrichtung begleiten“. ${ }^{133}$ Zwar fasst Feistner dabei etwas kurzschlüssig unter dem Element der Folter die Glaubenskraft und Opferbereitschaft des Märtyrers zusammen, unter dem des Wunders alle durch ihn gewirkten Wunder und damit auch die Bekehrungen, und unterschneidet damit die elementar wichtige Funktion der göttlichen Bewahrung, die das Martyriumsnarrativ und damit beide Elemente grundlegend bestimmen: Letztlich wirkt nicht der Heilige die Wunder, sondern Gott durch ihn, und alle Opferbereitschaft wäre vergebens, wenn ihr nicht die transzendente Wirklichkeit antworten würde. Dennoch benennt Feistner sehr treffend die Funktion der beiden Elemente Folter und Wunder, die

das Erzählsyntagma mit paradigmatischen (Minimal-)Episoden [besetzen], die dazu dienen, die Elemente des Basisnexus in variabler Dichte narrativ zu füllen und dabei noch zusätzlich die exemplarische Botschaft, die der Geschehenszusammenhang als solcher schon demonstriert, auch im Detail zu illustrieren. ${ }^{134}$

Die Glaubenshaltung des Märtyrers in den Foltern, seine wundersame Bewahrung, durch ihn gewirkte Wunder und Bekehrungen veranschaulichen also Tiefenstruktur und Kernbotschaft des Martyriums, wonach die vermeintliche christliche Ohnmacht und die ebenso nur vermeintliche heidnische Überlegenheit sich letztlich in ihr Gegenteil verkehren müssen: Das Sterben für Gott wird zum Heilsweg und damit zeichenhaft zum Zeugnis für die Wahrheit des christlichen Glaubens.

Wenn dieses Narrativ unter äußeren Bedingungen, in denen das Martyrium eine real mögliche beziehungsweise noch als solche $\mathrm{zu}$ imaginierende Glaubenskonfrontation darstellt, eine konkret handlungsleitende und vor allem identitätsstiftende Funktion in der religiösen Selbstbehauptung gegenüber dem Heidentum haben mochte, so lässt sich seine Kernbotschaft später, als der religiöse Gegensatz in einer christlichen Mehrheitsgesellschaft zu einer rein symbolischen Funktion geworden ist, nach innen wenden. Dann wird die spirituelle Dimension des Martyriums umso

133 Feistner, Historische Typologie, S. 27.

134 Ebd., S. 28. 
wichtiger, weil sie dazu geeignet ist, geistliche Tugenden, die jeden Gläubigen betreffen, exemplarisch darzustellen, so eben am Beispiel von Margareta etwa Glaubenstreue, Standhaftigkeit, Leidensfähigkeit und unerschütterliches Gottvertrauen.

Diese didaktisch-paränetische Funktion der Märtyrerlegenden wird in der mittelalterlichen Vermittlung der Margaretenlegende an ein volkssprachig-laikales Publikum deutlich. Sie rückt im Passional gleich zu Beginn in einem knappen Prolog, eine eigenständige Zutat gegenüber der Legenda aurea, in der Darstellung der Heiligen selbst in den Fokus, die in ihrer Glaubenshaltung als vorbildhaft gilt:

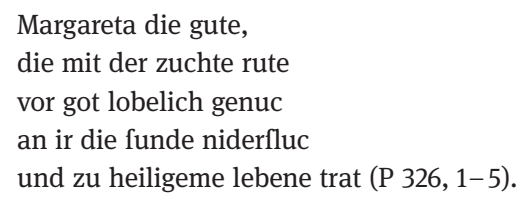

Mit dem Gedanken, dass Margareta nicht das Schlechte im Heidentum um sich her besiegt, sondern als Sünde an oder in sich selbst, und damit die Heiligkeit gewinnt, wird die äußere Glaubenskonfrontation zu einer inneren umcodiert. Das wird gerade dort explizit gemacht, wo vom historischen Kontext der Christenverfolgungen die Rede ist, in denen viele vom Glauben abfallen, einige hingegen in ihrer Standhaftigkeit die Heiligkeit gewinnen:

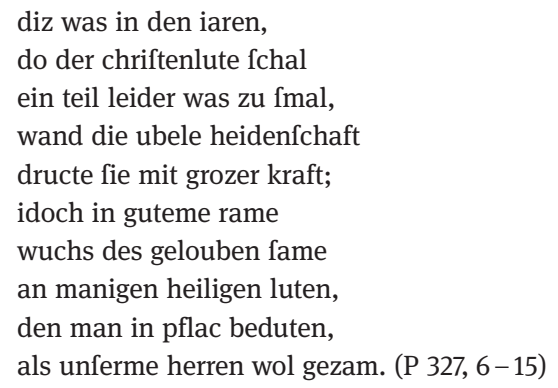

Die äußere Not der Verfolgungen wird zum Schauplatz eines geistlichen Ringens um Heiligkeit und das meint im Fall der heiligen Jungfrau die körperliche Keuschheit, die metonymisch für die Unversehrtheit des Glaubens steht:

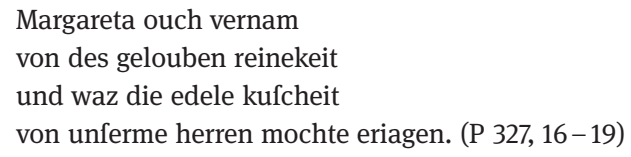

Die zum Vorbild erhobene Glaubenshaltung Margaretas wird dabei versreich und mit lyrisch Bildern ausgemalt, Gott selbst habe sie ihr eingegeben, wie „süßer Tau“, der herniederfällt: 


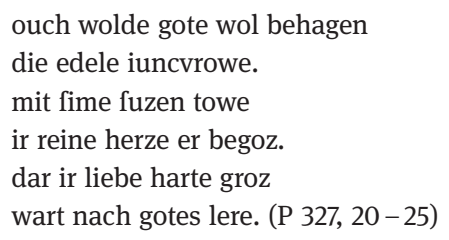

Diese innere Erleuchtung und Bekehrung erst ist die Grundlage für den äußeren Glaubenswechsel zum Christentum in der Taufe, die die vruntfchaft des Vaters ihr gegenüber erkalten lässt, was ihr freilich nichts ausmachen kann,

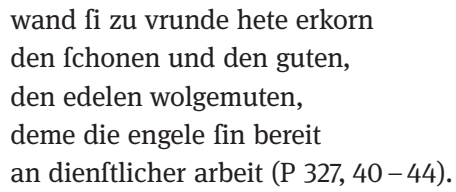

In andächtig umschreibender mystischer Sprache wird der Glaube an Christus, der alle innerweltlichen Bindungen übersteigt, neue Identität und Gemeinschaft stiftet und das Heil garantiert, einem Publikum vor Augen gestellt, das einer solchen Verinnerlichung im gläubigen Mitvollzug des Geschehens fähig scheint. Der heidnische Verfolger wird demgegenüber von vornherein als vom Teufel eingesetzter Gegenspieler in einem diabolischen Kampf vorgestellt:

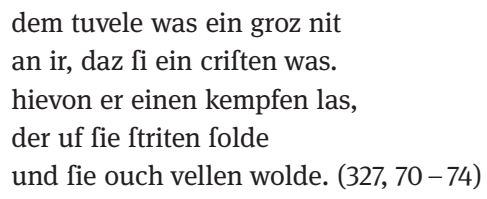

Damit ist das Martyrium nicht mehr nur ein exemplarischer Fall religiöser Konfrontation, sondern eine persönliche Versuchung Margaretas, die als kriegerische Fehde inszeniert wird, wenn Olybrius seine christliche Kontrahentin auffordert, sich ihm zu ergeben: ,la den kric und gib mirn / [...] von dem felben gote', worauf diese in einer Reizrede kampfeslustig zur Konfrontation drängt: ,la, [...] la ftrichen! / ich wil der martere vro fin.' (P 329, 18-19 und 26-27)

Diesem persönlichen Charakter der Versuchung entspricht, dass Olybrius im Passional anders als in der Legenda aurea durchweg bei seinem Namen genannt wird und nicht hinter eine herrschaftliche Funktion zurücktritt, zu Beginn schlicht in ritterlich-höfischen Kategorien ein herre uberz lant (P 327, 75) genannt wird. Sein Liebesbegehren ist, mit Anklängen an weltliche Minnemetaphorik, negativ konnotiert als Gewalterfahrung beziehungsweise Gewalthandeln an Margareta: ir liebe in fin herze brach, / die in befaz mit gewalt und fine knechte fante er hin / und liez fie mit gewalt ufnemen (P 327, 90-91 und 96-97). Auch dem Heiden wird dabei eine Binnenperspektive eingeräumt und damit im Kontrast zu Margaretas heiligmäßigem Streben sein sündhafter weltlicher Antrieb anschaulich gemacht, wenn es heißt: 
Olybrius der valfche man

fach fie gutlichen an

und hofte fie berouben

wol von deme gelouben,

uf den ihr herze was gewant. (P 328, 29-33)

Der Konflikt zwischen beiden ist also nicht nur der um den Wahrheitsanspruch von Heidentum oder Christentum, sondern zwischen falschem, weltlichem und richtigem, geistlichen Lebenswandel, und dieser Widerstreit wird mit den sprachlichen und inhaltlichen Mustern kriegerischen Kampfes imaginiert. Die folgenden Wechselreden folgen dabei inhaltlich sehr nah der Legenda aurea, werden aber dramatischer und ausführlicher gestaltet, wobei vor allem die katechetische Vermittlung von Glaubenslehren sowie die adhortative Hinführung zu rechter Frömmigkeit breiter ausgeführt werden. Exemplarisch dafür ist die predigtartige Verteidigungsrede Margaretas auf den Vorwurf des Heiden, der gekreuzigte Gott gezieme ihrer Schönheit nicht:

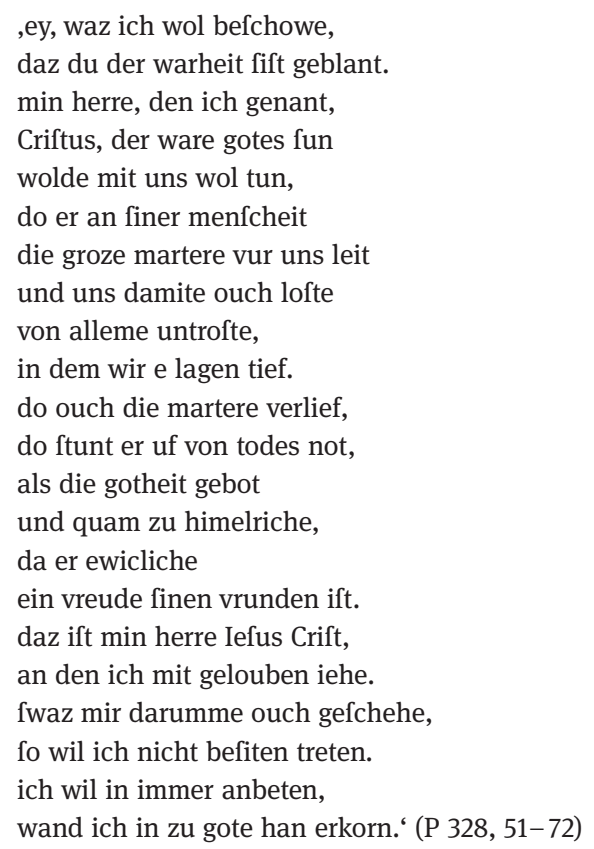

Charakteristisch für die hier erkennbare laienkatechetische Vermittlungsweise ist, dass das Heilsgeschehen nicht einfach behauptet, sondern in seiner Bedeutung für die christlichen Gläubigen - intradiegetisch wie für die Wir-Gemeinschaft der Rezipienten, die sich zu finen vrunden zählen dürfen - geschildert wird. In der Gewissheit der Auferstehung Christi, die heilsgeschichtlich auf seine Leiden folgen muss, gründen handlungsmotivierend der Bekennermut und die Standhaftigkeit Margaretas, sie soll zugleich aber im Martyrium und darüber hinaus dem Legendenpublikum als sichere und vor allem heilswirksame Glaubenslehre dargestellt werden. 
In der Grundstruktur und Kernbotschaft folgt die Margaretenlegende des Passionals dabei ganz der der Legenda aurea, selbst die Formel vom Haec carnis cruciato findet sich ins höfische Versmaß übertragen, wobei aber der Überbietungsgestus durch eine verdienstliche Kompensationslogik noch gesteigert wird, denn nun heißt es: ie grozer not der lib hat, / ie grozer lon die fele entpfat. (P 329, 73-74) Das Maß der Leiden in den Foltern soll also mit dem der göttlichen Gnade korrelieren und diese Heilslogik erscheint umso verbindlicher, als sie der Heiligen selbst in den Mund gelegt wird. Auch sonst liegt der Fokus in Verhör, Haft und Hinrichtung vor allem auf Margaretas Glaubenshaltung, so nimmt der Rezipient mit ihren Augen den Kerker und die Martern wahr und wird auf diese Weise unmittelbar in das Geschehen hineingenommen:

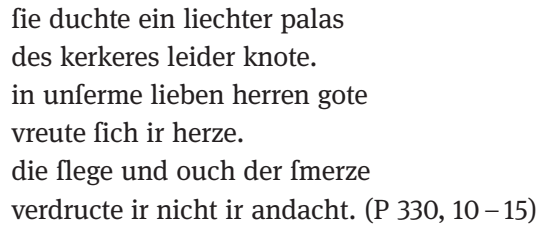

Der Erzählerkommentar liefert mit der Autorität auktorialer Unumstößlichkeit zugleich die aus christlicher Perspektive wahre, eigentlich angemessene Deutung der äußeren Bedrängnis in Haft und Folter, die im Sinne der von Margareta postulierten Heilslogik Grund zur Freude und Andacht sind. Der Wahrheitsanspruch dieser Perspektive findet sich auch im Passional wiederum in der Zeichenhaftigkeit des Martyriums narrativ umgesetzt, denn durch die wundersame Bewahrung Margaretas werden alle Umstehenden gewar (P 332, 21), dass Gott sie schützt:

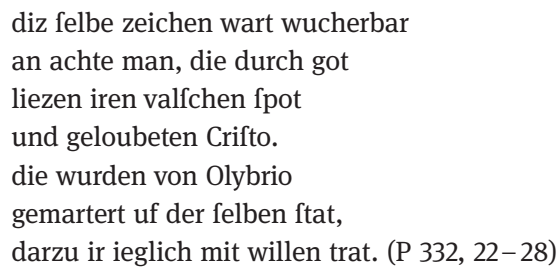

Das Wunder als heilspräsentisches zeichen bringt unmittelbar Frucht, auch wenn die Zahl der Folgemärtyrer hier deutlich überschaubarer, dabei aber wohl ,realistischer` und auf den einzelnen Gläubigen in seiner persönlichen Glaubensentscheidung konzentriert ist. Der Epilog greift inhaltlich den Prolog auf, bündelt aber die in der Legendenerzählung entwickelten Rezeptionspotentiale und bindet sie in der Gewissheit der Auffahrt Margaretas von aller leides klage / ze himel in der iuncvrowen fchar (P 332, 70 - 71) in einem formelhaften Gebetsschluss an die christliche Rezeptionsgemeinschaft, in der sie ihre Verwirklichung finden sollen: 


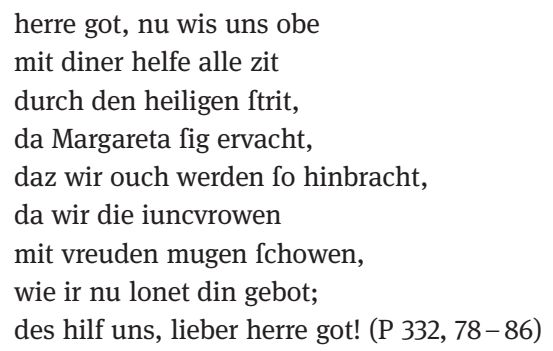

Die Zeichenhaftigkeit des Martyriums wird also auf die Funktion der Heiligen als erbauliches Beispiel und Vorbild für den geistlichen ,Kampf‘ jedes einzelnen Gläubigen hin ausgedeutet. Während die Legenda aurea eine allgemeine admiratio in der Vergegenwärtigung des Heilshandelns Gottes in seiner Märtyrerin befördert, zielt das Passional unmittelbarer auf die aedificatio und eine den äußeren Glaubenskampf gegen das Heidentum metaphorisierende imitatio, die den inneren Weg zum Heil meint.

Wie sehr volkssprachige Vermittlungen von Märtyrerlegenden gerade in der Inszenierung des religiösen Gegensatzes zum Heidentum auf einen entsprechenden Rezeptionsrahmen und Gebrauchszusammenhänge reagieren, lässt sich am Beispiel zweier ,höfischer ${ }^{6}$ Margaretenlegenden zeigen. ${ }^{135}$ Rudolf von Ems nennt im Dichterkatalog seines um 1235 entstandenen Alexanderromans einen Wetzel als Freund, attestiert ihm adlige Abkunft und preist seine Margaretenlegende. ${ }^{136}$ Genaueres über diesen Wetzel von Bernau, so die Selbstnennung in der Legende (WeM 90), ist nicht bekannt, weitere Werke sind nicht überliefert und auch der genaue Bezug zwischen Rudolf und ihm ist in der Forschung strittig. Offensichtlich aber ist die höfische Er-

$135 \mathrm{Zu}$ einer genaueren Analyse vgl. Feistner, Historische Typologie, S. 91-116, die insgesamt vier Versionen der Margaretenlegende „als exemplarische Fallstudie“ für „Typus und Variation“ der Märtyrerlegende untersucht. Ich beschränke mich auf die beiden aus der ersten Hälfte des 13. Jahrhunderts, an denen sich die höfische Stilisierung und eine entsprechende Akzentuierung des Heidenbildes zeigen lässt. Die Margaretenlegende Hartwigs von dem Hage - Hartwig von dem Hage: Margarete. Hrsg. von Wolfgang Schmitz. In: Die Dichtungen des Hartwig von dem Hage. Göppingen 1976, S. 259304. - lasse sich aus der Analyse ihrer Sprache ins Ende des 13. Jahrhunderts datieren (vgl. Feistner, Historische Typologie, S. 93) und sei eine ziemlich getreue Übersetzung der lateinischen Quelle, die keine eigene Vermittlungsweise entwerfe, sondern „statt dessen im Sinn eines subtilen hierarchischen Diskurses insinuierend belehrt“ (ebd., S. 112) und Margareta als Vorbild jungfräulichen Lebens für ein klösterliches Laienpublikum, besonders in einem Frauenkloster, nutze (vgl. ebd., S. 113). Die anonyme Marter der heiligen Margarete - Sankt Margareten Büchlein. Hrsg. von Moritz Haupt. In: ZfdA 1 (1841), S. 151-193. - arbeite das virginitas-Ideal sogar noch markanter heraus und lasse in ihrer ,,reißerische[n]' Aufmachung“ (Feistner, Historische Typologie, S. 114) eine öffentliche Predigtsituation vermuten und stamme wahrscheinlich noch aus dem 12. Jahrhundert (vgl. ebd., S. 93).

136 Sante Margarêten leben / hât uns gevuoge vür gegebn / mîn vriunt her Wetzel, des gihe ich. Rudolf von Ems: Alexander. Ein höfischer Versroman des 13. Jahrhunderts. Zum ersten Male herausgegeben von Victor Junk. Erster Teil: Buch 1-3. Leipzig 1928, V. 3259-3260. Vgl. Edith Feistner: Art. Wetzel von Bernau. In: ${ }^{2}$ VL 10 (1999), Sp. 975-977, hier Sp. 975. 
zählweise seines Textes, die sich schon im Eingang mit einem für das höfisch-laikale Legendenerzählen typischen Prolog von 102 Versen zeigt, der mit einer allgemeinen religiöser Sentenz beginnt - hier der Abgrenzung vom Sündenfall: wir sullent gehorsam sin gott / vnd gern halten sin gebott (WeM 35-36) - und diese wortreich ausdeutet, sie schließlich mit dem Erzählertopos der Bekehrung von der höfischen Dichtung zu geistlichen Werken - Ich han da her vil gelogen / an eigner auentur guott (WeM 80 - 81) - verknüpft, um schließlich die materia seiner Erzählung einzuführen.

Diese wird in direkter Publikumsansprache auf den Funktionszusammenhang der kultischen Verehrung der Heiligen als Vorbild und Mittlerin bezogen: [das ir] wunschent och $d z$ uwer botte / der raine maget süsse / ze gott wesen müsse (WeM 94-96). Innerhalb dieses Rezeptionsrahmen, der durch einen knappen Epilog geschlossen wird, finden sich auf der Ebene der histoire keine Änderungen, vielmehr liegt die Vermittlungsleistung an ein mit den Mustern und der Sprache der höfischen Literatur vertrautes Publikum im discours, besonders in einer entsprechenden Profilierung des Erzählaktes:

Während die Fakten selbst meist genau reproduziert werden, unterscheidet sich die diskursive
Vermittlung beträchtlich vom liturgischen Pathos der Quelle. Im Zuge einer nicht unbedingt
virtuosen, aber selbstbewußten laikalen Aneignungsstrategie [...] wird der Vortragsakt des Er-
zählers profiliert, der sich direkt ans Publikum wendet, bewunderndes Erstaunen äußert oder
Zeitkritik übt. Dementsprechend rückt an die Stelle der vertikalen Perspektive, nach oben' wie sie
sich beim Pseudo-Theotimus [= die lateinische Vorlage, F.P.] unter anderem in den Gebeten der
Heiligen artikuliert, eine szenische Vergegenwärtigung des Geschehens, die den Blick auf die
Interaktionen der Figuren richtet. ${ }^{137}$

Auf der histoire-Ebene ist es ,als einzig genuin höfisches Merkmal [...] die Stilisierung des Christenverfolger Olibrius zum enttäuschten Minnediener“138, die einen Anschluss an das entsprechende Wertesystem des Publikums schafft, das Martyrium dabei aber nicht mit diesem ,versöhnt‘ und abmildert, sondern den Gegensatz am Ende gar noch akzentuiert. Wenn es vom Erzähler heißt, dass der Heide Margareta hold von herczen [ward] (WeM 211) und dieser bekunden darf, sie in jedem Fall heiraten zu wollen, sei sie nun frei geboren oder nicht (WeM 219-226), und im letzteren Falle nicht etwa zur concubinam (LA 1216) oder als eine amien (P 327, 102) nehmen zu wollen; wenn seine Boten ihr gar seinen Minnedienst antragen, bei dem er sich wie ein Leibeigener unterwerfen würde: ,er wil dich jemer vlehen / rechte alz er din aygen si“ (WeM 244-245), dann verdeutlicht ihre beharrliche Ablehnung umso stärker den Kontrast zwischen seinem höfisch durchaus legitimen, gar edlen, aber letztlich eben weltlichen Begehren und ihrem heiligmäßigen Streben als Jungfrau. Denn dass er sie nicht gewinnen kann, lässt ihn schließlich toben recht alsam ein hund (WeM 329).

Die Dichotomie zwischen christlich-geistlichem Streben und höfisch-heidnischem Weltleben wird in einem längeren Erzählerkommentar aber schon vorher, als

137 Ebd., Sp. 976.

138 Ebd. Vgl. ausführlicher dazu auch Feistner, Historische Typologie, S. 98-99. 
Einschub zwischen der Jugendgeschichte der Heiligen und ihrer Begegnung mit Olibrius, rezeptionssteuernd explizit gemacht, wobei der Autor auf bemerkenswerte Weise die spirituelle Dimension und Funktion des Gegensatzes von Heiden und Christen benennt. Margaretas Verkündigung des Glaubens, die ihr den Tod bringt, habe die christliche Wir-Gemeinschaft von Erzähler und Legendenpublikum wohl nötig:

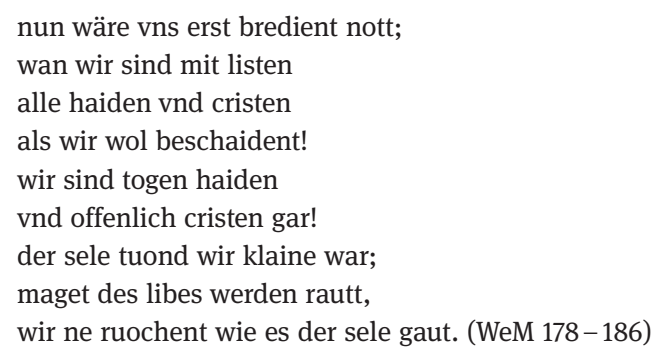

Der äußere Konflikt von Christentum und Heidentum, wie ihn die Legende zeichnet, erschließt sich in seiner Bedeutung für das christliche Publikum erst in dieser inneren Dimension, bei der Glaube und Unglaube in temporaler Spannung auf die endgültige Scheidung im jüngsten Gericht hin stehen, ${ }^{139}$ was hier zudem umgesetzt wird als Gegensatz von äußerem Schein und innerem Sein: Die Christen sind letztlich auch nur Heiden, wenn sie keine geistliche Gesinnung haben. In dieser Situation von ständiger Ungewissheit über Heil oder Verdammnis des einzelnen entfalten das Vorbild und die Mittlerfunktion der Heiligen, sowie das Erzählen davon im Modus der Legende, ihre eigentliche Funktion.

Während in Wetzels Margaretenlegende die Axiologie von höfisch-geistlich mit der von heidnisch-christlich und gar noch weltlich-heilig kontrastiv-verstärkend überblendet wird, nutzt die anonym überlieferte, aber „rhetorisch brillante“140 Wallersteiner Margaretenlegende ${ }^{141}$ das Potential höfischer Akkulturation auf andere Weise, um die Heiligkeit Margaretas in Absetzung vom Heidentum ihres Verfolgers zu akzentuieren. Sie lässt sich über die in ihrem Prolog (WaM 22) genannte Gönnerin Clementia von Zähringen datieren, die wegen Erbstreitigkeiten nach dem Tod ihres Mannes von ihrem Schwager und dessen Sohn zwischen 1218 und 1235 gefangengehalten wurde; das Werk ist also davor oder danach anzusetzen, wobei für die spätere Datierung

der tatsächlich suggestive Anspielungszusammenhang zwischen Margaretens Kerkerhaft in der Legende und der Kerkerhaft in Clementias Biographie spricht, der freilich im Text selbst nicht

139 Vgl. dazu oben in Kap. 2.2.1 Heidentum als dynamischer Gegenbegriff.

140 Feistner, Art. Wetzel von Bernau, Sp. 976.

141 Auch wegen seiner sprachlichen Qualität ist der Text in der Forschung zunächst irrtümlich Wetzel zugeschrieben und unter seinem Namen ediert worden: Karl Bartsch: Wetzels heilige Margarete. In: Germanistische Studien 1 (1872), S. 1-30. 
aktualisiert ist und keineswegs unbedingt eine Voraussetzung dafür sein mußte, daß eine ohnehin so allgemein beliebte Heiligenlegende in die Volkssprache übersetzt wurde. ${ }^{142}$

Über die Profilierung des Erzählaktes und die diskursive Vermittlung in den sprachlichen Mustern der höfischen Literatur ließe sich für die Wallersteiner Fassung Ähnliches herausarbeiten wie für die Margaretenlegende Wetzels von Bernau, wenngleich sie fragmentarisch überliefert ist und bereits nach der ersten Folter abbricht. Interessanter ist an dieser Stelle aber ohnehin der Umstand, dass sie auf der histoire-Ebene die höfische Zeichnung des Olibrius auf entgegengesetzte Weise nutzt, um die christliche Wir-Gemeinschaft vom Heidentum abzugrenzen.

Denn während das Minnemotiv in Wetzels Legende darauf zielt, dass sich die höfischen Rezipienten in der Figur des Heiden wiedererkennen, um in seinem vergeblichen weltlichen Streben ihr eigenes ,Heidentum` zu überwinden, wird höfische Motivik in der Wallersteiner Legende im für das Legendenpublikum positiven Sinne genutzt, um dessen Gegensatz zum Heidentum herauszuarbeiten. Das in der lateinischen Tradition vorgezeichnete negative Bild des Heiden Olibrius wird dabei noch verstärkt und zwar indem ihm hier nun höfische Werte gänzlich abgesprochen werden. ${ }^{143} \mathrm{Er}$ wird als grausamer Verfolger vorgestellt, der über das gesamte Repertoire an Grausamkeiten verfügt, die dem heidnischen Herrscher der Märtyrerlegenden gegenüber den Christen zur Verfügung stehen:

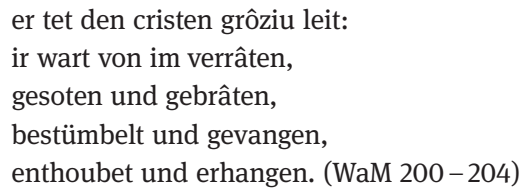

Dieses Spiel mit dem reimenden und alternierenden Wortklang der Martern und Torturen wird man nicht nur im Sinn effektvoller Klage über das Los der Verfolgten und erschauernden Bewunderung für ihr Opfer lesen können, sondern zugleich als Ausweis der quasi sadistischen Ergötzung des Verfolgers an ihren Qualen. Seiner erbarmungslosen und brutalen Jagd fallen so viele Christen zum Opfer, dass er nicht anders denn als des tiufels geselle (WaM 210) gelten kann. Sein Hass aber hindert ihn nun gar an den Freuden höfischen Weltlebens, dessen Werte als durchaus positiv geschildert werden:

er was sô sêre in gehaz daz er noch trinken noch maz, weder singen noch sagen, weder beizen noch jagen, noch schoener frouwen friuntschaft

142 Feistner, Historische Typologie, S. 93.

143 Vgl. ebd., S. 99-100. 
noch seiten spil noch ritterschaft

nimmer dar vor erwelte

swenne er die cristen quelte. (WaM 219-226)

Allein bei Margareta vergisst er sînes grimmes, aber nicht aus Edelmut, sondern weil seine Sinne von einer anderen Macht, von frouwe Minne, in Besitz genommen sind (WaM 237 und 238). In seinem Verfolgungsrausch aber ist er blind für die höfischen Werte, die dem Erzähler und seinem Publikum ein fragloses Gut sind, und diese Axiologie verfestigt den Gegensatz: Der Heide hat nicht nur den falschen Glauben, sondern erweist sich auch auf der Ebene möglicherweise verbindender Werte als negatives Gegenbild.

Doch überblendet die Wallersteiner Margaretenlegende am Ende nicht eindimensional die höfische Werthaltung ihres Publikums mit dem christlich-sakralen Gehalt der Erzählung - im Sinne einer Konstitution einer höfisch-christlichen WirGemeinschaft, die sich vom unhöfisch-heidnischen Verfolger abgrenzen dürfte -, sondern durchkreuzt diese allzu einfache Schematisierung und stellt höfisch-weltliche und geistliche Werte an anderer Stelle schroff gegeneinander. Nach der Kerkerhaft will Olibrius Margareta, wie in der Stofftradition vorgegeben, zur Umkehr bewegen und erinnert sie dazu an ihren, jungen lîbe, an den sô zuhtlîche site / und alsô michel schônheit / got mit flìze hât geleit‘ (WaM 447 und 448-450), der aber in der Umkehrung aller höfischen Weltfreude verderben müsse, wenn sie sich seinem Willen nicht beuge, denn dann werde , dîn gemach ein arbeit, / dîn herzeliep ein herzen leit“ (WaM 459460), und es folgen noch mindestens acht weitere solcher Oppositionen. Wenn sie sich hingegen von ihm zu Frau nehme lasse, solle es ihr ,uff erden nimmer baz geschehen (WaM 485), dazu stellt er ihr alle höfischen Ehren und Güter in Aussicht:

,du gewinnest hêrlîchen rât,

beide schatz unde wât,

dar zuo gib ich dir in dîn hant

beide bürge und ouch lant.' (WaM 487-490)

Dem begegnet die Heilige mit der bekannten martyrologischen Überbietungs- und Inversionslogik und benennt das epistemische Defizit der Sicht des Heiden, wenn sie seine Worte ,anders“, also im richtigen Sinn auslegen will:

,ich wil dir und den liuten

dîn rede ander tiuten.

ez waere harte missetân,

den lîp, den ich von gote hân

sô schœnen und alsô gestalt,

als du mir hâst vor gezalt,

ob ich den für ein abgot

neigte durch dîn gebot.' (WaM 499-506) 
Die Logik ist wiederum deutlich: Der äußere Schein der Dinge trügt, die Schönheit des Körpers ist nur von vorläufigem Wert und hat einen höheren, metaphorischen Sinn. Denn nur dann, wenn sie seinem Drängen nachgebe, würde geschehen, was er ihr androht. Wenn sie seinem Willen aber widerstehe, werde ihr höchste Freude zuteil, dann erlange sie ,diu himelische crône“ (WaM 524). Die weltliche Sicht des Heiden, die er hier gerade mit der Berufung auf höfische Werte entwickelt, wird als defizitär entlarvt und demonstriert in ihrer kontrastiv-überbietenden Umkehr den alleinigen Wert himmlischer Freuden. Diese Botschaft richtet sich freilich an das christlich-höfische Legendenpublikum, während für den Heiden innerhalb der Handlung Margaretas Verkündigung vergeblich bleibt, wie es mit Bezug auf das biblische Bild vom Samenkorn, das auf harten Boden fällt, heißt: dâ von der wuocher ouch verswant; / ir lêre was an im verlorn (WaM 586-587).

\subsubsection{Das Martyrium als Glaubensdisput: Katharina}

Im narrativen Muster des Martyriums dient das Verhör zunächst nur „dem Aufweis der

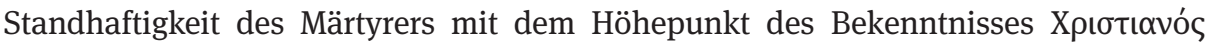

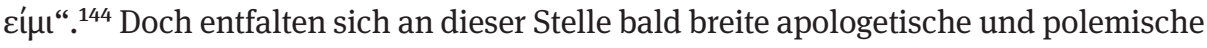
Reden des Märtyrers, die die eigene Überlegenheit und die Geringschätzung der heidnischen Gerichtsbarkeit, wo es um Fragen religiöser Wahrheit geht, demonstrativ herausarbeiten. Der Prozess erfährt damit aus christlicher Perspektive eine grundlegende Umwertung oder „Umwidmung“, die Justiz wird zur „Werbung für die Sache ihrer Opfer" genutzt. ${ }^{145}$

Dabei gehen Apologetik und Polemik in vielen Märtyrerlegenden in ihrem Umfang weit über das erzähllogisch erforderliche Maß hinaus, was darauf schließen lässt, dass sie der Didaxe und Paränese im binnenchristlichen Diskurs dienen, die weit über das Beispiel eines als historisch verbürgt angenommenen Glaubenszeugen und seines singulären Sterbens für Gott hinausgehen. Das Martyrium erscheint dabei als Glaubenszeugnis in Zeichen und Wort, die beide ein didaktisches Potential entfalten, insofern einerseits zeichenhaft vorbildliche Glaubenshaltung und Heilsgewissheit profiliert, andererseits diskursiv Glaubenslehren vermittelt werden. Gerade in Letzterem macht Feistner die Eignung der Märtyrerlegende für die Laienkatechese und den Grund für ihre anhaltende Popularität in volkssprachigen Übertragungen aus:

Noch wichtiger als die Möglichkeit, Glaubensüberzeugung und Opferbereitschaft bis zur äußersten (und nach dem Ende der Christenverfolgung in dieser Form kaum mehr direkt imitierbaren) Konsequenz zu demonstrieren, war dabei der didaktische Anknüpfungspunkt, den gerade

144 Vgl. Buschmann, Martyrium Polycarpi, S. 329.

145 Detlef Liebs: Umwidmung. Nutzung der Justiz zur Werbung für die Sache ihrer Opfer in den Märtyrerprozessen der frühen Christen. In: Märtyrer und Märtyrerakten. Hrsg. von Walter Ameling. Stuttgart 2002 (Altertumswissenschaftliches Kolloquium. 6), S. 19-46. 
die spezifische Konfrontation zwischen Christentum und Heidentum bot, um den Heiligen beim Verhör oder in den Bekenntnis- und Bekehrungsreden vor den Ungläubigen die theoretischen und praktischen Glaubensgrundlagen in den Mund zu legen. ${ }^{146}$

Diese Möglichkeit findet sich in den Legenden der heiligen Margareta nur ansatzweise verwirklicht, weil in ihnen der Fokus stärker auf dem Leiden der Märtyrerin und der Zeichenhaftigkeit des Martyriums liegt. In den Katharinenlegenden wird das Märtyrerschema dafür umso umfassender zu einem regelrechten Glaubensdisput mit den Heiden erweitert. Die Verbindung von Martyrium und Glaubensdisput versteht sich dabei in der eingangs beschriebenen doppelten Weise, dass das Martyrium einerseits Rahmen und Gelegenheit zu Bekenntnis und formalem Streitgespräch bietet, andererseits zugleich aber in einem umfassenderen metaphorischen Sinn den Disput performativ umsetzt. Leiden und Sterben der Märtyrerin, ihre Standhaftigkeit und ihr Gottvertrauen sowie ihre wundersame Bewahrung werden zu ,Argumenten“ eines zeichenhaften ,Disputs‘, die die heidnischen ,Argumente‘ der Qualen und Strafen und sonstiger weltlicher Machtdemonstrationen widerlegen.

Im Kult der heiligen Katharina gehen die im Martyrium bewahrte Jungfräulichkeit und ihre diskursive Verteidigung des Glaubens ineinander über: Im byzantinischen Bereich wird sie bis ins 11. Jahrhundert vor allem als Verteidigerin des Glaubens verehrt, ihre Jungfräulichkeit ist Zeichen ihrer geistlichen Kraft und stärkt ihre Rolle als Fürsprecherin. Im lateinischen Westen des 11. und 12. Jahrhunderts, also zur Zeit der Gregorianischen Reformen, deren Ziel im Kampf um die libertas ecclesiae unter anderem die Durchsetzung des Zölibats für den Klerus war, ist das Ideal eines jungfräulichen geistlichen Lebens von umso stärkerer Bedeutung. ${ }^{147}$ Ihr Martyrium wird in der hagiographischen Überlieferung in der letzten Phase der gesamtstaatlichen Verfolgungen Anfang des 4. Jahrhunderts in Alexandrien verortet, auch wenn die jeweils genannten Kaisernamen variieren. ${ }^{148}$ Allerdings gibt es keine zeitgenössischen Quellen, die ihr Martyrium oder überhaupt ihre Existenz belegen könnten, erst für das 7. Jahrhundert sind erste schriftliche Zeugnisse und ab dem 10. Jahrhundert ein Aufschwung ihres Kultes nachweisbar. Die überlieferte Passio entstand also weit nach den angeblichen Ereignissen, ab Beginn des 9. Jahrhunderts finden sich Übersetzungen ins Lateinische, griechische Handschriften sind hingegen nur aus dem 10. Jahrhundert erhalten. ${ }^{149}$

Da ihre Legende offenbar ohne historischen Kern ist, andererseits das Motiv ihrer großen Gelehrsamkeit auffällig scheint, ist in der christentumskritischen Forschung des 19. Jahrhunderts vermutet worden, ihre Darstellung greife das Schicksal der

146 Feistner, Historische Typologie, S. 91.

147 Vgl. Christine Walsh: The Cult of St Katherine of Alexandria in Early Medieval Europe. Aldershot [u. a.] 2007 (Church, Faith and Culture in the Medieval West), S. 146.

148 Die Legenda aurea nennt Maxentius, übt selbst aber historische Kritik an dieser Überlieferung, weil dieser nie für Ägypten zuständig war und eher Maximinus Daia dafür infrage kommt. Vgl. LA 2280-2282 sowie S. 2280, Anm. 43.

149 Vgl. Walsh, The Cult of St Katherine of Alexandria in Early Medieval Europe, S. 1-8. 
heidnischen Philosophin Hypatia von Alexandrien (um 355-455/416) auf, die von einer aufgeheizten christlichen Menge ermordet wurde, ${ }^{150}$ wobei die Rollen von Christen und Heiden in signifikanter Weise vertauscht worden wären: Der gewalttätige Übergriff gegenüber einer heidnischen Philosophin, der nicht ins Selbstbild der Verfolgung leidenden Kirche passt, wäre zur kompensatorischen Gegenerzählung geworden, die eine gelehrte und redegewandte Christin Gewalt von den Heiden erleiden lässt - was auf bemerkenswerte Weise die identitätsstiftende Funktion des Martyriumsnarrativs veranschaulichen würde, die freilich auch ohne solche Spekulationen in der Katharinenlegende erkennbar ist.

Das Narrativ der jungfräulichen Märtyrerin wird jedenfalls bei Katharina um einige entscheidende Motive erweitert: Sie ist nicht einfach die reine Jungfrau, die wie Margareta zufällig zum Opfer der sexuellen Begierde eines heidnischen Mannes wird, sondern tritt aus freien Stücken den Heiden entgegen und sucht die Glaubenskonfrontation im Kontext einer systematischen Christenverfolgung. Dazu gehört wesentlich das Motiv ihrer überragenden Bildung und Redegewandheit, denn sie ist nicht nur edler Abkunft, sondern wird in der Legenda aurea als regis filia omnibus liberalium artium studiis erudita (LA 2262) ${ }^{151}$ vorgestellt. Als Katharina 18 Jahre alt ist, erfährt sie, dass Kaiser Maxentius alle Untergebenen nach Alexandria gerufen habe, ut idolis immolarent et christianos immolare nolentes puniret (LA 2262). ${ }^{152}$ Offenbar befindet sie sich in Hörweite des Geschehens, was der Situation und ihrer Reaktion darauf eine besondere Dramatik gibt. Denn umgehend verlässt sie den Palast voller Reichtümer und Diener, in dem sie sich befindet, eilt zum Ort des Tribunals und erblickt dort multos christianos metut mortis sacrificia duci (LA 2262). ${ }^{153}$ Angesichts dieser Verfolgung ihrer Glaubensgenossen und des drohenden Glaubensabfalls, so heißt es, konfrontiert sie den Kaiser mit dem Anspruch des christlichen Gottes auf absolute und alleinige Autorität, bekennt sich also freiwillig und liefert sich damit ohne eigentliche Not selbst aus. Ihre Worte an den Kaiser sind programmatisch für die christliche Ablehnung der religiösen Ansprüche des Heidentums, nicht aber des heidnischen Staates grundsätzlich, wie sie sich immer wieder in Märtyrergeschichten formuliert findet: ,Salutationem tibi proferre et ordinis dignitatis et rationis via promovebat, si creatorem caelorum agnosceres et a diis animum revocares.' (LA 2262) $)^{154}$

Die von Katharina aktiv betriebene religiöse Konfrontation schreibt sich also inhaltlich ein in die apologetischen Bestrebungen der Kirche der ersten Jahrhunderte, den christlichen Glauben als der Vernunft gemäß zu profilieren und dabei die heidnischen Götter als Trugbilder zu entlarven. Darüber disputiert sie unmittelbar vor dem

150 Ebd., S. 10. Da auch christliche Quellen von dieser Ermordung berichten und diese teils trotz des religiösen Gegensatzes verurteilen, scheint sie historisch durchaus plausibel.

151 „Katharina, Tochter des Königs Costus, wurde in allen Fächern der freien Künste erzogen.“

152 „[D]aß sie den Götzen opfern sollten, und um die Christen, die nicht opfern wollten, zu bestrafen“. 153 „[V]iele Christen, die unter Androhung des Todes zum Opfer geführt wurden“.

154 „,Dir einen Gruß zu entbieten riet mir die Würde deines Standes und der Weg der Vernunft, um zu sehen, ob du den Schöpfer der Himmel anerkennst und dich von den Göttern abwendest.““ 
Tempel, der zum Ort des öffentlichen Tribunals gegen die Christen dienen soll, auf höchstem rhetorischen und logischem Niveau per varias syllogismorum allegorice et metanomice, diserte et mystice, zunächst vertraulich mit dem Kaiser, bevor sie, wie es heißt, ad commune colloquium (LA 2262) ${ }^{155}$ zurückkehrt und ihn in der für die Märtyrerreden üblichen Polemik angreift, warum er als so weiser Mann so viele Menschen versammelt habe, um die „Dummheit der Götzen“ zu verehren. Der kostbar verzierte heidnische Tempel selbst dient ihr als Beispiel, dass alles Irdische vergehen werde, während der Himmel und der Lauf der Gestirne die Macht des Schöpfers erkennen ließen, dem allein Anbetung zukomme, weil er ,deus deorum et dominus dominantium (LA 2262) ${ }^{156}$ sei. Katharinas Worte über die Inkarnation Gottes lassen den Kaiser vor Staunen sprachlos zurück, sodass er erst wieder zu sich finden muss, um das Opfer zu beenden und Katharina zu seinem Palast bringen zu lassen. Hier wird nun das Motiv der redegewandten Glaubensstreiterin mit dem der jungfräulichen Bekennerin verschränkt, denn der Kaiser bewundert ihre Klugheit ebenso wie ihre körperliche Schönheit, die der Erzähler selbst rühmt: Erat enim speciosa valde et incredibili pulchritudine omnium oculis admirabilis videbatur. (LA 2264) ${ }^{157}$ Im Palast entspinnt sich ein neuerliches Gespräch.

Entscheidend für die Figurenzeichnung der Glaubenszeugin sind ihre Worte, in denen sie sowohl ihre edle Abkunft als auch und gerade ihre Weisheit und Beredsamkeit als nichtig angesichts der christlichen Wahrheit darstellt: , haec tamen omnia contempsi et ad dominum Iesum confugi' (LA 2264-2266). ${ }^{158}$ Ihre eigene Bekehrung zum wahren Glauben setzt sie dem falschen und vergeblichen des Heiden entgegen, denn dessen Götter könnten weder ihm noch anderen helfen. Dem Kaiser selbst sind daraufhin Worte in den Mund gelegt, die aus Katharinas Bekenntnis die letzte Konsequenz ziehen und dabei die Überbietungs- und Umkehrungslogik des Martyriums ebenso formulieren wie das Motiv der Zeugenschaft: ,Si it est, ut assertis, ergo totus mundus errat et tu solda verum dicis. Cum tamen omne verbum in ore duorum vel trium testium confirmetur, si angelus esses, si caelica virtus, adhuc tibi credere nemo deberet, quanto minus, cum femina fragilis esse probaris. ' (LA 2266) ${ }^{159}$ Gerade die vermeintliche weibliche Schwäche und die ihr zugeschriebene mangelnde Vertrauenswürdigkeit wird in der folgenden Handlung aber konterkariert werden. Denn die Zeichenhaftigkeit des Martyriums, also das mutige Bekennen und standhafte Leiden der Heiligen,

155, ,M]ittels verschiedener syllogistischer Schlüsse, allegorisch und metanomisch, rhetorisch und mystisch. Darauf kehrte sie wieder zur üblichen Sprechweise zurück“.

156 „,Gott der Götter und der Herr der Herrscher.““

157 „Katharina war nämlich äußerst stattlich und in ihrer unglaublichen Schönheit schien sie in aller Augen bewundernswert.“

158 „,[D]och dies alles [habe ich] verworfen und meine Zuflucht bei Jesus dem Herrn gesucht““.

159 ,,Wenn das so ist, wie du behauptest, dann irrt die ganze Welt und du allein sagst die Wahrheit. Da jedoch jedes Wort durch die Aussage zweier oder dreier Zeugen bestätigt werden muß, würde dir niemand glauben, auch wenn du ein Engel wärst und Himmelskräfte hättest, um so weniger, als du eine schwache Frau bist.“ 
vor allem aber ihr Glaubenszeugnis im Wort in Disput, Verkündigung und Unterweisung erweisen sich auf der Handlungsebene als höchst wirksam in der Bekehrung von Heiden, die ihrerseits zum Martyrium bereit sind.

Zunächst überwindet Katharina 50 heidnische Gelehrte, qui omnes mortales in omni mundana sapientia excellebant (LA 2266), ${ }^{160}$ die der Kaiser aus allen Provinzen seines Reiches gegen sie aufbietet. Die Inszenierung dieses Disputs, der wohl wiederum als öffentliches Tribunal vorzustellen ist, nutzt alle Muster und Motive des entsprechenden Narrativs, um den symbolischen Gehalt der Glaubenskonfrontation zwischen Katharina und Maxentius - als exemplarische Auseinandersetzung zwischen Christentum und Heidentum sowie zwischen geistlicher Wahrheit und weltlicher Vergeblichkeit - herauszustellen. Die vom Kaiser herbeigerufenen Gelehrten reagieren zunächst mit Zorn und Spot, als sie erfahren, dass dieser ,ob unius degenerem puellae conflictum sapientes mundi de remotis partibus advocavit, cum unus ex nostris clientulis eam poterat levissime confutare (LA 2266). ${ }^{161}$ Der Kontrast und das nach weltlichen Maßstäben offensichtliche Machtgefälle zwischen der vermeintlichen Beschränktheit des einzelnen „Mädchens“ auf der einen, der versammelten Menge männlicher Gelehrter auf der anderen Seite, wird noch verstärkt durch die großmütig wirkende Erklärung des Kaisers, er habe sie wohl mit Gewalt zum Opfern zwingen können, doch habe er es für besser erachtet, ihren Glauben mit den Argumenten der heidnischen Meistern zu widerlegen. Für das christliche Publikum der Legende muss dies freilich als Zeichen seiner hoffnungslosen Verblendung erscheinen, ebenso wie die voreilige Siegesgewissheit der Meister diese selbst entlarvt: ,Adducatur coram nobis puella, ut sua temeritate convicta numquam se sapientes vidisse agnoscat. (LA 2266) $)^{162}$

Katharina aber vertraut gerade nicht auf ihre Weisheit, sondern allein auf Gott, dem sie sich angesichts des bevorstehenden Wettstreits anbefiehlt. Zu dieser geistlichen Zeichnung ihrer Rolle im Disput passt, dass sie nun durchweg als virgo bezeichnet wird. Die Vision, die ihr zuteilwird, schildert der Erzähler als objektives Geschehen mit Adressierung an sein christliches Publikum: Et ecce, angelus domini astitit et, ut constanter staret, admonuit asserens, quia non solu ab illis vinci non potertit, sed insuper illa ipsos conversos ad palmam martyrii destinabit. (LA 2268) ${ }^{163}$ Damit wird der Ausgang des Disputs explizit vorweggenommen und im göttlichen Ratschluss verankert, gleichzeitig die Wirksamkeit von Katharinas Zeugnis im Martyrium kon-

160 ,[D]ie alle Sterblichen an irdischer Weisheit in den Schatten stellten“.

161 ,,[W] $[$ egen eines lächerlichen Streites mit einem einzigen Mädchen die Weisen aus den entferntesten Teilen der Welt hat kommen lassen, wo doch ein bescheidener Schüler von uns sie mit großer Leichtigkeit hätte widerlegen können““.

162 „,Man soll uns das Mädchen vorführen, damit ihre Vermessenheit erwiesen wird und sie einsieht, daß sie noch nie einem Weisen begegnet ist.“ “

163 „Und siehe, der Engel des Herrn trat zu ihr hin und ermahnte sie, standhaft zu bleiben, wobei er versicherte, daß sie nicht nur von ihnen nicht besiegt werden könne, sondern daß sie sie zudem bekehren und zur Märtyrerpalme bestimmen werde.“ 
kretisiert: Konversion und Folgemartyrien scheinen dessen logische Konsequenz zu sein, die völlige Überwindung der heidnischen Gelehrten soll sich darin zeigen, dass diese selbst für den Glauben sterben und der Heiligkeit teilhaftig werden.

Der Inhalt des Disputs ist nur knapp wiedergegeben und topisch: Die Heiden nehmen Anstoß an der christlichen Lehre von der Menschwerdung Gottes, doch Katharina beweist ihnen, dass ebendiese von den Heiden selbst, namentlich Plato und Sybille, bereits vorausgesagt worden sei. Entscheidender als der Inhalt des diskursiven Glaubenszeugnisses im Wort ist seine performative Wirkung: Angesichts der einleuchtenden Argumente der Jungfrau hätten die heidnischen Meister vor Staunen nicht mehr gewusst, was sie sagen sollten, und seien völlig verstummt, woran dann auch der Zorn des Kaisers, den sie wegen dieser Schande auf sich ziehen, nichts mehr ändern kann. Einer der Meister tritt nun stellvertretend für die anderen dem Kaiser entgegen und bekennt, dass der Geist Gottes aus diesem Mädchen spreche und, da sie solcherart überwunden seien, sich alle zu Christus bekehren sollten. Während die heidnischen Gelehrten also in ihrer Konversion und gleich darauf in ihren Martyrien die Wahrheit der christlichen Botschaft bezeugen und damit in die christliche Rezeptionsgemeinschaft inkludiert werden, exkludiert sich der Kaiser aus ihr. Er wird zum tyrannus (LA 2268), der voller Wut befiehlt, die Gelehrten mitten in der Stadt verbrennen $\mathrm{zu}$ lassen. Katharina tritt nun als Lehrerin und Begleiterin im Martyrium auf: At virgo ipsos confortanes ad martyrium constantes effecit et de fide diligenter eos instruxit. (LA 2268) ${ }^{164}$ Vor allem verheißt sie ihnen, schon vor ihrem eigenen Tod also Heilsmittlerin, die himmlische Herrlichkeit, denn auf das Bedauern der Neubekehrten, dass sie ohne Taufe sterben sollen, bestärkt sie sie, dass ihre Bluttaufe die Wassertaufe ersetzen werde: ,Ne timeatis, quia effusio vestri sanguinis vobis baptismus reputabitur et corono. ' (LA 2268) 165

Der Kaiser, weiterhin tyrannus, versucht Katharina nun mit den höchsten weltlichen Ehren und appelliert an ihre Jugend, bietet ihr den Platz nach der Königin an, will ein Bildnis von ihr machen und sie als Göttin verehren lassen. Doch mit dieser rein immanenten Argumentation entlarvt das Heidentum sich in seinem höchsten Repräsentanten als euhemeristischer Götzendienst. Als „Braut Christi“ weiß sich Katharina in Gottes Allmacht geborgen: ,Ego me Christo sponsam tradidi, ille gloria mea, ille amor meus, ille dulcedo et dilectia mea. Ab eius amore nec blandimenta nec tormenta me poterunt revocare. (LA 2270) ${ }^{166}$ Dem Heiden hingegen bleibt in seiner Ohnmacht nur, Katharina geißeln und in den Kerker werfen zu lassen.

Das gibt der Heiligen einerseits die Gelegenheit, ihre Bekehrungsarbeit weiter fortzusetzen, andererseits erweist sich in ihrer wundersamen Bewahrung in Folter

164 „Doch die Jungfrau ermutigte sie zum Martyrium, machte sie standhaft und unterrichtete sie sorgfältig im Glauben.“

165 „,Fürchtet euch nicht, denn das Vergießen eures Blutes wird euch als Taufe und als Märtyrerkrone angerechnet werden.““

166 „,Ich habe mich Christus zur Braut gegeben, er ist mein Ruhm, er meine Liebe, er meine Lust und Wonne. Von seiner Liebe werden mich weder Schmeicheleien noch Foltern abbringen können.““ 
und Haft ihre Heiligkeit und damit die zeichenhafte Dimension des Martyriums. Denn als der Kaiser außer Landes ist, eilt die Königin, in geistlicher „Liebe entbrannt“, mitten in der Nacht in den Kerker, sieht diesen „von unglaublichem Glanz erleuchtet“ und Engel, die die Wunden der Heiligen salben, als Boten der Transzendenz also die körperliche Unversehrtheit der Gemarterten wiederherstellen. Auch die Königin ist in der Logik der Legende zu Konversion und Martyrium bestimmt: Incipiensque virgo aeterna ei gaudia praedicavit et ad fidem convertens coronam martyrii eidem praedixit (LA 2270). ${ }^{167}$ Nach ihr bekehren sich auch der Heerführer Porphyrius, der sie begleitet hatte, und zweihundert Soldaten. Aber der Wunder sind noch nicht genug: Christus sendet der Jungfrau eine weiße Taube, die ihr himmlische Speise bringt, weil der tyrannus befohlen hatte, sie zwölf Tage hungern zu lassen. Und der Herr erscheint ihr inmitten seiner Engel und bestärkt sie, den „mühevollen Kampf“ für ihn standhaft fortzuführen. Als der Kaiser sie bei seiner Rückkehr solchermaßen bewahrt antrifft, kommt es zur neuerlichen und finalen verbalen Konfrontation, die abschließend die axiologische Tiefenstruktur des Martyriums formuliert: Seinem Angebot, sie solle als ,regina potens et delecta decore in regno meo ${ }^{168}$ triumphieren, hält sie entgegen, dass sie damit nicht den ,potentem, aeternum, gloriosum et decorum, sondern den infirmum, mortalem, ignobilem et deformem ' wählen würde. ${ }^{169}$ Für Christus wolle sie alle Foltern erleiden und ihm ihr Fleisch und Blut opfern, da er sich selbst für sie geopfert habe.

Doch das mit eisernen Sägen und spitzen Nägeln versehene Räderwerk, das eigens angefertigt wird, um der Jungfrau einen qualvollen Tod zu bereiten, wird auf ihre Bitte hin von einem Engel zerschmettert, mit solcher Wucht, dass auch viertausend Heiden umkommen. Über den metaphorisch gemeinten und mitunter in Teufelsmanifestationen imaginierten Kampf gegen den Unglauben und das Böse hinaus, sind Märtyrerlegenden also durchaus Ort von Gewaltfantasien und Rachegefühlen von christlicher Seite. Aber nicht der Märtyrer selbst übt physische Gewalt aus, kann es angesichts der irdischen Machtverhältnisse auch gar nicht, sondern allein Gott kann die Heiden bestrafen. Nur „[i]n der Welt des Geistes ist der Märtyrer damit auch ein Kämpfer“170, so wie Margareta den Unglauben nur, dafür dann aber umso expliziter in Gestalt des Teufels leibhaftig bekämpft, ansonsten aber im Leiden ihren eigentlichen Kampf besteht.

Nacheinander bekennen sich schließlich die Königin, der Heermeister und seine Soldaten zu ihrem neuen christlichen Glauben und erleiden auf Befehl des erzürnten

167 „Da begann ihr die Jungfrau von den ewigen Freuden zu predigen, bekehrte sie zum Glauben, sagte ihr die Märtyrerkrone voraus und so zog sich das Gespräch bis Mitternacht hin.“

168 ,,[A]ls mächtige Königin und mit erlesenem Schmuck in meinem Reich““.

169 ,,[D]en Mächtigen, Ewigen, Glorreichen und Schönen oder den Schwachen, Sterblichen, Unberühmten und Häßlichen““.

170 Daniel König: Christliche ,Helden‘ und Gewalt. In: Mittelalter im Labor. Die Mediävistik testet Wege zu einer transkulturellen Europawissenschaft. Hrsg. von Michael Borgolte [u. a.]. Berlin 2008 (Europa im Mittelalter. Abhandlungen und Beiträge zur historischen Komparatistik. 10), 483 -492, hier S. 485 . 
Kaisers das Martyrium. Schließlich wird Katharina selbst enthauptet, aber nicht bevor sie noch auf der Hinrichtungsstätte Jesus, ,spes et salus credentium, decus et gloria virginum ‘ und ,rex bone` (LA 2274) ${ }^{171}$, bittet, gnädig die Bitten derer zu erhören, die ihr Gedächtnis feiern und sie anrufen werden. Eine Stimme vom Himmel, die ihr das Himmelstor offen heißt, verspricht ihr diesen Beistand, legitimiert also wie in der Margaretenlegende als transzendenter Einbruch in die Immanenz der Legendenerzählung die Heiligenverehrung und beglaubigt sie in ihrer Wirksamkeit.

Interessant für das Katharinenbild der Legenda aurea ist neben der eigentlichen Erzählung die scholastisch-theologische Kommentierung im Anschluss an den Märtyrertod und zwei drauf folgende posthume Wunderberichte. Es erweise sich nämlich, dass die heilige Katharina in insgesamt fünf Punkten admirabilis apparet (LA 2276): Weisheit, Beredsamkeit, Standhaftigkeit, Bewahrung der Keuschheit, Vorrang der Würde hinsichtlich der ihre Heiligkeit erweisenden Wunder. Das Motiv der Jungfräulichkeit und auch ihre Standhaftigkeit in den Foltern scheint in diesem Zusammenhang ihrem Zeugnis im Wort nachgeordnet. Die Beredsamkeit bezieht sich expressis verbis auf ihre Fähigkeit zu predigen, auf die Anziehungskraft und die Wirksamkeit ihrer Rede, andere für den Glauben zu gewinnen und den heidnischen Unglauben zu widerlegen. Auch wenn Katharina dadurch zugleich eine Vorbildfunktion in der Verkündigung des Glaubens im Wort gewinnt, so zielt die Zeichenhaftigkeit ihres Martyriums, die die Legenda aurea im bekannten Wechselspiel von heidnischer Ermächtigung und göttlicher Bewahrung, vor allem aber auch in der performativen Wirkung ihres Zeugnisses entfaltet, auf ihre admiratio.

Vor diesem Hintergrund wird die veränderte Akzentsetzung des Katharinenbildes im Passional deutlich, die sich auch in der amplificatio der Legende niederschlägt. Zwar sind Erzählzusammenhang wie Figurenrede in der Legenda aurea bei allen Heiligen auf das handlungslogisch Notwendige verknappt, im Passional hingegen generell breiter ausgeführt. Während aber die sieben Seiten, die die Katharinenlegende in der hier genutzten Edition der Legenda aurea umfasst, im Passional auf 2266 Verse erweitert werden, stehen den etwa dreieinhalb lateinischen Seiten der Margaretenlegende nur 582 mittelhochdeutsche Verse gegenüber. Selbst wann man berücksichtigt, dass der Autor des Passionals eine zweite und ausführlichere Quelle genutzt und mit dem Stoff der Legenda aurea verbunden hat, ${ }^{172}$ zeigt sich an diesem Verhältnis, welche Bedeutung der Heiligen und dem didaktisch-paränetischen Potential ihrer Legende zugemessen wird, zumal diese die Auswahl des mittelhochdeutschen Legendars beschließt und damit an prominenter Stelle steht.

Eine Besonderheit innerhalb des Passionals und vor allem originäre Zutat seines Autors ist der ganze 68 Verse umfassende Prolog, der eine eigene Poetik dieser Ka-

171 „,O Hoffnung und Heil der Gläubigen, o Zierde und Ruhm der Jungfrauen, Jesus, guter König““. 172 Vgl. dazu Heinrich Bobbe: Mittelhochdeutsche Katharinenlegenden in Reimen. Eine Quellenuntersuchung. Berlin 1922 (Germanistische Studien. 19), der das in einem detaillierten Vergleich herausarbeitet und zum Ergebnis kommt (S. 65-66): „Mosaikartig, - man fühlt sich versucht zu sagen: raffiniert! - hat der Dichter zwei Quellen [...] ineinander verwoben.“ 
tharinenlegende entwirft. Er beginnt topisch mit einem Anruf und der Widmung an die Heilige selbst, entfaltet dann aber, schon weit weniger konventionell, in reicher Naturmetaphorik das Bild von Christus als aller kufcheite boum (P 667, 7), an dem nun Katharina ein edler Ast mit schönen Blumen und Blättern sei, ohne einen einzigen dürren Zweig, weil frei vom Wurm der Unzucht, genauer der wille an befer luft (P 667, 23), der oft genug gute Frucht befalle:

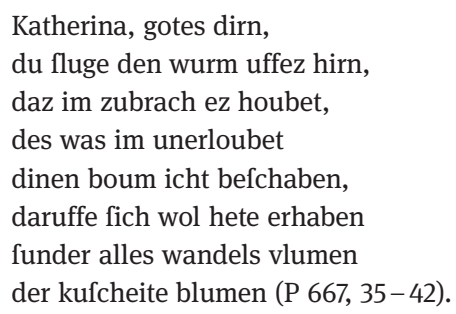

Das lyrisch-rühmende Lob der Heiligen meint auch im Weiteren allein ihre Jungfräulichkeit, die sie im Martyrium bewahrt:

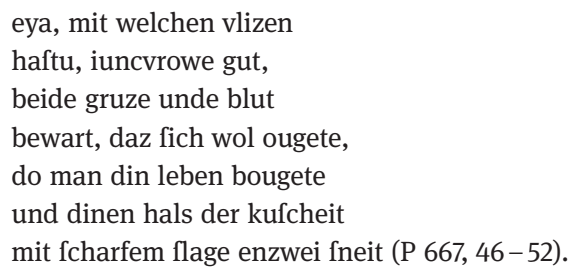

Hierin gründe auch der besondere Rang Katharinas unmittelbar nach der Gottesmutter selbst:

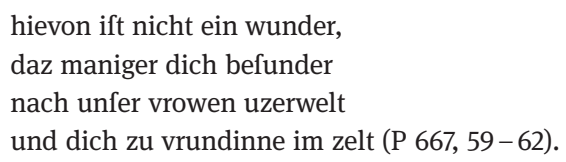

Ihre kultische Verehrung wird hier also als Ausgangspunkt und Bedingung des Erzählens vorausgesetzt: Die Legende erweist weniger die Heiligkeit der Heiligen im Sinne einer Beglaubigung, ${ }^{173}$ sondern erzählt das bereits von allen gemeinsam Geglaubte weiter aus und kann den Schwerpunkt dabei auf die ,innere‘, geistliche Dimension des Geschehens in seiner Bedeutung eben für diese christliche Rezeptionsgemeinschaft legen.

173 Eine narrative Operation, die für den Großteil christlicher Heiligenlegenden, so sie nicht eine unmittelbare Funktion in einem formalen Heiligsprechungsprozess haben, ohnehin rein symbolischer Natur ist.Vgl. oben in Kap. 2.1.1 Legendarisches Erzählen zwischen Transzendenz und Immanenz, S. 26. 
In der Vermittlung der Legende und ihrer Rezeptionspotentiale an ein volkssprachig-laikales, aber wohl durch Sprache und Muster der höfischen Kultur geprägtes Publikum nutzt das Passional ebendiese Kategorien und stilisiert den heidnischen Verfolger zum ritterlichen Herrscher. Maxentius gilt als ein wolgeborner man, / ein richer ritter und ouch edel (P 668, 2-3), aber auf die Erklärung, dass sein Rang als Augustus ein name der eren gewesen sei, reimt sich die Klage über seine Christenverfolgungen: o we do wart fich keren / der criften vreude in ein leit (P 668, 14-15). Die blutigen Verfolgungen der Kirche - von des kuniges gebote / fluc man dort und hie / die criften nieder als ein vie (P 668, 38-40) - stehen dabei in drastischer Analogie zu den Tieropfern im heidnischen Tempel, zu denen der Kaiser die Verfolgten zwingen will: fich hub da michel buten, / wand man den goten niderfluc / zu lobe des viehes vil genuc (P 668, 86-88). Und Katharina wird ihm in ihrer ersten Konfrontation mit wörtlichem Bezug auf diesen Erzählerkommentar entgegenhalten, der wahre Gott brauche keine solchen Opfer: ez ift um in alfo gewant, / daz im deifwar ift unnot / diffes armen vihes tot. (P 670, 92-94)

Die hohe Weisheit Katharinas wird auch im Passional zu Beginn angeführt, sie wird hier aber, im Gegensatz zur Legenda aurea, in ihren Verteidigungs- und Verkündigungsreden nicht weiter betont und auch von einem Wechsel der Sprachregister ad commune colloquium ist keine Rede. Viel konsequenter und explizit werden dafür in der volkssprachigen Fassung in der Figur Katharinas Keuschheit und Gotteserkenntnis enggeführt, wie es sich im tertium comparationis der Reinheit, des Körpers wie des Geistes, anbietet. Beide sind motivisch unauflösbar miteinander verflochten, wenn die Reinheit des Geistes zur Keuschheit führt, um im Martyrium dann mit und metonymisch in dieser verteidigt zu werden:

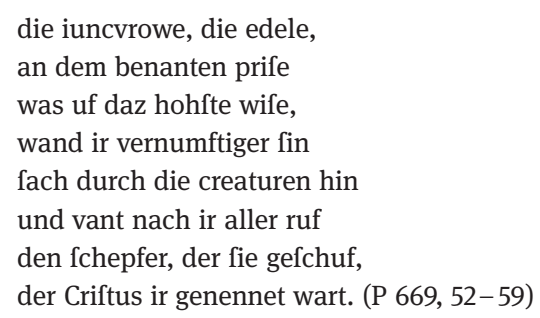

Die Erkenntnis Gottes und guter lute lere lassen ihr Herz uf unfers herren liebe entbrennen (P 669, 61 und 63) und in der Abkehr vom Bösen wählt sie die Keuschheit: dem alten helldediebe, / der manigen fûlt der kufche wat, / dem widerftunt ir edel rat (669, 64-66). Dieses christlich-geistliche Verständnis wird verstärkt, indem der Zusammenhang von körperlicher Schönheit und Weisheit als auch in der heidnischen und damit weltlich-höfischen Sicht des Maxentius gültig behauptet wird:

an deme herzen ftete im hienc daz fchone antlitze iener maget und ouch fwaz fi da gefaget 
fo rechte wiflich hete,

da uf gedachte er ftete (P 671, 88-92).

Ebenso wie Schönheit aber nur in der Keuschheit ihren eigentlichen, geistlichen Wert erhält, meint Weisheit nicht einfach allein Gelehrsamkeit, sondern Gotteserkenntnis: Wo in der Legenda aurea beides noch unproblematisch ineinander übergeht, Vernunft zur Einsicht in den wahren Glauben führen kann, so wie es dem Ansatz der frühchristlichen Apologetik, aber auch dem gelehrt-klerikalen Entstehungs- und Rezeptionskontext des lateinischen Legendars entspricht, wird hier ein Konflikt zwischen weltlich-heidnischer Schriftgelehrsamkeit und prophetisch vermittelter geistlicher Erkenntnis inszeniert. Wenn Maxentius Katharina aus heidnisch-immanenter Sicht hinsichtlich ihrer Verspottung seiner Götter vorwerfen kann: ,daz krenket dine wifheit / und machet fie gar hingeleit‘ (P 672, 29-30), dann erklärt Katharina, dass sie wohl von den besten Meistern unterrichtet worden und daher ,in den schriften kluc' (P 672, 54) sei, aber schließlich eine höhere Weisheit erkannt habe:

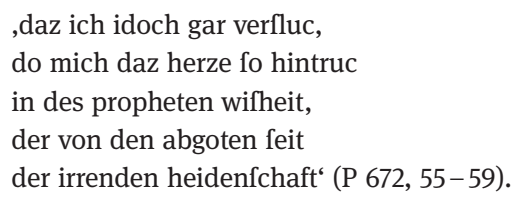

Die Darstellung des Passionals geht also über die der Legenda aurea hinaus, denn sie zeigt Katharinas Bekehrung nicht allein ,als Schlusspunkt eines rationalen Erkenntnisprozesses“, auch wenn sie diesem Muster zunächst folgt, wenn, wie oben zitiert, ir vernumftiger fin „,in scheinbar lineare[r] Konsequenz“ zur Erkenntnis Gottes führt. ${ }^{174}$ Mit der Negierung der heidnischen Schriftgelehrsamkeit durch das prophetische Wort wird „eine kategoriale mediale Differenz aufgemacht“, die Bekehrung als Bruch narrativiert: „[I]st das eine verstandesmäßig erworbenes Wissen, in einen Prozess des Lernens eingebunden [...], ist das andere ein Moment der Herzenseinsicht, eine in der Gegenwärtigkeit sich ereignende Wissensschau“. ${ }^{175}$ In dieser „radikalen Umkehr der Erkenntnislogik“, die auf religiöse Erfahrung und Präsenz des Heiligen abstellt, wird mit Blick auf das Legendenpublikum Unmittelbarkeit inszeniert, entsprechend gipfelt ihre Verkündigung vor dem Kaiser in einem stoßhaften Gottesbekenntnis: ${ }^{176}$

,do ouch min herze daz gefach,

zehant ich mich fo hinbrach

an den got,

174 Mireille Schnyder: Staunen und conversio. In: Zwischen Ereignis und Erzählung. Konversion als Medium der Selbstbeschreibung in Mittelalter und Früher Neuzeit. Hrsg. von Ruth von Bernuth, Werner Röcke, Julia Weitbrecht. Berlin/Boston 2016 (Transformationen der Antike. 39), S. 169-185, hier S. 173. 175 Ebd., S. 174.

176 Vgl. ebd. 
des gebot

gemachet hat

mit richer tat

den himel und die erden` (P 672, 65-71).

Der intendierte Unmittelbarkeitseffekt dieser und anderer Gebetsformeln - das ist eine Besonderheit der Gestaltung des Passionals, die auf die Katharinenlegende beschränkt ist - wird auch medial umgesetzt, indem sie als „inspirierte Rede“ mit „drängenden, verkürzten Versen“ kenntlich gemacht werden. ${ }^{177}$ Das gilt nicht für jede direkte Rede der Heiligen, ist dieser aber vorbehalten. ${ }^{178}$

Die für das frühe Christentum in seiner narrativen Identitätsbildung legitimatorisch und apologetisch wichtige Ablösung und Überwindung der heidnischen Philosophie durch die biblische Offenbarung wird also im Motiv der hohen Gelehrsamkeit einer heiligmäßig tugendhaften Jungfrau als Bekehrungsgeschichte inszeniert. So führt sie später auch im Disput mit den heidnischen Meistern den biographischen Bruch ihrer Bekehrung als Argument ins Feld:

,die meifterfchaft der heiden

liez ich do bliben alzuhant, wand ich nicht darinne vant, daz den menfchen ebene truge zu rechtem lebene.' (P 677, 22-26)

Dieses Selbstzeugnis im Disput wird dadurch unterstrichen, dass es, anders als die vorangehenden Gespräche, in direkter Rede vorgetragen wird. ${ }^{179}$ Die heidnische Philosophie hat sie als untauglich erkannt und die christliche Weisheit erlaubt ihr schließlich mit fulcher vuge / an worten fere kluge (P 672, 85-86) die heidnischen Götter herabzusetzen und verbal zu vernichten. Ihre rhetorische und intellektuelle Überlegenheit wird dabei stets rückgebunden an die göttliche Weisheit im mensch-

177 Ebd., S. 179.

178 Vgl. dazu auch Koch, Formen und Bedingungen von Sprachgewalt in Katharinenlegende und -spiel, die auf Bobbe, Mittelhochdeutsche Katharinenlegenden in Reimen, S. 47 und 58 verweist, der metrische Ähnlichkeiten zur liturgischen Dichtung feststellt: „Sollte diese Annahme zutreffen, würde Katharinas Rede durch die Annäherung an rituelle Formen religiöser Kommunikation auratisiert.“ (Koch, S. 25, Anm. 39) Allerdings, so merkt Koch auch an, bleibt diese metrische Form nicht nur auf hymnische Reden Katharinas beschränkt, sondern findet sich auch bei ihren Drohungen an die heidnischen Meister, siehe die Zitate unten S. 145. Einen anderen Aspekt, der meine Interpretation noch akzentuiert, arbeitet Andreas Hammer: Zwischen ratio und Erleuchtung. Religionsgespräche und Konversionserlebnisse in der mittelalterlichen Literatur. In: Sprechen mit Gott. Redeszenen in mittelalterlicher Bibeldichtung und Legende. Hrsg. von Nine Miedema, Angela Schrott, Monika Unzeitig. Berlin 2012 (Historische Dialogforschung. 2), S. 329-349, hier S. 349, heraus, wenn er die „Kontroverse zwischen Verstand und Glauben“ in Konversionserzählungen in der Katharinenlegende gerade darin verhandelt sieht, dass „ausgerechnet die die Vitentradition kennzeichnenden Apologien und Dispute in hymnisch-inspiriertes Sprechen aufgelöst werden“.

179 Vgl. Schnyder, Staunen und conversio, S. 174-175. 
gewordenen Gottessohn, dem sie sich vor dem Disput mit den heidnischen Meistern im Gebet anbefiehlt: ,o Iefu, gotes wifheit / [...] / gib lieber herre, in minen munt / wort, die wol fich lenken / und die meiftere krenken' (P 675, 22 und 29-31). Der Sieg Katharinas im Disput erscheint daher schließlich nicht als Ergebnis ihres eigenen Vermögens, sondern des Handeln Gottes, der in seinen Märtyrern gegenwärtig ist, nicht nur im Sterben, sondern gerade auch in ihrem Zeugnis im Wort, ein Motiv, das sich schon in den Evangelien findet, wo Jesus seinen Jüngeren verheißt: Cum autem tradent vos, nolite cogitare quomodo aut quid loquamini, dabitur enim vobis in illa hora quid loquamini, non enim vos estis qui loquimini, sed Spiritus Patris vestri qui loquitur in vobis (Mt 10, 19-20). ${ }^{180}$ Darauf zielt Katharinas Bitte: ,herre, du falt mich leren, / wand ich bin felber an mir blint` (P 675, 35-36), auf die hin ihr der Erzengel Michael erscheint und ihr den Beistand Gottes zusagt, im Disput wie im Martyrium überhaupt: ,fin wifheit und fin gewalt / wil dir helfen wol gefigen‘ (P 675, 57-58).

Was hier zunächst als individuelle, freilich schon transzendent abgesicherte und beglaubigte Glaubenshaltung der zur Heiligkeit Berufenen inszeniert wird, wird freilich wiederum narrativ umgesetzt, also durch die Handlung selbst belegt und somit zum für das christliche Publikum verbindlichen Heilswissen. Es sind schließlich gerade die heidnischen Meister, die erkennen, dass Katharinas Weisheit von ganz anderer Art ist als ihre eigene und es daher Gott selbst ist, der sie verstummen lässt:

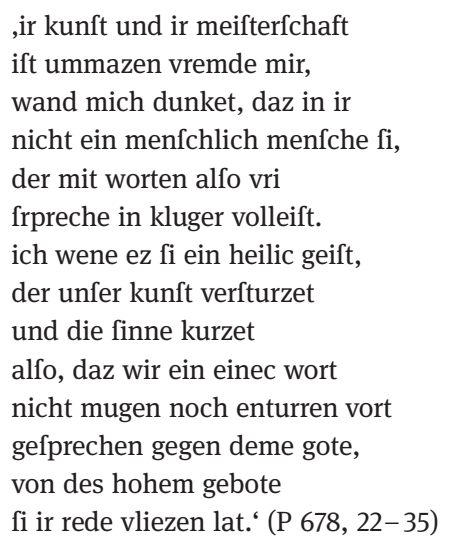

Die Inversions- und Überbietungslogik, die ja nicht nur das Martyriumsnarrativ, sondern letztlich das legendarische Erzählen insgesamt bestimmt, findet sich in der Katharinenlegende also auch im Disput verwirklicht, das setzt das Passional expliziter um als die Legenda aurea und legt es den Heiden als Erkenntnis selbst in den Mund. In der dirn (P 674, 60), die sie erzürnt und siegessicher mit Spott überziehen, offenbart

180 „Wenn sie euch nun überantworten werden, so sorgt nicht, wie oder was ihr reden sollt; denn es soll euch zu der Stunde gegeben werden, was ihr reden sollt. Denn nicht ihr seid es, die da reden, sondern eures Vaters Geist ist es, der durch euch redet.“ 
sich ihnen eine ganz andere, vremde, übermenschliche Wirklichkeit, die all ihr eigenes, menschliches Vermögen entwertet und sie sprachlos zurücklässt. Der Sieg Katharinas im Disput, so stellt es die Legende dar, gilt ihnen als Einbruch der Transzendenz in ihre immanenten Wissensordnungen und Erkenntnismöglichkeiten. Sie schreiben diese Erfahrung noch unspezifisch einem heiligen Geist zu, ohne wissen zu können, dass sie damit eine zentrale Glaubenslehre bestätigen, die freilich dem christlichen Publikum verbindliches Glaubenswissen ist und sich diesem hier in ihrer Wirksamkeit zeigt.

Der diskursive Kern der religiösen Auseinandersetzung der Katharinenlegende ist die Frage nach der Wahrheit des christlichen Glaubens, demgegenüber das Heidentum als Götzendienst erscheint und zugleich jede menschliche Gelehrsamkeit versagen muss - beides wird in der Erkenntnis Gottes überwunden. Dieser, im metaphorischen Sinn, grundlegende Glaubensdisput wird in der eigentlichen Disputation entworfen und dann im Martyrium im Medium physischer Gewalt beziehungsweise dem des Heiligenkörpers auserzählt. Physischer und spiritueller Kampf sind aber auch schon vorher überblendet, denn Gewalt wird in der Disputation auf sprachlicher Ebene als verbale Aggression realisiert, so wie das Disputationswesen bis in die Neuzeit mit Metaphern körperlicher Gewalt verbunden ist und als Form des Kampfes erscheint. ${ }^{181}$ In diesem Zusammenhang kann auch die Märtyrerin selbst als Gewalthandelnde auftreten, wenn sie die heidnischen Gelehrten in ihrem Status als Meister schmäht: ,wand uwer meifterlicher name / fal mit fchame / erwinden' (P 676, 50 - 52). Mittels invektiver Sprache greift sie gerade die Dimension der Person ihrer Gegner an, „die allein durch Sprache konstituiert ist. Der Status der Gelehrten manifestiert sich in dem Titel, der ihnen zuerkannt wird, und diesen spricht Katharina ihnen mithilfe göttlich begnadeter Rede ab.“182 Dem entspricht die Reaktion des heidnischen Herrschers, der die Schmähung aufgreift und seinen im Disput überwundenen Gelehrten ihre Meisterschaft abspricht: ,und o ir tummen lute, / wie ift uch vor uns hute / die meifterfchaft entrunnen' (P 677, 91-93).

Der Tendenz des Passionals entsprechend, die Wahrheit des Glaubens in der Legendenhandlung nicht nur als objektives Heilsgeschehen darzustellen, sondern als unmittelbare religiöse Erfahrung in ihrer Wirksamkeit auch für das Legendenpublikum, wird das auf den Glaubensdisput folgende Martyrium Katharinas weit dramatischer ausgestaltet als in der Legenda aurea. Der Disput im Wort tritt im zweiten Teil der Legende vollends hinter der Zeichenhaftigkeit des Martyriums zurück, das den grundlegenden Disput um die Wahrheit des christlichen Glaubens am Heiligenkörper sichtbar machen soll. Folglich rücken Inszenierungen von Sichtbarkeit und Heilspräsenz in den Mittelpunkt, die dem Rezipienten eine unmittelbare Anteilnahme am Geschehen suggerieren. So folgt er dem Blick des Königs auf die Standhaftigkeit Ka-

181 Koch, Formen und Bedingungen von Sprachgewalt in Katharinenlegende und -spiel, S. 16. 182 Ebd. 
tharinas und ,sieht‘, wie dieser seine ungunft am Körper der Heiligen mit Blutstriemen und aufplatzender Haut $f$ chowen lässt:

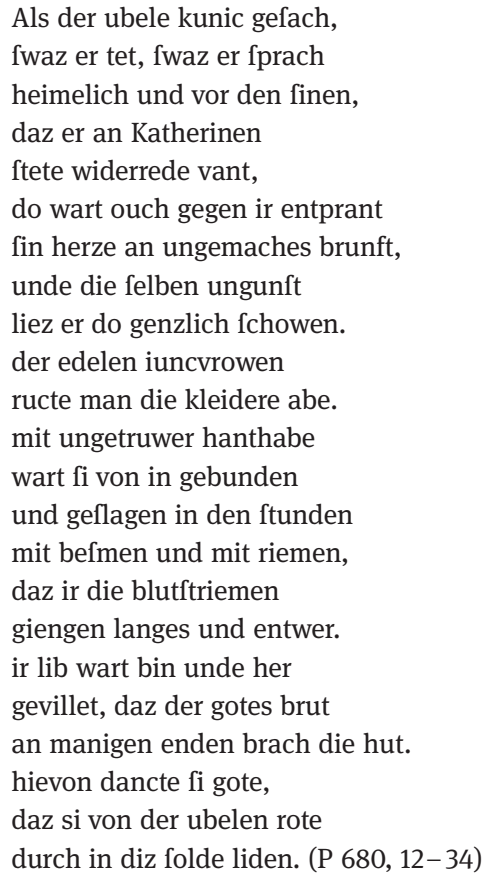

Aber nicht nur die blutige Marter wird als Moment der Sichtbarkeit inszeniert, sondern mehr noch die wundersame Überzeichnung der Spuren dieses vergeblichen Bemächtigungsversuchs über die Heilige und das Geschehen: Als die Engel Katharina im Kerker heilen mit fulchen arzedien / fwa man fie vor des zufluc (P 681, 45-46), ist das mehr als ein auktorialer Erzählerkommentar, sondern als sichtbares Heilsgeschehen ausgestellt, denn die Königin und der Heerführer sehen diese Szene als ein wunder (P 681, 33 und 48) in blendendem Glanz, der den Kerker erfüllt und vor Schreck zu Boden fallen lässt (P 681, 49-50). Wiederum folgt der Rezipient dabei der Blicklenkung durch den Erzähler und über die Figuren der Handlung: „Die von außen eintretenden Machtträger werden im geblendeten Blick auf das Wundergeschehen im Kerker Teil einer invertierten Machtordnung, wie sie sich im Licht des Kerkers installiert. "183 In diese Ordnung aber werden sie von Katharina integriert, ${ }^{184}$ die damit gleichsam auch den christlichen Rezipienten der Legende anspricht:

,got hat uch felber im erlefen

zu vrunden, des habet gedult,

183 Schnyder, Staunen und conversio, S. 177.

184 Vgl. ebd. 
wand ir giezen durch in fult

mit der martere uwer blut.' (P 681, 65-68)

Bezeichnenderweise werden die beiden Zeugen des Geschehens durch diese prophetische Ansprache gleich zu Beginn zu Märtyrern bestimmt und erst darauf dann von Katharina durch Predigt und Lehre (P 681, 70) in den Glauben eingeführt, woraufhin sie sich bekehren. Ganz im Sinne der Erkenntnislogik einer „in der Gegenwärtigkeit sich ereignender Wissensschau“"185 bei Katharinas eigener Bekehrung steht die zeichenhaft sichtbare Präsenz des Heils vor der diskursiven Unterweisung im Glauben, so betont auch der Erzähler die überwältigende Ereignishaftigkeit ihrer Bekehrung als lebenswendender Transzendenzerfahrung:

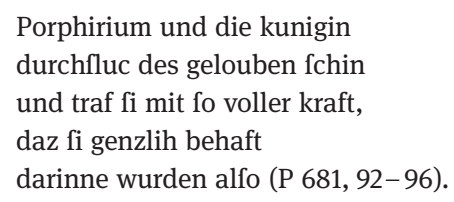

Dieser „Durchschlag“ wiederholt andererseits als von persönlicher Erkenntnis geleiteter Glaubenswechsel die Ablösung des Heidentums durch das Christentum:

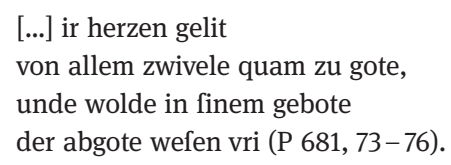

Aus den Heiden werden Christen und schließlich selbst Heilige. Das wird in der Szene ihrer Erwählung performativ und vor himmlischer Zeugenschaft bekräftigt, wenn Katharina einem der umstehenden Engel die Krone abnimmt und sie - in zeichenhafter Vorwegnahme des folgenden Geschehens - der Königin aufsetzt und ihr verheißt, sie werde in drei Tagen ins Himmelreich kommen. Das ist abermals in direkter Rede der Heiligen als göttliche Vision nicht nur den intradiegetischen Zeugen unmittelbar vor Augen gestellt, sondern auch den Legendenrezipienten: ,nu fich, dir ift erloubet', / fprach fi, ,alfus gezieret wefen, / wand dich im got hat uzerlefen.' (P 681, $85-87)$

Die Zeichenhaftigkeit des eigentlichen Martyriums Katharinas wird im Passional schließlich noch dramatisch gesteigert, wenn sie trotz grausamster Qualen und wiederholter Drohungen von Maxentius diesen gar herausfordert, sie auf alle Arten zu martern, weil sie das Geschehen im göttlichen Willen abgesichert weiß: ,erfuche alle die erge din / an mir, fwie got verhenge / da wider ich mich nicht fpenge ‘ (P 683, 38-40) und sich dabei gerade auf das Leiden Christi berufen kann. Ihr Sterben wird schließlich als öffentlich sichtbares Ereignis in seiner Wirkung auf das intradiegeti-

185 Ebd., S. 174. 
sche Publikum inszeniert, dem sie zugleich die geistliche Dimension des Geschehens in einer letzten Predigt offenlegt. Als nämlich die umstehenden Heiden sie unter Weinen bitten, ihren Leib und ihr Leben - lip umfasst metonymisch ja beides - zu schonen, do was ir leit unde leit / des armen volkes blindekeit, / die fie zoch uf krummen fin (P 687, 67-69). Sie legt ihnen daraufhin den martyrologischen Umschlag irdischer Schmach in himmlische Ehre offen und bekundet ihre Heiligkeit wiederum in einem Sichtbarkeitseffekt, denn sie behauptet ihre Gottesunmittelbarkeit nicht nur, sondern erblickt Christus als ihren Bräutigam, der sie zu sich ruft:

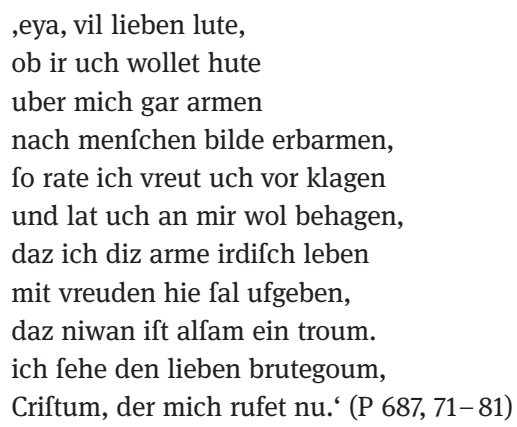

Abermals darf sich das christliche Legendenpublikum von dieser Verkündigung, dem ,Ruf' Gottes, angesprochen fühlen, der den Eintritt der Heiligen in die communio sanctorum verbürgt.

Mit all dem wird in der Katharinenlegende des Passionals die Zeichenhaftigkeit des Martyriums, in der unbeirrbaren Standhaftigkeit Katharinas trotz grausamster Qualen auf der einen, ihrer wundersamen Bewahrung, Heilung und Heiligung durch Gott als dem eigentlichen Lenker des Geschehens auf der anderen Seite, gegenüber der Legenda aurea noch gesteigert und vor allem in seiner Relevanz für den einzelnen Gläubigen auserzählt. Die abschließende Inszenierung der Erzählerfigur im Epilog, die als Vermittlungsinstanz des Legendengeschehens dessen angemessene Rezeption exemplarisch verkörpert, macht diese Funktion der Heiligen und ihres Opfers deutlich, wenn es heißt:

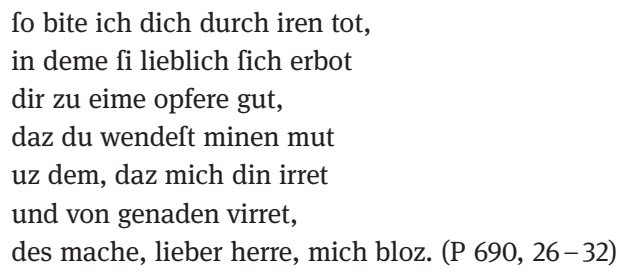

Das Martyrium der Heiligen ist damit auch in dieser volkssprachigen Vermittlung nicht nur Anlass zu distanzierter admiratio, sondern wird für einen geistlichen Mitvollzug in aedificatio und imitatio funktionalisiert, der zugleich eine kollektive identitätsstiftende Funktion im Hinblick auf das Legendenpublikum hat. Die Disputation 
mit den Heiden, vor allem mit dem Kaiser, nimmt weit breiteren Raum ein als in der Legenda aurea, Katharinas Reden dienen dabei aber weit weniger der diskursiven Vermittlung von Glaubenslehren, als dass sie stets schon Teil der narrativen Inszenierung des Martyriums als zeichenhafter Glaubensdisput sind. Im Vordergrund steht die Mittlerschaft der Heiligen, also „weniger ihre diskursive als ihre gnadenhaft-performative Macht“, die sich in den Konversionswellen niederschlägt. ${ }^{186}$

\subsubsection{Verstockung oder Bekehrung im Angesicht des Martyriums: Die Rolle der Heiden}

Wenngleich der christliche Märtyrer natürlich immer schon als Glaubenszeuge in heidnischer Umgebung erscheint, erfüllt er seine Funktion zunächst einmal nicht als Muster tatsächlicher religiöser Auseinandersetzung mit den Heiden, sondern als geistliches Vorbild und spiritueller Mittler im christlichen Binnendiskurs: Sein Beispiel im Martyrium macht ihn zum Vorbild an Tugendhaftigkeit, Standhaftigkeit und Glaubensstärke, in seinem Leiden und Sterben, aber auch über den Tod hinaus erweist sich seine Heiligkeit in Wundern und erfolgreicher Fürsprache vor Gott. Die Heiden sind dabei allerdings nicht nur notwendige Bedingung für die Möglichkeit eines Sterbens für Gott als Glaubenszeugnis, auch nicht bloße Statisten des Geschehens, sondern auch ihnen beziehungsweise ihrer Entscheidung im Angesicht des Martyriums kommt eine Funktion zu, die von entscheidender Bedeutung für das gesamte Narrativ ist: An ihnen, als Zeugen des Martyriums, muss sich die Wahrheit des christlichen Glaubens erweisen.

Zunächst einmal sind die Heiden natürlich gerade in der narrativen Konstellation der Märtyrerlegende, die eine heidnische Umwelt und deren Feindseligkeit gegenüber dem christlichen Glauben voraussetzt, das religiöse Gegenbild des Unglaubens. Ob rein äußerlich in ihrem ,falschen' Kult oder gleichzeitig spiritualisiert in ihrer Sündhaftigkeit und inneren Gottesferne bieten sie die Kontrastfolie für die Exemplarizität des christlichen Heiligen. Gleichzeitig gilt auch ihnen als Geschöpfen Gottes die Botschaft des Glaubenszeugen, der sie mit der Möglichkeit der Bekehrung konfrontiert und damit vor die Wahl stellt: den christlichen Glauben anzunehmen und in die christliche Wir-Gemeinschaft inkludiert zu werden, oder aber sie abzulehnen und sich damit selbst als ,Ungläubige‘ zu exkludieren. Das narrative Risiko des Martyriums, das ja immer gegen die Infragestellung der christlichen Wahrheit - diskursiv durch die heidnische Polemik, performativ durch die Folter und Marter des Glaubenszeugen anerzählen muss, führt also in jedem Fall zu einem Erfolg im Sinne christlicher Identitätsbildung in Abgrenzung vom Heidentum. Denn in ihrem Verhalten auf das Zeugnis des Märtyrers, im Wort wie in der Zeichenhaftigkeit des Geschehens, belegen sie beispielhaft seine Heiligkeit und veranschaulichen die Scheidung zwischen

186 Weitbrecht, Imitatio und Imitabilität, S. 214-215. 
Glaube und Unglaube, Heil und Verdammnis, die sich in jedem Gläubigen fortsetzen muss.

Eine Bekehrung der Heiden zeigt die Wahrheit des christlichen Glaubens in performativer Umsetzung, nicht als abstrakte Lehre, sondern als heilspräsentisches Ereignis, das in der Geschichte wirksam wird: Das Martyrium eines Heiligen führt zur Bekehrung von Heiden und damit meist unmittelbar zu Folgemartyrien, also weiteren Heiligen, die selbst zum Gegenstand legendarischen Erzählens werden, was in einer zyklisch fortgesetzten Reproduktion von Heiligkeit schließlich auch auf die Rezipienten der Legende ausgreift, die von der Wirkmacht des Heiligen, dessen Mittler die Heiligen sind, erfasst werden sollen. ${ }^{187}$ Die intendierte Rezeptionshaltung angesichts des Glaubenszeugnisses eines Märtyrers erweist sich also bereits innerhalb der Legende und wird dort beispielhaft veranschaulicht. Wenn in der Katharinenlegende „weniger die Heiligung der Protagonistin selbst im Mittelpunkt steht als vielmehr die von ihr geleistete Heilsvermittlung, wenn also Katharina stetig weitere Proselyten produziert, die öffentlich, in Konversionswellen oder ganzen Konversionsfesten, der Heiligen in Christentum und Martyrium nachfolgen“, dann stellt „die Legende intradiegetisch ihre eigene Wirksamkeit zur Schau“ und erweist sich die „performative Dimension des Sprechens vom Heiligen“. ${ }^{188}$ Die imitatio Christi, die der Heilige in der Legende vollzieht, bringt innerhalb und außerhalb der Erzählwelt erneut imitatio hervor. ${ }^{189}$ Damit wird der Märtyrer zu einem

Medium kultureller Serienproduktion. Nicht nur in der klassischen christlichen Version der Imitatio Christi stellen sich Märtyrerfigurationen als Modelle der Nachahmung dar. Wo ein Märtyrer auftritt, da wird es bald viele geben. Die Nobilitierung des Todes als [...] Opfer für einen höheren Wert [...] macht den Märtyrer zu einem Vorbild, das Nachfolger hervorbringt und auf diese Weise eine Genealogie von Märtyrern stiftet. [...] An die Stelle der consanguinitas (lat. Verwandtschaft) tritt die Gemeinschaft der conmartyres - und in deren Folge das Publikum als Affektgemeinschaft der compassiones. ${ }^{190}$

In der Bekehrung der Heiden und der Produktion neuer Heiliger, die alle Teil der christlichen Wir-Gemeinschaft der Rezipienten werden, liegt also das Potential gerade des Märtyrers, als Heiliger zur Integrationsfigur in Bezug auf die Heiden zu werden. ${ }^{191}$

187 Ein Zusammenhang, den Edith Feistner für das Gedächtnis von Heiligen in der Legende zeigt: Imitatio als Funktion der Memoria. Zur Selbstreferentialität des religiösen Gedächtnisses in der Hagiographie des Mittelalters. In: Kunst und Erinnerung. Memoriale Konzepte in der Erzählliteratur des Mittelalters. Hrsg. von Ulrich Ernst, Klaus Ridder. Köln/Weimar/Wien 2003 (Ordo. 8), S. 259-276, hier S. 266.

188 Weitbrecht, Imitatio und Imitabilität, S. 208. Strohschneider, Höfische Textgeschichten, S. 200, spricht von „Heiligungsvorgänge[n] zweiter Stufe“.

189 Vgl. Köbele, Die Illusion der ,einfachen Form', S. 366.

190 Sigrid Weigel: Schauplätze, Figuren, Umformungen. Zu Kontinuitäten und Unterscheidungen von Märtyrerkulturen. In: Märtyrer-Porträts. Von Opfertod, Blutzeugen und heiligen Kriegern. Hrsg. von ders. München 2007, S. 11-37, hier S. 20.

191 Vgl. oben in Kap. 2.2.3 Die Dynamik der Mission, S. 62. 
Bekehrung wie Martyrium erweisen sich als „kollektive Phänomene, die eine regelrechte Sogwirkung entfalten. Heiligkeit erscheint dabei insofern sozial konstituiert, als sie in ihrer Wirkung auf andere gezeigt wird und eine übergreifende Heilsgemeinschaft stiftet. “192

Die beharrliche Ablehnung der Wahrheit des christlichen Glaubens, die die Heiden im Zeugnis des Heiligen ja nun vor Augen haben, zeugt hingegen umso drastischer von ihrer ,Verstockung ${ }^{693}$ und Grausamkeit, und macht sie vollends zum Gegenbild, vor dem das Zeugnis des Märtyrers sich umso bewundernswürdiger und umso ,heiliger' abheben muss. Nach der Aufhebung der überkommenen Unterscheidungen der Menschheit durch ihre Erlösung durch Christi Tod und Auferstehung besteht die fundamentale Antithese im wahren Glauben, der allen Menschen gilt, aber eben auch abgelehnt werden kann. ${ }^{194}$ Die dynamische und temporale Spannung, in die Christen und Heiden dabei bis zur letzten Scheidung im Jüngsten Gericht verwiesen sind, wird zumindest in der zeitlichen Spanne der Legenderzählung zu einem endgültigen Punkt geführt, wenn die blindwütigen Verfolger die Verdammnis und mitunter gleich der Tod als unmittelbare Strafe Gottes trifft. Hier wird im Rücken der Stiftung einer übergreifenden Heilsgemeinschaft die Wirkung der Ablehnung der Heiligkeit und überhaupt der christlichen Botschaft gezeigt, wobei die Asymmetrie zwischen den Vielen in die Heilsgemeinschaft Inkludierten und den einzelnen Verdammten die kollektive Identitätsstiftung befördern kann.

Der identitätsstiftende Gehalt des Martyriums liegt im Kern also darin, dass es in der religiösen Konfrontation die Unterscheidung beider Möglichkeiten, der Annahme des Heils wie dessen Ablehnung, im äußeren Gegensatz von Christentum und Heidentum, Glaube und Unglaube offenbar macht. Es geht in der Heiligung des einzelnen Märtyrers immer zugleich „um einen Kampf kontradiktorischer heilsgeschichtlicher Optionen“195, einen Kampf, der freilich im Letzten längst entschieden ist, aber im Einzelnen dennoch immer wieder neu aktualisiert werden muss. So zeigt sich im Leben des Heiligen exemplarisch die Überwindung der Sünde und aller weltlichen Versuchungen, die oftmals heidnischen Ursprungs sind oder gar noch in seinem Heidentum gründen, und zugleich die typologische Überwindung des Heidentums

192 Weitbrecht, Imitatio und Imitabilität, S. 217.

193 So der theologische Terminus für die Unempfänglichkeit gegenüber dem christlichen Glaubenszeugnis. Das Thema begegnet schon im Alten Testament als Verstockung Israels gegenüber Gott, im Neuen Testament bezieht es sich ,auf das Verhalten derer, die sich der gepredigten frohen Botschaft verschließen“. Dabei umschreibt der Ausdruck, Verstockung“ ,in bildlicher Redeweise die anhaltendwiderständliche Verschlossenheit des Menschen gegenüber dem geschichtliche widerfahrenden Willen Gottes in Wort, Geist und Ereignis. Die ,Verblendung der Augen', die ,Taubheit der Ohren' und die ,Verhärtung des Herzens‘ bezeichnet in der Verkehrung der ursprünglichen Bestimmung der Sinnesorgane eine wesenhafte Verkehrung des Menschen gegenüber Gott.“ Franz Hesse, Raul Gyllenburg, Jürgen Moltmann: Art. Verstockung. In: ${ }^{3}$ RGG 6 (1986), Sp. $1383-1385$, hier Sp. 1384 und Sp. 1384-1385. 194 Vgl. dazu oben in Kap. 2.2.1 Heidentum als dynamischer Gegenbegriff, S. 47-48.

195 Gemeinhardt, Märtyrer und Martyriumsdeutungen, S. 295. 
durch den neuen Glauben. ${ }^{196}$ Daher kann es bei den Heiden speziell der Märtyrerlegende letztlich nicht um eine realistische oder persönlich-differenzierte Darstellung gehen, denn ebenso wie die Heiligen sind sie funktionale Größen. In ihrer Haltung, ob ablehnend oder befürwortend, bezeugen sie die Wahrheit des christlichen Glaubens.

\subsection{Heilszeugnis und Selbstheiligung in der Mission: Franziskus}

\subsubsection{Martyrium und Mission im frühen Franziskanertum}

In der franziskanischen Neubegründung der Mission wird das Glaubenszeugnis im ,Sterben für Gott‘ durch die Hand der Heiden wieder zu einer tatsächlichen Option. Diese Aktualisierung des Märtyrerideals geschieht im Streben nach einer Erneuerung der vita apostolica, in dem sich die franziskanische Bewegung

einem fundamentalen, das mittelalterliche Europa erfassenden religiösen Aufbruch zuordnen [lässt]. Zahlreiche Männer und Frauen brachen zu Beginn des 13. Jahrhunderts aus ihren adeligen oder bürgerlichen Existenzen aus und wählten ein Dasein in Armut, Askese und Selbsterniedrigung. ${ }^{197}$

Mit diesem Ideal standen die dabei entstehenden Gemeinschaften durchaus in der Tradition der monastischen Erneuerung und Kirchenreform des 11. und 12. Jahrhunderts, doch lag ihr charakteristisches Novum darin, dass ihnen dessen Verwirklichung nur in Verbindung mit der Sorge um das Heil der in der ,Welt' verbleibenden Mitmenschen denkbar war: paupertas und praedicatio, als die beiden Leitideen einer neuen apostolischen Frömmigkeit, waren bei ihnen untrennbar miteinander verbunden. ${ }^{198}$ Die breite Kreise erfassende laikale Armutsbewegung und die mendikantischen Ordensgründungen des 13. Jahrhunderts lassen sich dabei als Ausdruck einer einzigen, umfassenden religiösen Erneuerungsbewegung im Zeichen evangelischer Armut und apostolischer Predigt verstanden werden. ${ }^{199}$ Der Verkündigungsanspruch

196 Das gilt insbesondere, aber nicht nur für den Typus des Sünderheiligen. Vgl. Dorn, Der sündige Heilige, S. 142.

197 Christina Andenna: Neue Formen der Frömmigkeit und Armutsbewegung. In: Verwandlungen des Stauferreichs. Drei Innovationsregionen im mittelalterlichen Europa. Hrsg. von Bernd Schneidmüller, Stefan Weinfurter, Alfried Wieczorek. Darmstadt 2010, S. 246-263, hier S. 248.

$198 \mathrm{Vgl}$. ebd. Armut und Buße sowie Verkündigung stehen dabei in einem engen konzeptionellen Zusammenhang: „Predigt der Armut und der Buße wie zugleich Vorleben dieser Armut und Bußübung zur Bestätigung der Predigt“. Angenendt, Heilige und Reliquien, S. 40.

199 So die grundlegende These bei Herbert Grundmann: Religiöse Bewegungen im Mittelalter. Untersuchungen über die geschichtlichen Zusammenhänge zwischen der Ketzerei, den Bettelorden und der religiösen Frauenbewegung im 12. und 13. Jahrhundert und über die geschichtlichen Grundlagen der Deutschen Mystik Berlin 1935 (Historische Studien. 267). Sonderausgabe. Reprografischer Nachdruck. 4., unveränderte Aufl. Darmstadt 1977. Die Auffassung Grundmanns, wonach Papst Innozenz III. (1198-1216) die am Vorbild des Urchristentums orientierten und damit immer in Häresiegefahr ste- 
der sich formierenden Bettelorden erstreckt sich aber nicht nur auf die geistlichmoralische Erneuerung der Christenheit, im Kampf insbesondere der Dominikaner gegen die Häretiker und in den Bemühungen um eine vertiefte Laienfrömmigkeit, sondern wurde in einem neu aufkommenden weltmissionarischen Streben vor allem von den Franziskanern auch nach außen getragen.

Auch wenn die franziskanische Frömmigkeit eng mit einer Neubelebung der Mission verbunden ist, sodass man gemeinhin vom Beginn einer „neue[n] Epoche der Missionsgeschichte, auch der sogenannten Heidenmission“200 spricht, ist sie kein singuläres Phänomen. Vielmehr verdichten sich in ihr die lange tradierten Vorstellungen einer Verbindung heiligmäßigen Lebens mit dem Glaubenszeugnis auch über die Grenzen der Christenheit hinaus. So werden auch nicht erst hier, sondern überall, wo im frühen und hohen Mittelalter das Ideal apostolischer Lebensweise und Verkündigung zum Tragen kommen, Mission und Martyrium zu konkreten Optionen religiöser Auseinandersetzung mit den Heiden. ${ }^{201}$

Der Anspruch, wonach ,universale Glaubensverkündigung ein verbindliches Grundprinzip apostolischer Lebensweise und folglich oberste Verpflichtung der Kir-

henden Laienbewegungen erst in die katholische Kirche integriert, die neuen Orden also deren kirchlich-institutionell eingebundene Ausformung im Kampf eben gegen die häretischen Strömungen von Waldensern und Katharern darstellen, lässt sich allerdings korrigieren oder zumindest akzentuieren mit Verweis auf die Bemühungen ebendieses Papstes um eine Reform der Gesamtkirche, die das Laientum über den Entwurf eines eigenen Büßerstandes und dessen Förderung in Predigt und Seelsorge einbeziehen soll. Vgl. Martina Wehrli-Jons: Voraussetzungen und Perspektiven mittelalterlicher Laienfrömmigkeit seit Innozenz III. Eine Auseinandersetzung mit Herbert Grundmanns „Religiöse Bewegungen“. In: Mitteilungen des Instituts für Österreichische Geschichtsforschung 104 (1996), S. 286-309, hier S. 295-298, die kritisiert, Grundmanns These „von einer die ständische Ordnung der Kirche überwindenden apostolischen Bewegung“ (S. 294) speise sich aus seiner Sympathie für die „Dissidenten des religiösen Diskurses“ (S. 288) und der grundsätzlichen Annahme eines Widerspruchs zwischen katholischer Kirche und religiöser Bewegung. Diese anachronistisch-protokonfessionelle Einseitigkeit Grundmanns lässt sich aus seiner protestantisch-pietistischen ,Erweckung‘ erklären, die sein Schüler Arno Borst „die tiefste Wurzel für sein Lebenswerk“ genannt hat: Ders.: Herbert Grundmann (1902-1970). In: Deutsches Archiv für Erforschung des Mittelalters 26 (1970), S. 327-353, hier S. 328. In jedem Fall wurden die Mendikanten „von der Kirche als Instrument zur Homogenisierung und Kanalisierung der pauperistischen Strömungen erkannt und eingesetzt wurden“. Andenna, Neue Formen der Frömmigkeit und Armutsbewegung, S. 256.

200 Dieter Berg: Kreuzzugsbewegung und propagatio fidei. Das Problem der Franziskanermission im 13. Jahrhundert und das Bild von der islamischen Welt in der zeitgenössischen Ordenshistoriographie. In: Orientalische Kultur und europäisches Mittelalter. Hrsg. von Albert Zimmermann, Ingrid CraemerRuegenberg. Berlin/New York 1985 (Miscellanea Medievalia. 17), S. 59-76, hier S. 59.

201 Vgl. Kaspar Elm: Franz von Assisi: Bußpredigt oder Heidenmission? In: Vitasfratrum. Beiträge zur Geschichte der Eremiten- und Mendikantenorden des zwölften und dreizehnten Jahrhunderts. Festgabe zum 65. Geburtstag. Hrsg. von dems., Dieter Berg. Werl 1994 (Saxonia Franciscana. 5), S. 155-171, hier S. 163-171. Für die Verknüpfung von Mission und Märtyrertum bei Adalbert von Prag vgl. Wieslaw Sieradzan: Der gottgefällige Bischof oder Missionar-Märtyrer? In: Ständische und religiöse Identitäten in Mittelalter und früher Neuzeit. Hrsg. von Stefan Kwiatkowski. Toruń 1998, S. 147-161, hier S. 152. 
che ist“ und daher auch „,von deren ,Gliedern“ eingelöst“ werden muss, ${ }^{202}$ ist demnach zwar unbestrittener Bestandteil der kirchlichen Tradition, wird aber vom frühen Franziskanertums auf eigene Weise umgesetzt, indem es ihn nicht mehr an einzelne delegiert, sondern „das propositum der Heidenpredigt als gemeinschaftliches Leitprinzip für sich monopolisierte und als Konsequenz einer spezifischen Spiritualität und Lebensweise in noch radikaleren Formen als bislang umzusetzen versuchte““.203 Die Heidenmission stellt dabei nicht bloß ein weiteres Betätigungsfeld für die Mendikanten dar, sondern ist konzeptionell eng mit der Bußpredigt verbunden, denn beide entspringen dem Ideal konsequenter Christusnachfolge in der vita apostolica, und auch inhaltlich ergibt sich eine unmittelbare Beziehung dieser Anliegen, „insofern beide den Aufruf zur Umkehr implizierten“. 204

Innerchristliche und Heidenmission sind daher in der Biographie und im Denken des heiligen Franziskus, soweit sich diese aus den Viten und den von ihm überlieferten Schriften überhaupt ,authentisch ${ }^{`}$ rekonstruieren lassen, nicht $\mathrm{zu}$ trennen, sondern „Zwei verschiedene Formen eines universal verstandenen Apostolates“. ${ }^{205}$ So verpflichtet Franziskus beispielsweise in seinem Brief an alle Brüder oder den gesamten Orden die Adressaten auf die allen gemeinsame Aufgabe, den christlichen Glauben in Wort und Tat zu bezeugen und das ,in der ganzen Welt“: quoniam ideo misit vos in universo mundo, ut verbo et opere detis testimonium voci eius et faciatis scire omnes, quoniam non est omnipotens prater eum (Epistola toti Ordini missa, Prologus 9). ${ }^{206}$

Das sich daraus abgeleitete Modell der Heidenmission lässt sich anhand der Regula non bullata darstellen, der als frühes und ,unverfälschtes`Zeugnis gemeinhin

202 Anne Müller: Bettelmönche in islamischer Fremde. Institutionelle Rahmenbedingungen franziskanischer und dominikanischer Mission in muslimischen Räumen des 13. Jahrhunderts. Münster 2002 (Vita regularis. 15), S. 7. Vgl. außerdem Dies.: Bettelmönche und Islam. Beobachtungen zur symbolischen Darstellung von Missionsprinzipien der Mendikanten in Text, Handlung und Bildkunst des 13. Jahrhunderts. In: Lateinisch-griechisch-arabische Begegnungen. Kulturelle Diversität im Mittelmeerraum des Spätmittelalters. Hrsg. von Margit Mersch, Ulrike Ritzerfeld. Berlin 2009 (Europa im Mittelalter. 15), S. 285-308; Das Missionsverständnis des Franziskus von Assisi und der frühen franziskanischen Bewegung. In: Das Charisma des Ursprungs und die Religionen. Das Werden christlicher Orden im Kontext der Religionen. Hrsg. von Petrus Bsteh, Brigitte Proksch. Münster 2011 (Spiritualität im Dialog. 3), S. 171-205; Die frühe Franziskanermission im muslimischen Orient. Ideen, normative Grundlagen und Praxis. In: Missionen. Hrsg. von Giancarlo Collet und Johannes Meier. Paderborn 2013 (Geschichte der sächsischen Franziskaner-Provinz von den Anfängen bis zum Ende des 20. Jahrhunderts 4), S. 33-56.

203 Müller, Bettelmönche in islamischer Fremde, S. 25. Den Anspruch auf „missionarische Originalität“ darf es deshalb auch dann erheben, wenn „wesentliche Ideen doch in der Kontinuität der Armutsbewegung zu sehen" sind.

204 Münkler, Erfahrung des Fremden, S. 68. Vgl. zu dieser Frage auch insgesamt Elm, Franz von Assisi: Bußpredigt oder Heidenmission?

205 Berg, Kreuzzugsbewegung und propagatio fidei, S. 61.

206 „Denn dazu hat er euch in die Welt gesandt, dass ihr durch Wort und Werk seiner Stimme Zeugnis gebt und alle wissen lasst, dass niemand ist allmächtig außer ihm.“ 
bescheinigt wird, „in besonderer Weise das Denken und Wollen des heiligen Franziskus“ widerzuspiegeln und „tiefe Einblicke in seine Religiosität und Geistigkeit“ zu gewähren - man wird diesen Eindruck aber weniger mit der älteren Ordensgeschichtsschreibung auf den „freie[n] Schwung seines kühnen Idealismus“207 zurückführen können, als vielmehr auf die noch weniger stark ausgeprägte institutionelle Einbindung und funktionale Ausdifferenzierung der franziskanischen Bewegung. ${ }^{208}$ Sie wurde jedenfalls auf Grundlage der erweiterten ,Urregel‘, die Franziskus schon 1209 oder 1210 Papst Innozenz III. vorgelegt und mündlich bestätigt bekommen hatte, Pfingsten 1221 vom Generalkapitel des Ordens erstellt, weil angesichts des raschen und steigen Wachstums der Gemeinschaft eine verbindlichere Begründung der gemeinschaftlichen Lebensform notwendig geworden war, allerdings nicht päpstlich approbiert.

Hinsichtlich der Predigt formuliert die Regula non bullata in Kapitel 17 De praedicatoribus überraschend restriktiv: Nullus frater praedicet contra formam et institutionem sanctae Ecclesiae et nisi concessum sibi fuerit a ministro suo. Et caveat sibi minister, ne alicui indiscrete concedat. (NbR XVII, 1-2) ${ }^{209}$ Das Verbot unbefugter Predigt ist allerdings mit dem Verweis einer Verkündigung in den „Werken“, also dem persönlichen Vorbild, verbunden, die alle Brüder üben können und sollen: Omnes tamen fratres operibus praedicent. (NbR XVII, 3) 210 $^{10}$ Dieser scheinbare Widerspruch erklärt sich vor dem Hintergrund der kirchlichen Bemühungen um eine Reglementierung der Laienpredigt, die mit den Armutsbewegungen gerade in ihren häretischen Formen zu einem Problem geworden war, weshalb das Vierte Laterankonzil 1215 alle Laien mit dem Bann belegte, die ohne Erlaubnis des örtlichen Bischofs predigten. Das aber zielte auf die praedicatio als Verkündigung von Glaubensinhalten und nicht die allen Gläubigen zustehende Bußpredigt, die exhortatio, die allgemein zu Umkehr und Reue und einem Leben nach Evangelium aufruft und die von den Franziskanern ursprünglich allein geübte Verkündigungsform darstellte. Im Zuge ihrer institutionellen Einbindung bekommen sie dann aber bald, möglicherweise noch von Innozenz III., also vor 1216, spätestens aber bis 1221, das Predigtamt übertragen, das freilich dann nicht mehr allen Brüdern gilt. ${ }^{211}$

207 So insgesamt die Einschätzung in: Die Schriften des heiligen Franziskus von Assisi. Hrsg. von Lothar Hardick und Engelbert Grau. Kevelaer 2001, S. 176, deren Erstausgabe von 1951 stammt.

$208 \mathrm{Zu}$ einer in diesem Sinne differenzierteren Einschätzung der Regula non bullata als dem ,zentralen Dokument für die Interpretation der Geschichte des frühen Franziskanertums und dessen ursprünglicher Intentionen“ vgl. Feld, Franziskus von Assisi, S. 11-12, Zitat S. 12.

209 „Keiner der Brüder soll gegen Vorschrift und Anordnung der heiligen Kirche predigen und nur, wenn es ihm von seinem Minister erlaubt ist. Der Minister hüte sich jedoch, jemandem unüberlegt die Erlaubnis zu erteilen.“

210 „Alle Brüder sollen jedoch durch Werke predigen.“

211 Vgl. Rolf Zerfaß: Der Streit um die Laienpredigt. Eine pastoralgeschichtliche Untersuchung zum Verständnis des Predigtamtes und zu seiner Entwicklung im 12. und 13. Jahrhundert. Freiburg i. Br. 1974 (Untersuchungen zur Praktischen Theologie. 2), S. 284-289. 
Für die Heidenmission bedarf es dabei aber ohnehin einer besonderen Berufung durch Gott und sie ist nicht Teil der allgemeinen Gehorsamspflicht der Brüder. So widmet sich das in der Regula non bullata vorangehende Kapitel eigens und ausführlich denen, „die unter die Sarazenen und andere Ungläubige gehen wollen“, $D e$ euntibus inter saracenos et alios infideles (NbR XVII), wobei nicht von ad, sondern von inter die Rede ist, wie um zu unterstreichen, dass es nicht um eine bloße Verkündigung an die Heiden geht, sondern um ein zeugnisgebendes Leben ,unter ${ }^{6}$ ihnen. ${ }^{212}$ Auch dafür bedürfen die Brüder der Erlaubnis ihres Ministers, doch ist die Regelung weit weniger restriktiv gehalten, sondern auf die Gewährung hin angelegt:

\footnotetext{
Unde quicumque frater voluerit ire inter saracenos et alios infideles, vadat de licentia sui ministri et servi. Et minister det eis licentiam et non contradicat, si viderit eos idoneos ad mittendum; nam tenebitur Domino reddere rationem, si in hoc vel in aliis processerit indiscrete. (NbR XVI, 3-4)

Daher soll jeder Bruder, der auf göttliche Eingebung hin unter die Sarazenen und andere Ungläubige gehen will, mit der Erlaubnis seines Ministers und Dieners gehen. Der Minister aber soll ihnen ohne Widerspruch die Erlaubnis geben, wenn er sieht, dass sie zur Mission tauglich sind; denn er wird dem Herrn Rechenschaft ablegen müssen, wenn er hierin oder in anderen Dingen unüberlegt vorgegangen ist.
}

Für die Brüder aber, die ausgesandt werden, gibt es dann zwei verschiedene Möglichkeiten des missionarischen Wirkens:

Fratres vero, qui vadunt, duobus modis inter eos possunt spiritualiter conversari. Unus modus est, quod non faciant lites neque contentiones, sed sint subditi, ,omni humanae creaturae propter Deum' et confiteantur se esse christianos. Alius modus est, quod, cum viderint placere Domino, annuntiant verbum Dei, ut credant Deum omnipotentem [...] et ut baptizentur et efficiantur christiani (NbR XVI, 5-7).

Die Brüder, die dann hinausziehen, können in zweifacher Weise unter ihnen geistlich wandeln. Eine Art besteht darin, dass sie weder zanken noch streiten, sondern ,um Gottes willen jeder menschlichen Kreatur' (1 Petr 2,13) untertan sind und bekennen, dass sie Christen sind. Die andere Art ist die, dass sie, wenn sie sehen, dass es dem Herrn gefällt, das Wort Gottes verkünden, damit jene an den allmächtigen Gott glauben [...] und sich taufen lassen und Christen werden.

Nach dem persönlichen Beispiel des Missionars im Mitleben ,unter den Heiden erscheint die tatsächliche Glaubensverkündigung im Wort erst als zweiter Schritt geboten. Als Drittes, weniger als eigenständige Form der Mission denn als mögliche

212 Vgl. Kajetan Eßer: Das missionarische Anliegen des heiligen Franziskus. In: Wissenschaft und Weisheit. Franziskanische Studien zu Theologie, Philosophie und Geschichte 35 (1972), S. 12-18, hier S. 14, Anm. 6. Sicher ist darin einer missionarische (Neu-)Konzeptionalisierung zu sehen, die „von vornherein jede sich distanzierende Haltung verhindern will“ (ebd.), Eßers Kontrastierung der „Missionsmethode des heiligen Franziskus“ mit der „Gewalttätigkeit der Kreuzritter“ (S. 14) und der Kreuzzüge, die der Heilige nicht gewollt habe, bleibt aber rein spekulativ. 
Konsequenz radikal missionarischen Daseins, ${ }^{213}$ rückt schließlich das Martyrium in den Blick, denn omnes fratres, ubicumque sunt, recordentur, quod dederunt se et reliquerunt corpora sua Domino Jesu Christo. Et pro eius amore debent se exponere inimicis tam visbilibus (NbR XVI, 10-11). ${ }^{214}$ Darauf folgt eine dichte Zusammenstellung verschiedener Zitate aus der heiligen Schrift, die das Erleiden von Verfolgung und die Hingabe des Lebens im Glaubenszeugnis zum Inhalt haben.

Auf diese Weise werden Mission und Martyrium diskursiv miteinander verknüpft; Letzteres wird - gegenüber der frühmittelalterlichen ,Entschärfung` dieser Konsequenz - wieder und auf neue Weise Fluchtpunkt missionarischer und überhaupt christlicher Existenz in der Welt. Novum und Proprium des franziskanischen Missionsideals liegen nicht allein darin, dass es die Vorbildlichkeit des Missionars und seine Beglaubigung der Botschaft durch die eigene Lebensweise zum Maßstab nimmt. ${ }^{215}$ In einer radikalen imitatio Christi umfasst sein Zeugnis vielmehr in letzter Konsequenz auch das Sterben für und wie Christus, also die Bereitschaft zum Martyrium, und verknüpft auf diese Weise Heilszeugnis und Selbstheiligung miteinander: „Die Angleichung an die Sendung Christi gibt der Mission jene spirituelle Vertiefung, die durch das Zeugnis bis hin zum Martyrium überzeugen will.“216

Diese Verknüpfung von Heilszeugnis und Selbstheiligung konkretisiert sich in den tatsächlichen missionarischen Bemühungen der Franziskaner. Die ersten fünf franziskanischen Märtyrer sollen von Franziskus selbst auf dem Generalkapitel Pfingsten 1219, also kurz vor seiner eigenen Orientreise und zwei Jahre vor Entstehen der Regula non bullata, ausgesandt worden und über Spanien nach Marokko gelangt sein. Dabei ist ihnen wohl bekannt, dass Mission in den islamischen Herrschaftsgebieten ein aussichtsloses Unterfangen darstellt, da dort das Predigen eines anderen Glaubens unter Todesstrafe verboten ist. Ihre Reise ist also offenbar ganz wesentlich von der Sehnsucht nach dem Martyrium motiviert, der die mögliche Ausbreitung des christlichen Glaubens als Zweck untergeordnet ist. Dennoch müssen sie sich durchaus anstrengen, um das Bild, dem sie folgen, auch erfüllen zu können: Öffentlich schmähen sie den Propheten und den islamischen Glauben, sogar aus dem Gefängnis heraus, werden zweimal des Landes verwiesen und kehren zurück, und erst nach wiederholten Provokationen werden sie 1220 in Marrakesch, angeblich vom dortigen Kalifen selbst, mit dem Schwert hingerichtet. ${ }^{217}$ Der heilige Berard und seine Gefährten gelten als die franziskanischen ,Protomärtyrer‘ und es folgen ihnen im Laufe

213 Anders Eßer, ebd., S. 15, der Mitleben, Verkündigung und Martyrium als drei Formen, „Nichtchristen von der Wahrheit der Frohbotschaft zu überzeugen“, versteht.

214 „Und alle Brüder, wo sie auch sind, sollen beherzigen, dass sie sich unserem Herrn Jesus Christus übergeben und ihm ihre Leiber überlassen haben. Um seiner Liebe willen müssen sie sich den sichtbaren wie den unsichtbaren Feinden aussetzen“.

215 Vgl. Münkler, Erfahrung des Fremden, S. 70.

216 Sievernich, Die christliche Mission, S. 119.

217 Vgl. Tolan, Saint Francis and the Sultan 2009, S. 6-7. 
des 13. Jahrhunderts bald etliche weitere: 1227 bereits der heilige Daniel und sechs Gefährten ebenfalls in Marokko, andere später im Heiligen Land und in Tripolis. ${ }^{218}$ Doch bleibt die kirchlich-offizielle Rezeption der franziskanischen Märtyrer ambivalent; kanonisiert werden sie erst, und auch dann nicht alle, im 15. und 16. Jahrhundert, als ihr Martyrium in den Türkenkriegen seitens der Kurie propagandistisch genutzt werden kann. ${ }^{219}$ Aber auch die überlieferten Reaktionen des Ordensgründers auf die Martyrien der von ihm ausgesandten Brüder sind widersprüchlich: In der Chronik Jordans von Giano, verfasst ab 1262 als Geschichte der deutschen Ordensprovinz, wird berichtet, Franziskus habe erlebt, wie sich andere Brüder mit dem Martyrium der fünf gebrüstet hätten, und daraufhin die Lektüre ihrer Vita und Legende verboten mit den Worten: ,Unusquisque de sua, et non de aliena passione glorietur. ' (Jord 8, 1) ${ }^{220}$ Vage ausdeutend erklärt der Chronist die Erfolglosigkeit der ersten Aussendung damit, quia forte tempus mittendi adhuc non venerat, cum omnis rei tempus sit sub coelo (Jord 8, 2). ${ }^{221}$ In der gut hundert Jahre jüngeren Chronica XXIV Generalium Ordinis Fratrum Minorum wird es hingegen heißen, Franziskus habe auf die Nachricht vom Martyrium der Fünf geantwortet, nun könne er wahrlich sagen, dass er fünf Brüder habe. ${ }^{222}$ Das entspricht ganz der Darstellungstendenz dieser Chronik, die aus größerem zeitlichen Abstand und mit apologetischem Interesse über die Ordensgeschichte seit Franziskus berichtet und in diesem Zusammenhang ausführlich auf die verschiedenen Wunder und Martyrien franziskanischer Brüder in der Mission seit Anfang des 14. Jahrhunderts in Zentralasien, Indien und Ägypten eingeht. $^{223}$

Die spezifische Verbindung von Martyrium und Mission stellt also offensichtlich ein zentrales Element der franziskanischen Selbstvergewisserung dar. Insofern wird

218 Vgl. zum Martyrium der franziskanischen Protomärtyrer, seiner bildhaften Darstellung und deren Verbreitung Jürgen Werinhard Einhorn: Unter den Fuß gebracht. Todesleiden und Triumph der franziskanischen Märtyrer von Marokko 1220. In: Europa und die Welt in der Geschichte. Festschrift zum 60. Geburtstag von Dieter Berg. Hrsg. von Raphaela Averkorn. Bochum 2004, S. 447-483.

219 Vgl. insgesamt James D. Ryan: Missionary Saints of the High Middle Ages. Martyrdom, Popular Veneration, and Canonization. In: The Catholic Historical Review 90, 1 (2004), S. 1-28.

220 „Jeder soll sich seiner eigenen und nicht fremder Leiden rühmen.“ Lateinischer Text nach: Chronica fratris Jordani a Jano O.F.M. In: Analecta Franciscana 1 (1885), S. 1-19.

221 „Und so führte die gesamte erste Aussendung zu nichts, weil vielleicht die Zeit des Entsendens noch nicht gekommen war“.

222 Cum autem beatus Franciscus adhuc vivens dictorum fratrum martyrium audivisset, exsultans supra modum et gaudens dixit: ,Nunc possum veraciter dicere, quod habeo quinque fratres‘. Chronica XXIV generalium Ordinis minorum. Quaracchi 1897 (Analecta Franciscana. 3), S. 593.

223 Zur Entwicklung des Martyriums in der Heidenmission zum franziskanischen Identitätsmerkmal im 14. Jahrhundert, nach der anfangs auffallend geringen Rezeption der fünf in Marokko hingerichteten Brüder, vgl. Isabelle Heullant-Donat: Martyrdom and Identity in the Franciscan Order (Thirteenth and Fourtheenth Century). In: Franciscan Studies 70 (2012), S. 429-453. Vgl. dazu auch Diess.: Franciscains, martyrs et ,mission‘ aux XIII et XIV ${ }^{\mathrm{e}}$ siècles. In: Vom Blutzeugen zum Glaubenszeugen? Formen und Vorstellungen des christlichen Martyriums im Wandel. Hrsg. von Gordon Blennemann, Klaus Herbers. Stuttgart 2014 (Beiträge zur Hagiographie. 14), S. 179-194. 
man nicht einfach urteilen können, dass die ,ersten Bemühungen, an die Moslems heranzukommen, [...] von einem unglaublichen Optimismus und zugleich von erschreckender methodischer Hilflosigkeit“ zeugen, und auch Franziskus kann man in dieser Hinsicht nicht einfach „Unerfahrenheit“ vorwerfen. ${ }^{224}$ Denn diese Bemühungen zielen nicht auf missionarischen Erfolg, der sich an der Zahl bekehrter Muslime messen ließe, sondern sind Ausdruck eines religiösen Strebens, in der Nachfolge Christi den christlichen Glauben mit der eigenen Lebenshingabe zu bezeugen. Daher erklärt sich auch, „daß Mission im frühen franziskanischen Schrifttum, anders als man erwarten sollte, nie als ein eigenes geistliches Werk beschrieben und definiert wird“, sondern „sprachlich und sachlich in auffällige Nähe zu anderen geistlichen Leistungen: zu Pilgerwesen und Martyrium“. ${ }^{225}$ Bußpredigt und Heidenmission haben in der sich auf Franziskus berufenden Frömmigkeit letztlich „kein Eigengewicht mehr, sie sind Ausfluß ein und derselben Haltung: der bis zur Expropriatio geleisteten Anpassung an den zu einem verachteten Menschen gewordenen Gott“. ${ }^{226}$ Wie alle anderen Elemente der franziskanischen Lebensweise entspringen sie dem Motiv einer konsequenten imitatio Christi, in deren Verwirklichung nun auch die universale missionarische Sendung als Grundbedingung apostolischer und damit christlicher Existenz allgemein wieder ins Recht gesetzt wird.

Damit aber wird auch im Fall der franziskanischen Mission der Glaubensgegensatz zu den Heiden nicht in missionarischem Interesse, sondern vor allem zum Zweck christlicher Sinnstiftung und Identitätsbildung in Anspruch genommen. Franziskus ist demnach nicht in erster Linie als Beispiel für einen neuen Umgang mit den Ungläubigen zu verstehen, sondern Spiegelbild verstärkter innerchristlicher Bemühungen um Erneuerung der Christenheit im Zeichen der vita apostolica. Wiederum erscheint hier die innere Homogenisierung der lateinischen Christenheit des 13. Jahrhunderts als Grundlage und Bedingung, aber auch als Ergebnis ihrer Expansion. In diesem Rahmen erst erschließt sich das Motiv des Strebens nach dem Martyrium in der Mission in seiner vollen Bedeutung, denn es sucht die alten Muster christlicher Identitätsbildung in der Konfrontation mit dem Heidentum wieder in Geltung zu bringen: „By preaching to the infidel, and by accepting martyrdom from him if necessary, the Franciscan friar could reenact the drama of the apostles an recreate the religious fervor of a bygone age.“227

224 Blanke, Die Mohammedanermission im Mittelalter, S. 79.

225 Elm, Franz von Assisi: Bußpredigt oder Heidenmission?, S. 160.

226 Ebd., S. 163. Noch pointierter: „Die Wanderschaft in heidnischen Ländern wird in der Regula non bullata folglich als qualitativ besonders hochwertige Form der franziskanischen vita religiosa propagiert, und zwar offenbar in erster Linie nicht, weil hier Ungläubige zum Christentum bekehrt werden können, sondern weil diese Wanderschaft zur eigenen Ausgrenzung und Selbstverdemütigung bis hin zur imitatio Crucis führen und damit selbstheiligend sein konnte.“ Müller 2002, Bettelmönche in islamischer Fremde, S. 121.

227 Tolan, Saracens, S. 214, als Auftakt zum Kapitel, indem er unter dem bezeichnenden Titel „Franciscan Missionaries Seeking the Martyr's Palm“ den franziskanischen Anteil am Bild des Islam in der mittelalterlichen europäischen Vorstellung untersucht. 
Gerade in dieser Hinsicht lässt sich das franziskanische Missionsideal, auch wenn es fraglos auf physischer Gewaltlosigkeit beruht, nicht als friedlicher Gegenentwurf zum kriegerischen Vorgehen in den Kreuzzügen verstehen, wie sich ja auch am überlieferten Bild des heiligen Franziskus selbst kein Kontrast zwischen Mission und Krieg festmachen lässt: Zum einen ist sein Gespräch mit dem Sultan nicht so singulär, wie es scheinen mag, sondern durchaus im Rahmen zeitgenössischer Vorstellungen. Zum anderen scheint die friedliche Predigt bei Franziskus keine gegensätzliche, sondern eher eine ergänzende Alternative zu den Kreuzzügen, zumindest bleiben die Überlieferungen diesbezüglich widersprüchlich: Zwar gilt er seinem in der Nachwirkung wichtigsten Hagiographen, Bonaventura, als vir Dei non armis sed fide munitus (LM XI 3, 2), an anderer Stelle findet sich hingegen verbürgt, „daß der Ordensstifter wiederholt höchste Bewunderung für die Kreuzritter bekundet habe““.228 Es handelt sich bei Kreuzzug und Mission schlichtweg um zwei mögliche Optionen, den religiösen Gegensatz zum Heidentum zu bearbeiten, und damit um zwei Formen der kulturellen Selbstvergewisserung in der Konfrontation mit dem religiöse Fremden, die parallel realisiert werden und dabei ihre je eigene Funktion entfalten können. ${ }^{229}$ Die ironische Bemerkung: „Mendicant missionizing in Muslim countries was much more conductive to filling heaven with Christian martyrs than the earth with Muslim converts“'230, trifft dabei wohl die historischen Fakten, verfehlt aber den inneren Zusammenhang von Martyrium und Mission im franziskanischen Denken, darüber hinaus auch den identitätsstiftenden Kern der entsprechenden Narrative.

So ist gerade auch die Episode von der Predigt des heiligen Franziskus vor dem Sultan Gegenstand unterschiedlicher Bearbeitungen, die eng verknüpft sind mit der Entwicklung des Minoritenordens und seiner kirchlich-institutionellen Einbindung und die daher auch das Martyrium als Heiligkeitsmodell wie als Form der Aushandlung des religiösen Gegensatzes zum Heidentum auf jeweils eigene Weise inszenieren. ${ }^{231}$ Denn die verschiedenen Franziskuslegenden sind von Anfang an heftig umkämpft, einerseits zwischen Orden und Kurie, andererseits zwischen den rivalisierenden Fraktionen des Ordens im Streit besonders um die Armutsfrage, bei der die

228 Müller, Bettelmönche in islamischer Fremde, S. 255.

229 Vgl. dazu oben in Kap. 2.3.2 Das Verhältnis von Kreuzzug und Mission. Daher scheint mir selbst eine reflektiertere historische Einordnung der franziskanischen Mission in ihre Zeit fragwürdig, wenn sie sich nicht frei macht von teleologischen Formulierungen wie bei Berg, Kreuzzugsbewegung und propagatio fidei, S. 65: „Historisch signifikant ist schließlich die Tatsache, daß Franziskus mit seinen teilweise traditionsgebundenen Missionsvorstellungen exakt zu einem weltgeschichtlichen Zeitpunkt auftrat, als sich die Hoffnung auf eine militärische Lösung des Islamproblems bei den Förderern der Kreuzzugsidee als illusorisch erwiesen hatte und sowohl das Papsttum als auch die weltlichen Christenfürsten gegenüber einer friedlichen Kommunikationsweise aufgeschlossener waren.“

230 Kedar, Crusade and Mission, S. 155.

231 Vgl. dazu im Folgenden auch meinen Beitrag: Der heilige Franziskus vor dem Sultan. Erzählen von religiösen Gegensätzen und die Ästhetik der Legende. In: Himmlisch, irdisch, höllisch. Religiöse und anthropologische Annäherungen an eine historisierte Ästhetik. Hrsg. von Olivia Kobiela, Lena Zschunke. Würzburg 2019, S. 295-335. 
Franziskaner im Kontext der breiten religiösen Laienbewegung immer wieder in Gefahr stehen, unter Häresieverdacht zu geraten. ${ }^{232}$ Das Franziskusbild spielt in allen diesen Auseinandersetzungen deshalb eine zentrale Rolle, weil sich der Orden sehr stark aus dem Charisma und dem persönlichen Beispiel seines Gründers her legitimiert und weniger aus einer Ordensregel. ${ }^{233}$

Die Franziskuslegenden bewegen sich daher immer auch in einem Spannungsfeld zwischen charismatischer Legitimierung und institutioneller Sanktionierung des im Ordensgründer verkörperten religiösen Ideals. Das zeigt sich vor allem an den beiden maßgeblichen Viten des Heiligen, die beide im Laufe des 13. Jahrhunderts im Abstand von reichlich 30 Jahren verfasst werden und dabei in einem deutlichen Konkurrenzverhältnis stehen: Die Legenda maior Bonaventuras soll die Vita prima von Thomas von Celano und damit das darin entworfene Franziskusbild ablösen und zwar im ganz konkreten Sinn und mit ordensinternen Zwangsmaßnahmen. Die Episode der Predigt des Heiligen vor dem Sultan realisieren sie entsprechend ihrer funktionalen Ansprüche auf unterschiedliche Weise, wie ich im Folgenden zeigen werde.

Die anderen lateinischen Viten enthalten entweder die Episode gar nicht, so die als Nachtrag zur Vita prima 1246/47 von Thomas selbst verfasste Vita secunda oder sein zwischen 1250 und 1252 entstandenes Mirakelbuch, ebenso die Dreigefährtenlegende, die in Ergänzung zur Vita prima ,persönliche‘ Erinnerungen dreier Minderbrüder an den Ordensgründer bietet. Oder sie bringen gegenüber den beiden großen Viten nichts Neues, so die Legenda minor, die Bonaventura als gekürzte Fassung der Legenda maior gleichzeitig zu dieser verfasste und der Lesung im Chorgebet diente, die aber nur vom ersten vergeblichen Versuch der Überfahrt in den Orient berichtet, bei dem Gott den Heiligen und die in einen Sturm geratene Schiffsmannschaft durch eine wundersame Nahrungsvermehrung bewahrt. Da weder die Fassung der Franziskuslegende in der Legenda aurea noch, ausgehend von der Vorlage dieses lateinischen Legendars, die im Passional die Orientreise überhaupt erwähnen, bieten sie hier nur eine negative Vergleichsfolie: $\mathrm{Zu}$ fragen bleibt hier nur, warum sie ohne dieses Motiv auskommen. Eine volkssprachige deutsche Fassung der besagten Episode fin-

232 Zur Funktion von Legenden ,als Medien der Speicherung und Kommunikation relevanten Wissens" im Zusammenhang der hochmittelalterlichen religiösen Bewegungen und der Aushandlung widerstreitender Geltungsansprüche in den Prozessen ihrer Institutionalisierung vgl. grundlegend Cristina Andenna: Heiligenviten als stabilisierende Gedächtnisspeicher in Zeiten religiösen Wandels. In: Literarische und religiöse Kommunikation in Mittelalter und Früher Neuzeit. DFG-Symposion 2006. Hrsg. von Peter Strohschneider. Berlin/New York 2009 (Germanistische Symposien. Berichtsbände), S. 526-573, Zitat S. 572.

233 Wie zum Beispiel der etwa zeitgleich entstehende Dominikanerorden, der im Vergleich als eher ,uncharismatische', von Anfang an institutionell und funktional eingebundene päpstliche Auftragsgründung erscheint und in seiner inneren Ordnung rational auf den Predigtdienst ausgerichtet ist. Zur hier umrissenen Bedeutung der Franziskuslegenden in den Auseinandersetzungen um die Ausrichtung des Ordens vgl. Marina Münkler: Amicus Dei. Konstruktionsformen des Heiligen am Beispiel der Franziskuslegenden. In: Transzendenz und die Konstitution von Ordnungen. Hrsg. von Hans Vorländer. Berlin/New York 2013, S. 374-394, hier S. 382. 
det sich im 13. Jahrhundert hingegen im Sante Francisken leben Lamprechts von Regensburg, einer frühen Übertragung der Vita prima, die als erste Franziskusvita und überhaupt erstes nichtlateinisches Zeugnis minoritischer Literatur in deutscher Sprache Beachtung verdient.

\subsubsection{Franziskus als Vorbild apostolischen Lebens und missionarischer Sendung}

Die erste Lebensbeschreibung des heiligen Franziskus entsteht bereits 1228/29, also zwei Jahre nach seinem Tod und unmittelbar im Anschluss an seine Kanonisation, im Auftrag Papst Gregor IX. Dieser hatte die ungewöhnlich rasche Heiligsprechung entgegen dem gerade erst formalisierten kirchlichen Verfahren selbst durchgesetzt und bereits vor seinem Pontifikat, als Kardinal Hugolino von Ostia, die kirchliche Einbindung der Bettelorden und insbesondere der Franziskaner befördert. ${ }^{234}$ Thomas von Celano, selbst Franziskaner und in der Frühzeit in den Orden eingetreten, beansprucht zwar für sich, in seiner Vita prima über den Heiligen nur das zu erzählen, quae ex ipsius ore audivi, vel a fidelibus et probatis testibus intellexi (1 Cel, Prologus 1, 1). ${ }^{235}$ Doch entspricht diese Beteuerung ganz der Topik legendarischen Erzählens, gerade dem in Legendenprologen in der Erzählerrolle verdichteten Anspruch auf Verbürgtheit und wahrheitsgetreue Wiedergabe des Geschehens. Sie steht daher in keinem Gegensatz zur hagiographischen Stilisierung des Lebens des Heiligen, wie sie, kaum zehn Jahre nach dem angeblichen historischen Geschehen, gerade in der Episode der Orientreise deutlich wird.

Erfüllt von glühender Gottesliebe und sacri martyrii desiderio maxime flagrans sei Franziskus in den Orient aufgebrochen, ad praedicandam fidem christianam et poenitentiam Saracenis et caeterias infidelibus (1 Cel 55, 2). ${ }^{236}$ Die missionarische Zielsetzung dieses Aufbruchs entspringt also der heiligmäßigen Tugendhaftigkeit des Protagonisten und seinem Streben nach deren höchster Beglaubigung im Sterben für Gott. Gleichzeitig fängt die Bekehrungsabsicht seine „Sehnsucht nach dem Martyrium“ legitimatorisch ein: Die Möglichkeit des Martyriums gehört zur missionarischen Sendung in die Welt und kann als solche bewusst gesucht werden, bleibt aber letztlich eine Frage göttlicher Bestimmung. Die beiden ersten Versuche in muslimische Gebiete

234 Seine Rolle im Zusammenhang mit der Entwicklung des Ordens ist in der Forschung immer wieder umstritten gewesen hinsichtlich der Frage, ob er „das ursprünglichen Ideal des Franziskus [...] unter Bewahrung des Wesentlichen lediglich den Erfordernissen der Wirklichkeit angepaßt“ oder dabei eben vereinnahmend korrumpiert habe. So im aktuellen Standardwerk zum heiligen Franziskus: Feld, Franziskus von Assisi, S. 350. Letzteres ist insgesamt wohl Felds eigene Lesart.

235 „[W]as ich aus seinem eigenen Munde gehört und von glaubwürdigen und zuverlässigen Zeugen erfahren habe“.

236 „Im sechsten Jahre seiner Bekehrung wollte er nämlich aus flammender Sehnsucht nach dem heiligen Martyrium nach Syrien hinüberfahren, um den Sarazenen und anderen Ungläubigen den christlichen Glauben zu verkünden und Buße zu predigen.“ 
zu gelangen bleiben allerdings erfolglos, ganz im Muster einer reihenden Steigerung des Erzählten, das freilich im göttlichen Ratschluss abgesichert bleibt: Auf dem Weg nach Syrien habe Franziskus Schiffbruch erlitten, auf dem Weg nach Marokko schwer erkrankt umkehren müssen.

Das gibt ihm dafür aber die Gelegenheit, Thomas von Celano selbst in die franziskanische Gemeinschaft aufzunehmen, der seine Legitimität als Autor der Vita damit in einem spezifischen Syntagma erzählerisch fundieren kann, auch wenn dieser Zusammenhang nur angedeutet wird: Sed bonus Deus, cui mei et multorum sola benignitate placuit recordari, cum iam ivisset usque in Hispaniam, in faciem ei restitit, et ne ultra procederet, aegritudine intentata, eum a coepto itinere revocavit. $(1 \mathrm{Cel} 56,6)^{237}$ Denn zurück an der Portiuncula-Kapelle, dem Ursprungsort der franziskanischen Bewegung, schließen sich dem Heiligen quidam litterati viri et quidam nobiles (1 Cel 57, $1)^{238}$ bereitwilligen Herzens an, darunter eben auch Thomas selbst, auch wenn er sich selbst nicht nennt. Nur weil Gott die Pläne des Heiligen vereitelt, so darf der Leser oder Hörer der Legende schließen, kann dieser seinen späteren Biographen höchstpersönlich in die Gemeinschaft aufnehmen. Auf diese Weise hat der Legendenschreiber teil am Charisma des Gründers und verbürgt als einer derer, die von den Anfängen an dabei gewesen sind, die Wahrheit seiner Darstellungen.

Beim dritten Versuch schließlich sei Franziskus aber nach Syrien gelangt, cum quotidie bella inter christianos et paganos fortia et dura ingruerent (1 Cel 57, 5), ${ }^{239}$ und mit einem Mitbruder mitten durch die feindlichen Linien bis vor den Sultan gekommen. Dabei folgt Thomas ganz den hergebrachten Mustern der Märtyrerlegende, wenn er berichtet, wie die Leute des Sultans Franziskus schmähen und misshandeln, ihm Marterqualen in Aussicht stellen und mit dem Tode drohen, was den Heiligen aber nicht schrecken kann. Über den Inhalt der Verkündigung vor dem Sultan berichtet Thomas nichts, rühmt nur den Bekennermut des Heiligen angesichts der feindlichen Behandlung. Damit entproblematisiert er gleichzeitig den möglichen Eindruck mangelnder Verbürgtheit des Geschehens, denn die Reise zu den Heiden unternimmt Franziskus allein und sein einziger Begleiter bleibt namenlos und ist dazu im weiteren Verlauf völlig unsichtbar, sodass allein seine Erwähnung zu Anfang eine christliche Augenzeugenschaft garantiert. Völlig unklar bleibt dabei auch, wie sich die sprachliche Vermittlung zumal anspruchsvollerer Glaubensinhalte oder die interkulturelle Verständigung über die von Franziskus verkörperten Formen christlicher Heiligkeit vollzogen haben soll. Diese Leerstellen füllt Thomas aber eben nicht narrativ, sondern rhetorisch im Lob des Heiligen aus christlicher Binnenperspektive: Sed quis enarrare sufficiat, quanta coram eo mentis constantia consistebat, quanta illi virtute animi lo-

237 „Aber der gute Gott, dem es aus lauter Güte gefiel, meiner und vieler anderer zu gedenken, widerstand ihm, als er schon bis nach Spanien gekommen war, ins Angesicht und rief ihn, damit er seinen Weg nicht weiter fortsetze, durch eine Krankheit von der begonnenen Reise zurück.“

238 „[E]inige gelehrte Männer und einige Adlige“.

239 „[W]o täglich heldenhafte und erbitterte Kämpfe zwischen Heiden und Christen ausbrachen“. 
quebatur, quanta facundia et fiducia legi christianae insultantibus respondebat? (1 Cel $57,6)^{240}$

Im Kontrast zu den multis, die Franziskus feindselig und ablehnend begegnen, erscheint der Sultan, der ihn ganz im Gegenteil honorifice plurimum (1 Cel 57, 8), höchst ehrenvoll, empfängt. Die Geschenke, die er dem christlichen Glaubenszeugen anbietet, müssen in den Kategorien des Legendenerzählers freilich als Versuchung gelten: ad divitias mundi animum eius inflectere (1 Cel 57, 9). ${ }^{241}$ Doch als er sieht, wie Franziskus die Güter der Welt velut stercora, „wie Kot“, ablehnt, wird er von höchster Bewunderung für ihn ergriffen und betrachtet ihn quasi virum omnibus dissimilem (1 Cel 57, 10). ${ }^{242}$ In seiner Wertschätzung und Aufgeschlossenheit ist der Heide hier das offensichtliche Gegenbild zu seinen ,verstockten“ Untergebenen, damit aber auch zu den grausamen christenverfolgenden Statthaltern der üblichen Märtyrerlegenden. Daher kann sich auf ihn auch die Hoffnung einer friedlichen Überwindung des Heidentums richten. So berichtet Thomas, dass die Worte des Heiligen tiefen Eindruck auf ihn gemacht hätten - warum er sich dann aber nicht auch folgerichtig zum christlichen Glauben bekehrt und die Predigt des Franziskus mit offenkundigem Erfolg krönt, wird nicht erläutert.

Dennoch erscheint die doppelte Ergebnislosigkeit der Missionsreise des Heiligen, der ja weder den Sultan bekehren kann noch das ersehnte Martyrium erleiden darf, keinesfalls als Scheitern, denn sie wird in einem anderen narrativen Muster aufgefangen: Thomas beendet die Szene mit der Feststellung, der Herr habe den sehnlichen Wunsch des Heiligen, also den nach dem Martyrium, nicht erfüllt, praerogativam illi reservans gratiae singularis (1 Cel 57, 12), ${ }^{243}$ ein Verweis auf die spätere Stigmatisation des Heiligen, die das Martyrium in der Heidenmission also noch übersteigt und damit auch das Problem des Drängens nach diesem vollends entkräftet. Denn auf welche Weise Franziskus die Heiligkeit erringt beziehungsweise zugesprochen bekommt, erscheint als Gegenstand der göttlichen providentia; in seiner heiligmäßigen Bereitschaft erweist er sich aber als würdig dafür.

Märtyrer- und Bekennerlegende werden hier nicht nur motivisch im Gedanken eines ,unblutigen Martyriums‘ oder eines Märtyrertums ,dem Willen nach` enggeführt, sondern strukturell ineinandergeflochten: Das Syntagma des Martyriums wird, narratologisch gesprochen, in die Bekennerlegende hineingespielt, um sofort wieder abgewiesen und in der Stigmatisation paradigmatisch übererfüllt zu werden. Denn durch die Auszeichnung mit den Wundmalen des Erlösers wird dem Heiligen schließlich die höchstmögliche Christusförmigkeit zuteil, die ihn in späterer Über-

240 „Wer könnte schildern, mit welch aufrechter Seelenhaltung er vor ihn trat, mit welcher Geisteskraft er zu ihm sprach, mit welcher Beredsamkeit und Zuversicht er denen Rede und Antwort stand, die nur Hohn und Spott hatten für das christliche Gesetz?“

241 „Er ehrte ihn, so gut er konnte, und ging darauf aus, durch zahlreiche Angebote an Geschenken sein Herz den Gütern der Welt zugänglich zu machen.“

242 ,[W]ie einen Mann, der seinesgleichen auf Erden nicht hat“.

243 „[S]parte ihm aber den Vorzug einer einzigartigen Gnade auf“. 
lieferung schließlich gar als alter Christus erscheinen lässt, als einen zweiten Christus, der die Erlösung vollendet. ${ }^{244}$ Aber auch ohne diese in ihrer Konsequenz problematische, weil in gefährlicher Nähe zur Häresie stehende, Tendenz wird in der Vita prima deutlich, dass die Stigmatisation „die himmlische Legitimierung des an Armut gebundenen Apostolates des Franz als dem Martyrium gleichwertiges Lebenszeugnis“ bedeutet: „Der arme Prediger erhält eben die Stigmata, die das Leiden Christi in vielfältigen Darstellungen repräsentieren und wird so selbst noch zu Lebzeiten zu einem Repräsentanten der Leiden Christi und damit Christi selbst.“245

Der Gedanke der Stigmatisation, der überhaupt erst mit Franziskus in den Heiligkeitsdiskurs tritt und auch dann nur in der lateinischen Christenheit, ist insgesamt ein Ergebnis der frömmigkeitsgeschichtlichen Entwicklungen des 13. Jahrhunderts, die die Präsenz wie die Repräsentation von Heiligkeit intensiver denken lassen als zuvor. ${ }^{246}$ Dazu kommt, dass die Verehrung der Wunden des Erlösers und seiner Menschennatur in den Mittelpunkt rückt, was zur Grundlage einer „neuen ,jesuzentrischen“ Religiosität“ sowie einer „betont somatischen Imitatio“ wird: „Diese wird durch den Leib als Medium der Seele erreicht: Die Stigmen werden immer in Verbindung mit einer Vision empfangen, sind äußeres Zeichen der inneren Christusähnlichkeit“. ${ }^{247}$ Damit findet auch der Wandel der Heiligkeitskonzepte vom Märtyrer

244 Dieser motivische Zusammenhang ist schon in der Vita prima angelegt (1 Cel 94) und wird in späteren Fassungen explizit gemacht, so von Thomas von Celano selbst in seiner Dreigefährtenlegende (Gef 69). Die Bezeichnung als alter Christus, einhergehend mit der Vorstellung einer „vollkommenen Konformität, ja Identität des Franziskus mit Christus“, findet sich erst Anfang des 14. Jahrhunderts, in den Actus Beati Francisci, die insgesamt ein Zeugnis der fortgeschrittenen Legendenbildung um das Leben des Heiligen sind und in ihrer Übersetzung in die italienische Volkssprache, den Fioretti, das Franziskusbild in Europa nachhaltig geprägt haben. Vgl. Feld, Franziskus von Assisi, S. 44-45, Zitat S. 45.

245 Volker Leppin: Repräsentationsfrömmigkeit. Vergegenwärtigung des Heiligen in der Frömmigkeit des späten Mittelalters und ihre Transformation in der Wittenberger Reformation. In: Die Gegenwart des Gegenwärtigen. Hrsg. von Mario Fischer, Margarethe Drewsen. Freiburg i. Br./München 2006, S. 376-391, hier S. 385. Vgl. dazu auch Gábor Klaniczay: Stigmatisierung und Martyrium. In: Vom Blutzeugen zum Glaubenszeugen? Formen und Vorstellungen des christlichen Martyriums im Wandel. Hrsg. von Gordon Blennemann, Klaus Herbers. Stuttgart 2014 (Beiträge zur Hagiographie. 14), S. 139155.

246 Vgl. ebd., S. 386. Bei Franziskus geschieht das im Subjekt der Nachfolge, bei der heiligen Elisabeth von Thüringen (1207-1231), der ersten franziskanischen Heiligen beziehungsweise im franziskanischen Geist, dazu nördlich der Alpen, hingegen im Objekt der Zuwendung: Sie pflegt einen Aussätzigen im Bett ihres Mannes, doch der sieht den gekreuzigten Heiland: „Den tieferen Sinn dieser Zuwendung zum Nächsten begründet die Rede vom Großen Gericht Mt 25, in welcher Jesus mahnte, dass man in dem geringsten seiner Brüder ihm selbst begegne. Das bedeutet eine Art inverse Repräsentationsfrömmigkeit, die für eine Frau besonders gut realisierbar schien: Nicht die fromm Handelnde repräsentierte Christus, sondern sie begegnete diesem in den Menschen, denen sie sich zuwandte.“ Leppin, Geschichte des mittelalterlichen Christentums, S. 334.

247 Peter Dinzelbacher: Über die Körperlichkeit in der mittelalterlichen Frömmigkeit. In: Ders.: Körper und Frömmigkeit in der mittelalterlichen Mentalitätsgeschichte. Paderborn 2007, S. 11-49, hier S. 47. 
zum Asketen seinen stärksten Ausdruck: Das äußere Martyrium wird in ein inneres gewendet, dessen Beglaubigung aber nun wiederum körperlich sichtbar und im wahrsten Sinne des Wortes materiell-physisch ,fassbar' sein soll. Die Legenda maior wird später im Kontext der Aufbahrung und Erhebung des verstorbenen Heiligen berichten, die Brüder hätten die Wunden staunend berührt und geküsst und ein zweifelnder Ritter habe dem ungläubigen Thomas gleich den Finger in die Seitenwunde gelegt, sich daraufhin bekehrt und im Heiligsprechungsverfahren die Stigmatisation beeidet. ${ }^{248}$

Trotz dieses Verweises auf die Stigmatisation, die Franziskus zur überragenden Heiligengestalt machen wird, steht in der Episode seiner Predigt vor dem Sultan in der Vita prima noch nicht so sehr die Verehrung des alle Kategorien, selbst die der christlichen Heiligkeit, überschreitenden Heiligen in seiner uneinholbaren Distanz gegenüber den Gläubigen im Mittelpunkt, sondern seine vorbildhafte Verwirklichung des apostolischen Lebens in der Heidenmission als Ausdruck einer universalen christlichen Sendung usque ad ultimum terrae (Apg 1, 8). Dem entspricht, dass Thomas von Celano direkt auf die Predigt vor den Heiden die Episode der Vogelpredigt des Heiligen und weitere Beispiele vom „Gehorsam der Geschöpfe“ ihm gegenüber (Kapitel XXI De praedicatione avium et obedientia creaturarum) folgen lässt. Damit unterstreicht er einerseits die göttliche Begnadung seines Protagonisten, denn die Fähigkeit, alle Kreaturen als Teil der einen erlösungsbedürftigen Schöpfung Gottes anzusprechen, ist wundersamer Erweis von dessen Heiligkeit. Gleichzeitig verdeutlicht er in diesem naturmythischen Bild die missionarische Sendung in die Welt als Grundbedingung christlicher Existenz. Vor allem aber bewegt sich das Auftreten des Heiligen vor dem Sultan ganz in den herkömmlichen Mustern christlicher Verkündigung, wie sie die Evangelien mit den Worten Christi an die Jünger und die Berichte der Apostelgeschichte bieten. Sein Vorbild in der Heidenmission als exemplarische Verwirklichung der Nachfolge und imitatio Christi scheint als solches allgemeingültig und von allen umsetzbar, zumindest für die Brüder seines Ordens, die diese Lebensweise und dem Beispiel des Ordensgründers verpflichtet sind.

Wie sich dieses Bild von Franziskus als Vorbild apostolischen Lebens und missionarischer Sendung in der volkssprachigen Rezeption des 13. Jahrhunderts darstellen kann, zeigt sich an Lamprechts von Regensburg Sante Francisken leben, der ersten Franziskusvita in deutscher Sprache und dem ersten nichtlateinischen Zeugnis minoritischer Literatur in Deutschland überhaupt. ${ }^{249}$ Diese frühe und sehr getreue

248 Vgl. dazu Urban Küsters: Spuren der Heiligkeit. Formen der Körperwahrnehmung in mittelhochdeutschen Franziskus-Legenden. In: Mediävistik und Kulturwissenschaften. Akten des X. Internationalen Germanistenkongresses Wien 2000. Bern [u. a.] 2002 (Zeitenwende. Die Germanistik auf dem Weg vom 20. ins 21. Jahrhundert. 5. Jahrbuch für internationale Germanistik, Reihe A, Kongreßberichte. 57), S. 57-61, hier S. 57.

249 Vgl. Manfred Zips: Franziskus von Assisi, vitae via. Beiträge zur Erforschung des Geschichtsbewusstseins in den deutschen Franziskusviten des Mittelalters mit besonderer Berücksichtigung der deutschsprachigen Werke. Wien 2006, S. 49. 
Übertragung der Vita prima, entstanden vermutlich zwischen 1237 und 1239, bietet auch die erste deutsche Fassung der Orientreise des Heiligen und erhellt die Bedeutung der Verknüpfung von Martyrium und Mission in der Vermittlung des Franziskusbildes an ein laikales Publikum. Denn im Gegensatz zur lateinisches Prosa des Thomas von Celano, die sich an ein religioses oder klerikales Publikum richtet, schreibt Lamprecht in den paargereimten Versen der mittelhochdeutschen Epik, also für ein mit der höfischen Literatur vertrautes Laienpublikum, ${ }^{250}$ das wohl im Umfeld des Franziskanerkonvents in Regensburg zu verorten ist, wo die Franziskaner spätestens seit 1221 präsent waren. Insgesamt lässt sich das Sante Francisken leben in diesem Kontext als Darstellung und Rechtfertigung der noch recht jungen Lebensweise der Minoriten verstehen, die sich aus ihrer Kontinuität mit den ursprünglichen Idealen des Ordensgründers legitimiert. ${ }^{251}$ Dabei bietet sie aber gleichzeitig eine volkssprachige Vermittlung franziskanischer Frömmigkeit, in der sich „[d]ie trotz aller pastoralen Zielrichtung letztlich als historischer Bericht ausgelegte erste Vita Tommasos [...] in eine predigthafte franziskanische Exempeldichtung für einen nichtgeistlichen Leserkreis“ wandelt. ${ }^{252}$

Entscheidend für diese Darstellungsweise und Rezeptionslenkung ist die Verknüpfung der Erzählerrolle Lamprechts - er nennt sich selbst beim Namen als ein knappe, der diz hât gemacht in diutscher diute (SFL 376 und 374) - mit dem Vorbild des Heiligen, das zum Garanten seiner persönlichen Bekehrung wird. Die Erzählerinszenierung im Eingang mag dabei noch den üblichen Mustern der volkssprachigen Legendentopik entsprechen, vor allem im Topos der Jugendsünden, die Lamprecht begangen haben will und im scharfen Gegensatz stehen zum Gegenstand seiner Erzählung:

250 Norbert Richard Wolf: Beobachtungen zum Franziskusleben Lamprechts von Regensburg. In: Franziskanische Studien 60 (1979), S. 155-167, S. 165. Die germanistische Mediävistik hat dem Text kaum Beachtung geschenkt, was vermutlich auch an dem vernichtenden Stilurteil liegt, mit dem die ältere Forschung Lamprecht belegt hat: „Künstlerische Qualität hat L. nicht zu bieten. Sein Sprachstil und sein Versbau sind von der unauffällig soliden Durchschnittlichkeit, wie man sie damals von einem bescheidenen Talent erwarten konnte, dem die über Generationen gefestigte Tradition der dt. Reimpaardichtung zu Gebote stand.“ Joachim Heinzle: Art. Lamprecht von Regensburg. In: ${ }^{2}$ VL 5 (1985), Sp. 520-524, hier Sp. 522. Den Wert von Lamprechts beiden Werken als Zeugnis volkssprachiger religiöser Literatur erkennt Heinzle gleichwohl an. Würdigender auch hinsichtlich der literarischen Qualität des Sante Francisken leben sind Salome Solf-Maennersdoerfer: Francisk. Eine Deutung aus der Sprache des Lamprecht von Regensburg. In: Seligenthal 1231-1981. Beiträge zum 750-jährigen Jubiläum. Hrsg. von Gabriel Busch. Siegburg 1981 (Rhenania Franciscana antiqua. 1), S. 317-382 und Manfred Zips: Die Vita Prima S. Francisci des Thomas von Celano in einer mittelhochdeutschen Version des 13. Jahrhunderts als frühes Zeugnis der Aufnahme n Gedankengutes in Deutschland. In: Francescanesimo in volgare (secoli XIII-XIV). Atti del XXIV Convegno internazionale, Assisi, 17-19 ottobre 1996. Spoleto 1997, S. $179-217$.

251 Vgl. Zips, Franziskus von Assisi, S. 50, ebenso Feistner, Historische Typologie, S. 205.

252 Zips, Franziskus von Assisi, S. 52. 


\author{
wan swaz er alhie hât geseit, \\ dâ hât er lützel nâch getân. \\ im hât sînen tumben wân \\ diu werlt manic jâr betrogen. (SFL 309-312)
}

Diese Inszenierung rahmt aber nicht nur die Erzählung in Prolog und Epilog, sondern zieht sich durch den Text, wenn Lamprecht im Anschluss an die mündliche Bestätigung der Minoriten durch Innozenz III. und der solchermaßen legitimierten Predigttätigkeit des Franziskus und seiner Gemeinschaft den Orden mit dem Vorbild einiger ihm persönlich bekannter Brüder verteidigt, die er namentlich nennt, darunter ein Bertholt (SFL 1750), der vermutlich mit dem wirkungsreichen Regensburger Prediger (um 1210 - 1272) zu identifizieren ist. Das zeitgenössische und lokale Leben im Orden wird also direkt an die Frühzeit des Ordens und seine päpstliche Legitimation gebunden und zeigt seine Wirkung nun darin, dass sich Lamprecht diesen Brüdern nach gründlicher Prüfung ihrer Lebensweise anschließen will:

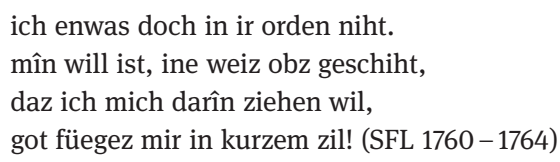

Aus einem zweiten unter seinem Namen überlieferten Werk, der Tochter Syon, einer allegorischen Darstellung der mystischen Hochzeit der Seele mit dem himmlischen Bräutigam in der Tradition Bernhards von Clairvaux, lässt sich erschließen, dass Lamprecht dann tatsächlich in den Regensburger Konvent eingetreten sei (TS 14061417). Selbst wann man die beiden biographischen Hinweise unter den Vorbehalt narrativer Inszenierung stellt, bleiben sie gerade als solche in ihrer textfunktionaltopischen Qualität aufschlussreich für die Funktionalisierung von Lamprechts Franziskusbild. Denn die „kulturelle und pastorale Intention des Autors“, die sich in seiner vermeintlichen oder tatsächlichen „persönlichen geistlichen Grundhaltung“ ausdrückt, stellt sich als „Zeugnis minoritischer Seelsorge wie individueller franziskanischer Frömmigkeit“ dar: „Lamprecht identifiziert sich selbst mit Franziskus, bevor er ihn seinen Lesern als Identifikationsfigur anbietet.“253 Damit steht er exemplarisch für den „geistesgeschichtlichen Prozess der Verinnerlichung, Individualisierung und einer wachsenden religiösen Unmittelbarkeit im Gottesverhältnis" und fraglos gilt das auch dann, „wenn es sich bei den Passagen persönlicher Betroffenheit und Identifi-

253 Cornelius Bohl: Belehren und Bekehren. Das Sante Francisken leben des Lamprecht von Regensburg als Zeugnis franziskanischer Bildung, Seelsorge und Frömmigkeit Mitte des 13. Jahrhunderts in Deutschland. In: Europa und die Welt in der Geschichte. Festschrift zum 60. Geburtstag von Dieter Berg. Hrsg. von Raphaela Averkorn. Bochum 2004, S. 574-592, hier S. 589. 
kation um bewusst als literarisches Mittel eingesetzte fiktionale Beschreibungen handelt".254

Das zeigt sich gerade in der kunstvollen Gestaltung des Prologs, der in der Gegenüberstellung von echter Weisheit und der Dürftigkeit unsrer broeden menschheit (SFL 6) die grundlegende Dichotomie von Gott und Welt herausarbeitet. Diese überwindet er sodann in Franziskus als dem erklärten Vorbild für geistliches Leben und die Abkehr von allem Weltlichen und gibt damit zugleich ein „Gegenbeispiel zu den Menschen, die nicht an die Erlösung denken“"255:

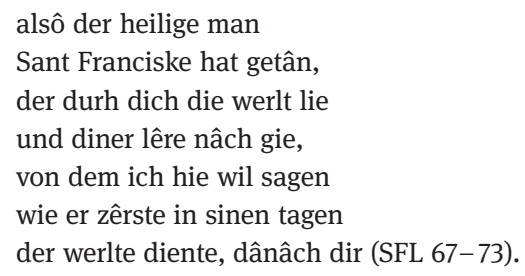

Die Bekehrung aus dem weltlichen Leben in die Nachfolge Christi, die Franziskus zum Heiligen gemacht hat, soll die Umkehr des Erzählers aus den eigenen sündhaften Verstrickungen garantieren, indem er nicht nur Gott darum bittet:

durh in, herre, hilf mir

mit dînes geistes lêre,

daz ich mich bekêre

mit riuwe von der missetât,

die mîn lîp begangen hat, (SFL 74-78)

sondern auch den Heiligen selbst als Mittler und Fürsprecher anruft:

sant Francisk ich bite dich

durh die grozen heilekeit,

die got an dich hat geleit,

daz du got bites umbe mich,

daz er min leben kere an sich. (SFL 83-87)

Indem die Rollen von Autor und Erzähler in dieser Inszenierung zusammenfallen, steht Lamprecht stellvertretend für sein Publikum, das er nicht nur belehren, sondern bekehren, also mit seinem eigenen Beispiel persuasiv bewegen will, das eigene Ver-

254 Ebd., S. 590. Denn eine „Mentalitätsgeschichte der Individualität“ lässt sich immer nur schreiben als die ihrer vor allem narrativen Inszenierung. Zur Bedeutung Lamprechts für eine solche vgl. auch Heinzle, Art. Lamprecht von Regensburg, Sp. 523.

255 Wolf, Beobachtungen zum Franziskusleben Lamprechts von Regensburg, S. 161. Wolf spricht von zwei „Isotopieebenen“, die in funktionaler Opposition zueinander stehen (S.160 - 162), der Bereich der imitatio Christi löst im Beispiel des heiligen Franziskus den der Welt ab. 
halten entsprechend zu gestalten. ${ }^{256}$ Daher beschließt er die Legende mit einem Gebetsruf, der das im gläubigen Mitvollzug vereinte Publikum auf die imitatio des Heiligen und damit die imitatio Christi verpflichtet:

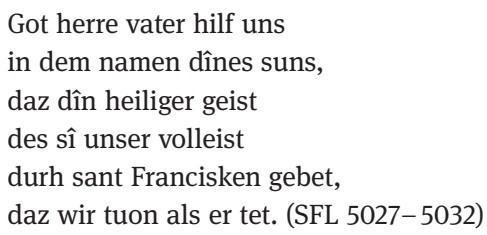

Aufschlussreich ist diese erste mittelhochdeutsche Franziskuslegende aber nicht nur hinsichtlich dieser frömmigkeitsgeschichtlichen Aspekte, sondern auch für das Selbstbild der Franziskaner wie für ihre Fremdwahrnehmung in der ersten Hälfte des 13. Jahrhunderts. Denn Lamprechts „Stellung zwischen den Franziskanern und der Laienwelt“ lässt sich auf zweifache Weise deuten: „[E]rstens ist seine Schrift eine Bewerbung, die ihn als Ordensmitglied empfehlen soll“, und dazu muss er, selbst wenn man diese biographische Aussage als Inszenierung versteht, „die Haltung des Ordens getreu widerspiegel[n]“, und [z]weitens ist Lamprecht als Nicht-Franziskaner vertrauter mit der Laienwelt“ als andere franziskanische Autoren wie Berthold von Regensburg und David von Augsburg. ${ }^{257}$ In diesem Kontext stellen die Episoden der vom Wunsch nach dem Martyrium bestimmten missionarischen Aufbrüche in den Orient und der Predigt vor dem Sultan ein selbstverständliches Element minoritischer Identität sowie des Franziskusbildes auch im deutschsprachig-laikalen Bereich dar. In enger Anlehnung an seine lateinische Quelle formuliert Lamprecht über den ersten Versuch des Heiligen, in den Orient zu gelangen:

in dem sehsten jâr sîner bekêre

gerte er der marter sêre.

des wolt er gein Syrie kêren

über mer und wolt dâ lêren

die heiden kristenlîche ê. (SFL 2266-2270)

Die Verbindung von Martyrium und Mission scheint keiner weiteren Begründung, das Streben nach ersterem keiner Problematisierung bedürftig, und so heißt es beim zweiten Versuch in schlichter Konzentration der lateinischen Prosa auf Versmaß: ze der marter strebte doch sîn ger: / durh daz sô wolde er / ze Marroch nâch der marter pîne (SFL 2330 -2332). Und wo es bei Thomas im Zusammenhang des dritten Aufbruchs in den Orient bildhaft umschreibend heißt, es habe Franziskus keine Ruhe gelassen, mit

256 Vgl. ebd., S. 165.

257 Christine Grieb: Die Selbst- und Fremdwahrnehmung der Franziskaner. Mendikantische Vorstellungen zwischen Ordensideal und Realität. Regensburg 2010 (Regensburger Beiträge zur Regionalgeschichte. 10), S. 15. Auch wenn der Status einer ,Bewerbungsschrift" kritisch zu relativieren wäre und hier auf die minoritische Identitätsbildung insgesamt angespielt wird. 
noch größerer Begeisterung auszuführen, wozu ihn „sein Herz in heiligem Drang“ trieb (1 Cel 57, 4), bringt Lamprecht es auf die Formel: mit grôzer girde sîn gedanc / noch allez zuo der marter ranc (SFL 2356-2357).

Bei der sich anschließenden Predigt vor dem Sultan folgt die mittelhochdeutsche Fassung treu der Vorlage. Wo aber in der lateinischen Vita das Kapitel der Orientreise mit dem objektivierenden Erzählerkommentar schließt, der Herr habe seinen Heiligen der besonderen Gnade der Stigmatisation aufgespart, ist diese Erklärung bei Lamprecht noch einmal an dessen Streben nach dem Martyrium gebunden:

swie gerne er hæte gesehen,

daz er gemartert wære

durh ein besunder mære,

sôn liez ez got niht geschehen,

des wir vür wunder müezen jehen. (SFL 2396-2400)

Der heilige Ordensgründer erscheint also auch in dieser ersten deutschsprachigen Franziskuslegende als Vorbild apostolischen Lebens und missionarischer Sendung, nur dass das Streben nach dem Martyrium gegenüber der Vita prima noch viel unproblematischer und expliziter zu diesem Ideal gehört. Allerdings scheint das Sante Francisken leben keine weitere Verbreitung gefunden $\mathrm{zu}$ haben. Es ist nur in einer einzigen Handschrift aus dem 13. Jahrhundert überliefert, was sich vermutlich aus dem bald folgenden Verbot der Vita prima erklärt, und bleibt damit ein punktuelles Rezeptionszeugnis. Das Franziskusbild wird in der Folge bestimmt werden durch das der Legenda maior, die auch die Konfrontation mit den Heiden in anderer Weise akzentuiert.

\subsubsection{Franziskus als religiöser Charismatiker in der Konfrontation mit den Heiden}

Die zweite große Lebensbeschreibung des heiligen Franziskus verfasst der im 15. Jahrhundert ebenfalls heiliggesprochene Bonaventura, zu diesem Zeitpunkt bereits Generalminister der Franziskaner, zwischen 1260 und 1263 im Auftrag des Generalkapitels. Seine Legenda maior wird das Franziskusbild maßgeblich prägen, allein schon deshalb, weil das Generalkapitel 1266 anordnet, dass alle vorherigen Franziskusviten im und, wo man ihrer habhaft werden könne, auch außerhalb des Ordens zu vernichten seien. Ganz offensichtlich geht es dabei um die Deutungshoheit angesichts veränderter institutioneller Bedingungen und funktionaler Ansprüche an das Bild des Ordensgründers, und das zeigt sich gerade an der Inszenierung der Episode von der Predigt des Heiligen vor dem Sultan. Auch Bonaventura stellt sie unter das Motiv glühender Gottesliebe und Martyriumssehnsucht. Doch entfaltet er dieses lyrisch und mystisch auf fast die Hälfte des insgesamt gegenüber der Vita prima fast dreifach so langen Kapitels (LM IX, 1-4), bevor er überhaupt auf die Aufbrüche des Heiligen in den Orient zu sprechen kommt. 
Bezeichnend ist dabei die Akzentuierung des Zusammenhangs von Martyriumssehnsucht und Heidenmission. Denn Letztere erscheint hier, gerade im Kontrast zur Begründung bei Thomas von Celano, als Mittel zum Zweck, wenn Franziskus ganz zum Märtyrer stilisiert wird, der in seiner glühenden Liebe dem gloriosum sanctorum Martyrum [...] triumphum nacheifert, in quibus nec amoris flamma exstingui, nec fortitudo potuit infirmari. Das Sterben für Gott wird dabei zum einzigen Zeichen der vollkommenen Liebe überhöht, quae foras mittit timorem und die Franziskus dazu treibt, per martyrii flammam hostiam Domino se offerre viventem. Schließlich soll auch nicht die Verkündigung des Glaubens im Wort, sondern ebendieses zeichenhafte Sterben die Menschen ad divinum amorem aufrufen (LM IX, 5, 1-2). ${ }^{258}$ Zwar wird seine Verkündigung nach dem ersten vergeblichen Aufbruch in den Orient als äußerst erfolgreich beschrieben, wenn er reportabat manipulos fructuosos. Doch treibt es ihn zur Lebenshingabe als dem verdienstvollsten aller Werke: Verum quia martyrii fructus adeo cor eius allexerat, ut pretiosam pro Christo mortem super omnia virtutum merita peroptaret. Daher macht er sich auf den Weg, um in Marokko das Evangelium zu predigen, si quo modo ad concupitam palmam [...] attingere (LM IX, 6, 1-3). ${ }^{259}$ Die missionarische Sendung des Heiligen wird damit seinem Streben nach dem Martyrium nachgeordnet, das allein als letztgültiges Glaubenszeugnis erscheint.

Die erfolgreiche Reise nach Syrien schließlich steigert Bonaventura in ihrer Dramatik, indem er die narrativen Strukturen und Motive der Märtyrerlegenden weiter auf die darin angelegte religiöse Konfrontation hin verdichtet. So betont er die Lebensgefahr, der sich Franziskus schon bei der Überschreitung der feindlichen Linien von Christen und Heiden ausgesetzt habe, zumal der Sultan das edictum crudele erlassen habe, ut quicumque caput alicuius Christiani afferret, Byzantium aureum pro mercede reciperet (LM IX, 7, 4). ${ }^{260}$ In dieser auf eine gewaltsame Entladung des religiösen Konfliktes konzentrierten Szenerie rühmt der Erzähler den Todesmut des Heiligen, der hier, wohlgemerkt auf dem Schlachtfeld, als intrepidus Christi miles, als „unerschrockener Ritter Christi“ (LM IX, 7, 5), bezeichnet wird, dessen Kampf aber keiner mit irdischen Waffen ist, sondern der geistliche des Märtyrers in der Nachfolge Christi. Denn als ihm und seinem Mitbruder, der hier bei Bonaventura den im Hinblick auf die „glühende“ Gottesliebe des Heiligen und die folgende Feuerprobe den sprechenden

258 „In seiner glühenden Liebe verlangte er nach dem herrlichen Sieg der heiligen Märtyrer, in denen die Flamme der Liebe nicht ausgelöscht und die Tapferkeit nicht gebrochen werden konnte. Erfüllt von jener vollkommenen Liebe, die alle Furcht vertreibt, verlangte auch er danach, sich dem Herrn in der Flamme des Martyriums als ein lebendiges Opfer darzubringen. So wollte er sich Christus, der sich für uns in den Tod hingegeben hat, dankbar erweisen und die Mitmenschen zur Gottesliebe ermuntern.“ 259 „Als er nunmehr das Meer verlassen hatte und über das Festland zog, um den Samen des Heiles dort zu säen, konnte er reiche Garben ernten. Die Frucht des Martyriums hatte jedoch sein Herz so sehr angezogen, dass er mehr als alle verdienstvollen Werke den kostbaren Tod für Christus ersehnte. Darum machte er sich auf den Weg nach Marokko, um dem Miramamolin und seinem Volke die Frohbotschaft Christi zu verkünden und, wenn möglich, die Palme des Martyriums zu erringen.“

260 „Der Sultan hatte das grausame Edikt erlassen, wer ihm das Haupt eines Christen bringe, solle als Lohn ein byzantinisches Goldstück erhalten.“ 
Namen „Illuminatus“ erhält, auf dem Weg zu den Heiden zwei Schäflein begegnen, spricht Franziskus voll Freude, an ihnen werde sich erfüllen, was der Herr bei der Aussendung der Zwölf seinen Aposteln zugesagt habe, nämlich, mit wörtlichem Zitat aus dem Evangelium: „Ecce ego mitto vos sicut oves in medio luporum.“ (LM IX, 8, 2)

Und als sie schließlich auf sarazenische Soldaten stoßen, heißt es ganz in Erfüllung dieses Motivs, dass diese die servos Dei feraliter ergreifen, tamquam lupi celerius accurrentes ad oves (LM IX, 8, 3), ${ }^{262}$ sie mit Grausamkeit und Verachtung behandeln, sie schmähen, schlagen, fesseln und erst solchermaßen übel zugerichtet vor den Sultan bringen. Dieser ist zunächst einmal recht wertfrei gezeichnet, wenn er die beiden Brüder fragt, wer sie gesandt habe und warum sie zu ihm gekommen seien. Im Fokus steht vielmehr Franziskus, der freimütig bekennt, ,non ab homine, sed a Deo altissimo se fuisse transmissum, ut ei et populo suo viam salutis ostenderet et annuntiaret Evangelium veritatis“ (LM IX, 8, 5). ${ }^{263}$ Die Unerschrockenheit und Kraft seiner Predigt gilt dem Erzähler wiederum als Erfüllung einer Verheißung Christi im Evangelium: ego enim dabo vobis os et sapientiam, cui non poterunt resistere et contradicere omnes adversarii vestri $(\mathrm{Lk} 21,15) .{ }^{264}$ Auch der Sultan habe aber admirandum in viro Dei fervorem spiritus [...] et virtutem erkannt, ihm gern zugehört und gedrängt, länger bei ihm zu bleiben (LM IX, 8, 7). ${ }^{265}$

Soweit bewegt sich die Darstellung Bonaventuras im Rahmen des bei Thomas von Celano Vorgegebenen, gänzlich neu ist hier aber das Motiv der Feuerprobe, als zeichenhafte Konkretion der ,glühenden', zur völligen Hingabe bereiten Martyriumsbereitschaft des Heiligen. ${ }^{266}$ Auf göttliche Eingebung hin habe dieser dem Sultan angeboten, mit einem der sarazenischen Geistlichen ins Feuer zu gehen, damit er dadurch erkennen möge, quae fides certior et sanctior non immerito tenenda sit, und sich vom legem Mahumeti abwende (LM IX, 8, 9). ${ }^{267}$ Den muslimischen Fürsten lässt Bonaventura angesichts dieses Ansinnens aber antworten, es finde sich wohl keiner seiner Priester bereit, propter fidem suam defensandam exponere, vel genus aliquod subire tormenti (LM IX, 8, 10), ${ }^{268}$ weil er bemerkt, wie sich ein hochrangiger Priester auf die Worte des Heiligen bereits aus dem Blickfeld entfernt hat. Und auch das Angebot des Heiligen, allein durchs Feuer zu gehen, wenn der Sultan ihm verspreche, sich mitsamt seinen Untertanen zu bekehren, wenn er unversehrt herauskomme, habe

261 „Siehe, ich sende euch wie Schafe mitten unter die Wölfe.“ (Mt 10, 16)

262 „Wie Wölfe sich auf Schafe stürzen, so ergriffen sie die Diener Gottes.“

263 „Da gab der Diener Christi Franziskus freimütig zur Antwort, nicht Menschen, sondern Gott, der Allerhöchste, habe sie gesandt, damit er ihm und seinem Volke den Weg des Heiles zeige und das wahre Evangelium verkünde.“

264 „Denn ich will euch Mund und Weisheit geben, der alle eure Gegner nicht widerstehen noch widersprechen können.“

265 „[D]ie wunderbare Glut und Kraft des Geistes bei dem Gottesmann“.

266 Vgl. Tolan, Saint Francis and the Sultan, S. 129.

267 „[W]elchen Glauben man mit mehr Recht als sicherer und heiliger festhalten muss“.

268 „,Ich glaube nicht, dass sich einer meiner Priester bereit findet, sich zur Verteidigung seines Glaubens ins Feuer zu begeben oder irgendeine Marter auf sich zu nehmen.““ 
dieser abgelehnt, was Bonaventura damit erklärt, er wage es nicht, weil er einen Aufruhr unter seinem Volk fürchte (LM IX, 8, 14).

Gerade mit diesem Motiv hat die Episode von der Predigt des heiligen Franziskus vor dem Sultan ihre ikonographische Ausformung und weite Verbreitung gefunden, ausgehend von der Darstellung im Freskenzyklus in der Oberkirche der Basilika von Assisi, entstanden vermutlich zwischen 1295 und 1299, die das Geschehen in einer einzigen Szene symbolisch verdichtet: ${ }^{269}$ Der Heilige steht ganz im Mittelpunkt der Szene und vereint alle Bildachsen auf sich. Während er in demütiger Haltung mit der Linken auf sich selbst deutet, zeigt er mit der Rechten auf das unterhalb von ihm brennende Feuer. Der Sultan, den er mit gesenktem Kopf anblickt, verlängert diese Achse, indem er von seinem Thron aus mit lang ausgestrecktem Arm ebenfalls auf das Feuer weist, sein Gefolge in aufmerksamer Haltung hinter ihm, wohingegen die Gruppe von muslimischen Geistlichen auf der anderen Seite des Feuers, auf die der feste Blick des Sultans über den Kopf des Heiligen hinweg gerichtet ist, eilig aus dem Bild drängt. Dass in der Legende gar keine Rede davon ist, dass ein Feuer entzündet worden sei, mag dabei nebensächlich sein: „This story, with its powerful visual image of the ordeal by fire, became the favourite version of later medieval hagiographers and mural painters, by whom it was repeatedly elaborated with a good deal of fantasy. “270

Und das, obwohl dieses Motiv durchaus nicht unproblematisch ist, denn schon vor dem 13. Jahrhundert waren Gottesurteile umstritten, auf dem 4. Laterankonzil 1215 wurden sie schließlich ganz verboten, und sie waren ohnehin nur einem Priester vorbehalten gewesen - ein solcher aber war Franziskus definitiv nicht. ${ }^{271}$ So unterstreicht die Feuerprobe auf eindrückliche Weise die Exzeptionalität dieses Heiligen, der

sich sogar auf dem Grenzgrat kirchenrechtlicher Orthodoxie bewegen und sich das anmaßen [darf], was weit über das in Theologie, Recht und Kult Übliche hinausging. Er kann sogar priesterliche Handlungen zelebrieren, auch wenn er überhaupt keinen Weihegrad besitzt, ja sogar beanspruchen, Prüfinstanz sakraler Wahrheitsfindung zu sein. ${ }^{272}$

Andererseits erlaubt die Feuerprobe eine besonders prägnante Umdeutung der Erfolglosigkeit seiner Predigt: Auch wenn sich die Heiden nicht bekehren, beweist der Heilige zeichenhaft die Überlegenheit des christlichen Glaubens, indem er die muslimischen Geistlichen beschämt und die Bewunderung des Sultans gewinnt, der sich zwar nicht bekehrt, immerhin aber Franziskus gebeten habe, ut praedicta susciperet pro salute ipsius Christianis pauperibus vel ecclesiis eroganda, was dieser freilich ab-

$269 \mathrm{Zu}$ dieser Darstellung vgl. Tolan, Saint Francis and the Sultan, S. 136-146.

270 Maier, Preaching the Crusades, S. 13.

271 Jürgen Werinhard Einhorn: Franziskus und der ,edle Heide‘. In: Text und Bild. Aspekte des Zusammenwirkens zweier Künste in Mittelalter und früher Neuzeit. Hrsg. von Christel Meier, Uwe Ruberg. Wiesbaden 1980, S. 630 -650, hier S. 643.

272 Müller, Bettelmönche in islamischer Fremde, S. 195. 
gelehnt habe, quia pondus fugiebat pecuniae et in animo Soldani verae pietatis non videbat radicem (LM IX, 8, 17-18). ${ }^{273}$

Seine eigentliche Bedeutung findet diese Erzählung damit nicht als Modell erfolgreicher Mission, sondern als Teil des christlichen Heiligkeitsdiskurses in der Abgrenzung vom Heidentum identitätsstiftend nach innen: Die Begegnung des Heiligen mit dem Sultan ist ein weiterer paradigmatischer Erweis der exorbitanten Heiligkeit des Franziskus, sie liegt in einer Linie mit seinem Streben nach dem Martyrium, das sich in der Stigmatisation vollenden wird. Damit wird das, was schon bei Thomas von Celano narrativ angelegt ist, insgesamt dramatisch zugespitzt auf das Motiv des Martyriums beziehungsweise dessen Abweisung und Übererfüllung hin:

Die Predigt vor dem Sultan erscheint [...] als Höhepunkt einer Entwicklung, die sich zuvor in den beiden vergeblichen Versuchen des Heiligen, das Martyrium zu erlangen, niederschlägt. Sie bringt dem Heiligen die offenbar gewissermaßen endgültige Erkenntnis, daß das Martyrium für ihn nicht vorgesehen sei. ${ }^{274}$

Denn nicht die bloße Erfolglosigkeit seiner Predigt, sondern erst eine göttliche Offenbarung, so schildert es der Erzähler, kann Franziskus dazu bewegen, heimzukehren: Videns etiam, se non proficere in conversione gentis illius nec assequi posse propositum, ad partes fidelium divina revelatione praemonitus remeavit (LM IX, 9, 1). ${ }^{275}$ Zugleich wird die signifikante Umbesetzung des Martyriumsbegriffs im Motiv der Stigmatisierung in der Legenda maior noch expliziter gemacht, wenn es heißt, ut et merito non careret optati martyrii es insigniendus servaretur in posterum privilegio singulari (LM IX, 9, 2). ${ }^{276}$ Er bleibt am Leben und kann dennoch als Märtyrer gelten.

Bonaventuras Ausgestaltung der Szene von Franziskus vor dem Sultan, als Urbild der franziskanischen Heidenmission, markiert damit einen Wandel im missionarischen Ansatz des Minoritenordens, der seiner zunehmenden kirchlichen Einbindung und institutionellen Ausformung entspricht. Bereits 1220, nach seiner Rückkehr aus dem Heiligen Land, zieht sich Franziskus von der Leitung des Ordens zurück, der in der Folge eine umfassende Disziplinierung und Klerikalisierung erfährt. Bestand die

273 „Er wollte zwar den christlichen Glauben nicht annehmen oder wagte es vielleicht nicht; doch bat er den Diener Christi inständig, er möge zum Heil seiner Seelen diese Gaben nehmen und für die christlichen Armen oder die Kirchen verwenden. Weil aber Franziskus die Last des Geldes floh und weil er erkannte, dass die wahre Frömmigkeit im Herzen des Sultans noch nicht Wurzeln geschlagen hatte, lehnte er dieses Angebot ab.“

274 Achim Wesjohann: Mendikantische Gründungserzählungen im 13. und 14. Jahrhundert. Mythen als Element institutioneller Eigengeschichtsschreibung der mittelalterlichen Franziskaner, Dominikaner und Augustiner-Eremiten. Berlin 2012 (Vita regularis. Abhandlungen. 15), S. 268.

275 „Da er nun sah, er werde weder die Bekehrung des Volkes erreichen noch die Erfüllung seines Wunsches erlangen, kehrte er, durch eine Offenbarung Gottes dazu gemahnt, in die Länder der Gläubigen zurück.“

276 „Aufgrund seines Verlangens sollte er das Verdienst des ersehnten Martyriums erhalten und zugleich am Leben bleiben, um später einer außergewöhnlichen Gnade gewürdigt zu werden.“ 
Gemeinschaft bislang vor allem aus Laien mit geringem Bildungsstand, so treten nun vermehrt junge und gebildete Kleriker in den Orden ein und bestimmen seine Entwicklung. ${ }^{277}$ Dieser soziologische Strukturwandel schlägt sich in der rechtlichen Ausformung nieder, die sich stärker an Organisation und Struktur der alten Orden orientiert und zur päpstlichen Approbation der Ordensregel im Jahr 1223 führt, und in der Abkehr von den bisherigen Vorbehalten gegenüber Bildung und Wissenschaft, die das minoritas-Ideal im Geiste des Gründers umfasste:

Seit den 30er Jahren wurde der ordo minorum nicht mehr nur durch die einfachen Brüder repräsentiert, die als minores in einfachen Behausungen lebten und ihren Mitmenschen ein Exempel christlicher Existenz boten. Gebildete Minoriten wurden nun vom Papsttum zu Gesandtschaften in politischer Mission, zur Reform des kirchlichen Lebens und zur Lehre an Schulen und Universitäten eingesetzt. ${ }^{278}$

In diesem Strukturwandel spielt nicht zuletzt die Einsicht in die Notwendigkeit theologischer Bildung für die Predigt- und Missionstätigkeit des Ordens eine entscheidende Rolle und das wirkt sich natürlich unmittelbar auf die franziskanischen Missionsmethoden aus: Zwar gibt es die urfranziskanische Missionsform, die fast zwangsläufig zum Martyrium führt, als ,private‘ Unternehmung weiterhin, doch unterstellen sich die gebildeten Franziskaner, die nun die missionarischen Aktivitäten des Ordens tragen, dem Schutz und der Förderung des Papstes. Seit 1225 gewähren ihnen zahlreiche päpstliche Schutzschreiben Privilegien in der Mission, wie die Dispens von wichtigen Vorgaben der Regeln, die das Leben unter den Heiden erleichtern sollte, sowie eine leichtere Gründung eigener Niederlassungen. ${ }^{279}$

Auch die Missionstechniken und -strategien wandeln sich dabei: „Nun war weniger das existentielle Beispiel gefragt, als eine solide theologische Bildung und die Fähigkeit zur Disputation." ${ }^{280}$ Der Orden verabschiedet sich in der Folge von der Mission im islamischen Herrschaftsgebiet, zumindest im Heiligen Land, widmet sich dafür der pastoralen Tätigkeit in den Kreuzfahrerstaaten und der Mission von Muslimen unter christlicher Herrschaft. ${ }^{281}$ Sein missionarisches Wirken erfährt schließlich eine kirchenpolitische Funktion, als im Rahmen der freilich erfolglosen ,Missionskampagne، von 1233 Franziskaner im offiziellen päpstlichen Auftrag in den Orient gesandt werden, um muslimischen Fürsten Briefe zu überbringen, in denen Gregor IX. sie auffordert, den christlichen Glauben anzunehmen. ${ }^{282}$ Dazu finden die Franziskaner ihre Aufgabe nun gerade auch als Kreuzzugsprediger, die zum Kampf gegen die

277 Vgl. Berg, Kreuzzugsbewegung und propagatio fidei, S. 65-66.

278 Ebd., S. 66.

279 Vgl. ebd., S. 66-67.

280 Ebd., S. 67.

281 Vgl. ebd.

282 Vgl. ebd., S. 68. 
Muslime aufrufen, neue Kämpfer werben und bestärken, was nicht in Gegensatz zu den missionarischen Bemühungen steht, die ungebrochen weiter betrieben werden. ${ }^{283}$

Bescheidene Erfolge in der eigentlichen Mission unter Muslimen erzielen die Franziskaner nur dort, wo das muslimische Herrschaftssystem nicht geschlossen ist, wie in Nordafrika, insgesamt aber entwickelte sich die franziskanische Sarazenenmission seit der Mitte des 13. Jahrhunderts nicht weiter und verliert mit dem Niedergang der Kreuzfahrerstaaten im Orient ihre Grundlage. ${ }^{284}$ Diese ernüchternde Bilanz der franziskanischen Missionsbemühungen erklärt sich nicht nur aus den äußeren Bedingungen, sondern auch daraus, dass es den Franziskanern, im Gegensatz zu den Dominikanern und trotz aller dem entgegengesetzten Bestrebungen, an einer tiefgreifenderen theoretischen Fundierung der Mission, an Sprachkenntnissen und Wissen über die Inhalte des islamischen Glaubens fehlt. Die Impulse Robert Bacons und Ramon Llulls bleiben letztlich vergeblich und entfalten keine Breitenwirkung, weil sie auf die im Orden weiterhin verbreitete Skepsis gegenüber der Berechtigung säkularwissenschaftlicher Studien stoßen. ${ }^{285}$

Die aus dieser Erfolglosigkeit herrührende „resignative-negative Haltung der Mendikanten in Theorie und Praxis der Heidenmission“ mag sich auch in der entsprechenden Darstellung der Muslime in den Franziskusviten sowie den historiographischen Werken, die sich mit dem Minoritenorden befassen, niederschlagen: Denn diese erscheinen schematisch negativ nur im Kontext der militärischen Konfrontation der Kreuzzüge, als widerrechtliche Usurpatoren der heiligen Stätten und im tödlichen Kampf gegen die Christen, und eben im Zusammenhang mit der Orientreise des Ordensgründers im Zeichen der Martyriumssehnsucht. ${ }^{286}$ Allerdings entspricht diese Inszenierung den hagiographischen Mustern der Märtyrerlegende und ganz offensichtlich schreibt nicht nur Franziskus sich in diese ein, sondern seine Biographen tun es ihm gleich und sind darin letztlich noch konsequenter und erfolgreicher. ${ }^{287}$ Die negative Zeichnung der Heiden ist also weniger als Ausdruck eines Wandels vom hoffnungsvollen missionarischen Aufbruch in der Frühzeit des Ordens zum hergebrachten Muster religiöser Konfrontation im Martyrium angesichts der ernüchternden Erfolglosigkeit dieser Bemühungen, sondern vor allem als Element der narrativen Aushandlung des religiösen Gegensatzes zu verstehen.

283 Mitunter ist ein und derselbe Bruder in beiden Aufgabenbereichen aktiv, predigt den Muslimen den christlichen Glauben und ruft zum Kreuzzug gegen sie auf und begleitet einen solchen auch selber. Vgl. Kedar, Crusade and Mission, S. 138-139.

284 Vgl. Berg, Kreuzzugsbewegung und propagatio fidei, S. 69-70.

285 Vgl. ebd., S. 71-72.

286 Vgl. ebd., S. 73-74, Zitat S. 73.

287 Darauf weist Berg letztlich selbst hin, ohne die interpretatorische Konsequenz zu ziehen: „In allen Gründerviten fanden Sarazenen nur Erwähnung im Zusammenhang mit den Missionsunternehmungen des Heiligen und seinem Wunsch nach dem Märtyrertod.“ (Ebd., S. 73.) Und: „Ihr Tötungswille ist Ausdruck des verwerflichen Irrglaubens, zugleich aber die Voraussetzung für die Christen, im Martyrium Jesus nachzufolgen.“ (Ebd., S. 74.) 
Der Wandel in der missionarischen Ausrichtung des Minoritenordens, wie er sich in Bonaventuras Gestaltung der Predigt vor dem Sultan mit dem Motiv der Feuerprobe darstellt, lässt sich jedenfalls auch an der Ordensregel festmachen: Die oben zitierten Bestimmungen der Regula non bullata von 1221 zur Mission unter den Heiden zielten vor allem auf eine radikale Nachahmung Jesu, auf ein Leben als Zeugnis in einer ,Mission der Tat‘, die in ihrer Zeichenhaftigkeit selbstevident sein sollte - etwaige Probleme in der interkulturellen Verständigung und Glaubensvermittlung scheinen nicht im Horizont dieser Grundlegung, die die „Erfolgsaussichten der Mission allein in der Vorbildhaftigkeit des Missionars“ gründen lässt. ${ }^{288}$ In der Regula bullata hingegen, die wohl von Franziskus selbst, aber unter Mitwirkung des Protektors des Ordens, des späteren Papstes Gregor IX., verfasst und 1223 von Honorius III. approbiert wurde, erscheint das Kapitel zur Heidenmission erheblich gekürzt. Hier finden sich nur mehr die juristischen Bestimmungen, wonach die Brüder von ihren Oberen die Erlaubnis erbitten müssen, um „unter die Sarazenen“ gehen zu dürfen, die Oberen diese Erlaubnis aber von der Tauglichkeit der Brüder abhängig zu machen haben, wobei die permissive Tendenz der ersten Fassung einem nüchternen Verbot gewichen ist:

Quicumque fratrum divina inspiratione voluerint ire inter saracenos et alios infideles petant inde licentiam a suis ministris provincialibus. Ministri vero nullis eundi licentiam tribuant, nisi eis quos viderint esse idoneos ad mittendem (BR 12, 1-2).

Jene Brüder, die auf göttliche Eingebung hin unter die Sarazenen oder andre Ungläubige gehen wollen, sollen dazu von ihren Provinzialministern die Erlaubnis erbitten. Die Minister aber sollen nur denen die Erlaubnis zu gehen erteilen, die sie für die Mission tauglich erachten.

Die spirituelle Grundlegung der Sendung der Nachfolger Christi in der Welt und der möglichen Lebenshingabe fehlt völlig. Stattdessen folgt auf die zwei knappen Sätze, die letztlich nur den formalen Rahmen der Aussendung zur Mission abstecken, eine Verpflichtung zur völligen Unterordnung der Brüder in ihrer minoritischen Lebensweise unter die Amtsgewalt des Papstes:

Ad haec per obedientiam iniungo ministris, ut petant a domino papa unum de sancte Romanae Ecclesiae cardinalibus, qui sit gubernator, protector et corrector istius fraternitatis, ut semper subditi et subiecti pedibus eiusdem sanctae Ecclesiae stabiles in fide catholica paupertatem et humilitatem et sanctum evangelium Domini nostri Jesu Christi, quod firmiter promisimus, observemus. (BR 12, 3-4)

Außerdem verpflichte ich die Minister im Gehorsam, vom Herrn Papst einen aus den Kardinälen der heiligen Römischen Kirche zu erbitten, der diese Bruderschaft lenke, in Schutz und Zucht nehme, auf dass wir, allezeit den Füßen dieser heiligen Kirche untertan und unterworfen, feststehend im katholischen Glauben, die Armut und Demut und das heilige Evangelium unseres Herrn Jesus Christus beobachten, was wir fest versprochen haben.

288 Münkler, Erfahrung des Fremden, S. 70. 
Inhaltlich scheint dieser Abschluss des Kapitels zunächst nicht unmittelbar die Festlegungen zur Heidenmission zu betreffen und man kann ihn auch damit erklären, dass er zugleich den Abschluss der Regula bullata markiert - das Kapitel ist also von einer recht zentralen Stelle in der ersten Fassung der Regel an ihr Ende gesetzt worden. Diese Festlegungen sind aber insofern im Zusammenhang mit der missionarischen Ausrichtung des Ordens zu verstehen, als sie alle dahingehenden Bestrebungen auf die Notwendigkeit kirchlicher Sanktionierung und Legitimierung verweisen und sie damit zum päpstlichen Instrument machen. ${ }^{289}$

Der Wandel in der missionarischen Ausrichtung der Franziskaner drückt sich dabei vor allem darin aus, dass sie die Möglichkeit des Martyriums in der Mission völlig auslässt. Denn kirchlich-institutionell betrachtet muss sich das ,ufranziskanische‘ Drängen zum Martyrium als dysfunktional bis problematisch erweisen, weil es einerseits einen missionarischen Erfolg in der konfrontativen Zuspitzung des religiösen Gegensatzes noch unwahrscheinlicher macht, wie sich schon am Beispiel der franziskanischen Protomärtyrer zeigt, dabei außerdem den unter muslimischer Herrschaft lebenden Christen schadet. ${ }^{290}$ Andererseits stellt es in letzter Konsequenz eine Form der Selbstheiligung dar, die in der Gefahr steht, sich dem klerikalen Einfluss und der kirchlichen Beglaubigung zu entziehen. Daher zeigen sich Papst und Kurie sehr zurückhaltend bei der Kanonisation der franziskanischen Märtyrer, ${ }^{291}$ binden dafür die Mission ebenso wie die Kreuzzüge in die päpstliche Politik ein und fassen sie dazu in denselben theologischen Kategorien: In einer Bulle vom 4. März 1238 an die

289 Ob man die Regula bullata damit auch schon als Ausdruck einer beginnenden „Begründung operativen Wissens über die zu Missionierenden“ (Münkler, Erfahrung des Fremden, S. 71) werten kann, weil sie die ,Mission“ der Tat verabschiedet und im dortigen Kapitel De praedicatoribus auch keine Rede mehr davon ist, dass alle Brüder mit ihren Werken predigen können, sondern die Verkündigung in der Kürze und Eindringlichkeit des Wort ins Zentrum rückt, scheint allerdings fraglich, weil sich Letzteres klar auf die innerchristliche Bußpredigt bezieht: Moneo quoque et exhortor eosdem fratres, ut in praedicatione, quam faciunt, sint examinata et casta eorum eloquia, ad utilitatem et aedificationem populi, annuntiando eis vitia et virtutes, poenam et gloriam cum brevitate sermonis; quia verbum abbreviatum fecit Dominus super terram. (BR IX, 3-4) „Ich warne auch und ermahne diese Brüder, dass in der Predigt, die sie halten, ihre Worte wohlbedacht und lauter sein sollen, zum Nutzen und zur Erbauung des Volkes, indem sie zu ihnen sprechen von den Lastern und den Tugenden, von der Strafe und Herrlichkeit, und dies mit kurzen Worten, weil der Herr auf Erden sein Wort kurz gefasst hat.“

290 Vgl. Heullant-Donat, Martyrdom and Identity in the Franciscan Order, S. 435.

291 Vgl. Ryan, Missionary Saints of the High Middle Ages, S. 1-2. Die Ausbildung des Heiligsprechungsverfahrens führt insgesamt erst einmal zu einer Begrenzung von Heiligsprechungen. Im gesamten 13. Jahrhundert werden dabei nur drei Märtyrer kanonisiert: „der 1079 ermordete Erzbischof Stanislaus von Krakau, der 1252 getötete dominikanische Inquisitor Petrus Martyr von Verona und der 1208 durch Schergen des Grafen von Toulouse zu Tode gebrachte Legat Innocenz' III. gegen die Katharer im Languedoc, Petrus von Castelnau, allesamt dem Papsttum hochverbundene Männer. Die zahlreichen franziskanischen Missionare, die (oft zunächst ohne päpstlichen Auftrag) in muslimischen Ländern wirkten und dabei zu Tode kamen, wurden dagegen nicht oder erst viel später zu den Ehren der Altäre erhoben.“ Gemeinhardt, Märtyrer und Martyriumsdeutungen, S. 311. 
Dominikaner und Franziskaner gewährt Gregor IX. denjenigen Brüdern, die in der Mission unter den Muslimen im Heiligen Land aktiv sind, den gleichen Ablass, den das Vierte Laterankonzil 1215 den Kreuzfahrern gewährt hatte. ${ }^{292}$

Diese Parallele ist aber nicht allein kirchenrechtlicher Natur, sondern signifikant für die Akzentuierung von Martyrium und Mission im kirchlichen Heiligkeitsdiskurs: Wie den Kreuzfahrer nicht die Heiligkeit in Kampf oder Sterben auf dem Schlachtfeld in Aussicht gestellt, sondern ein Ablass zugesagt wird, so gilt auch die Mission nicht als Heilsweg schlechthin. Allerdings lässt sich dabei dieselbe Unschärfe in der Verwendung des Märtyrerbegriffs beobachten wie im Kreuzzugsdiskurs, wenn die Kreuzfahrer nicht im technischen Sinn, aber doch im rühmenden und propagandistischen Verständnis als Märtyrer gelten. ${ }^{293}$ So richtet zum Beispiel Innozenz IV. mehrere Bullen an die beiden großen Mendikantenorden, in denen er denjenigen Brüdern Anerkennung zollt, die im Namen Christi getötet worden sind, und seine Gewissheit bekundet, dass sie zu den Märtyrer zu rechnen sind - wobei es einen entscheidenden Unterschied darstellt, dass diese Brüder allesamt in der Bekämpfung der Häretiker den Tod finden und nicht in der Mission von Heiden. ${ }^{294}$

Die franziskanische Mission der zweiten und vor allem der dritten Generation, die seit dem Ende 13. Jahrhundert nach Asien und bis China führt, gründet aber nun ohnehin nicht mehr im Martyriumsstreben, wie es das Vorbild ihres Ordensgründers präsent hält, sondern „erringt ihre Erfolge freilich nicht zuletzt deswegen, weil sie die ursprünglichen Missionsvorstellungen des Heiligen modifiziert und ihnen eine institutionelle Basis gibt“. ${ }^{295}$ Die Heidenmission erscheint jedenfalls immer weniger als allgemeiner Grundzug franziskanischer Frömmigkeit in der konsequenten Verwirklichung der vita apostolica, sondern immer mehr als Sonderaufgabe für begabte Kleriker im Orden, ganz wie es der institutionellen Einbindung und funktionalen Indienstnahme der Minoriten innerhalb der Kirche entspricht. Damit einher geht aber auch die funktionale Ausdifferenzierung des Bilds des Ordensgründers: Franziskus selbst erscheint in der Predigt vor dem Sultan wie generell in der Legenda maior weniger als imitabile, dem alle Brüder und Gläubigen nachstreben können, sondern in seiner uneinholbaren Exorbitanz als admirabile, das demütig verehrt werden soll. ${ }^{296}$

Bonaventura, der auch als zweiter Gründer seines Orden gilt, schafft damit zwei Generationen nach den historischen Ereignissen mit seiner Franziskus-Vita ein identitätsstiftendes Bild des heiligen Ordensgründers, das diesen gewandelten Ansprüchen genügt und sie befördern kann. Sein Entwurf der Begegnung des heiligen Franziskus mit dem Sultan hält das Modell des Martyriums in der Mission zwar prä-

292 Vgl. Kedar, Crusade ans Mission, S. 142.

293 Vgl. dazu auch unten in Kap. 4.2 militia Christi - Zwischen Dulden und Streiten für Gott.

294 Vgl. Ryan, Missionary Saints of the High Middle Ages, S. 4-5 und dort Anm. 14.

295 Elm, Franz von Assisi: Bußpredigt oder Heidenmission?, S. 171.

296 Entsprechend erscheint die ,Sehnsucht nach dem Martyrium‘ bei Bonaventura als ein für Franziskus spezifisches spirituelles Streben und keines, das die Brüder teilen oder realisieren könnten. Vgl. Heullant-Donat, Martyrdom and Identity in the Franciscan Order, S. 437. 
sent, hegt das eher dysfunktionale Streben danach aber institutionell ein, indem er es als Ausdruck des unvergleichbaren Charismas des Gründers quasi transzendent setzt - und damit zugleich in seiner Problematik entschärft. ${ }^{297}$ Denn Ziel und höchste Bestätigung findet die Martyriumssehnsucht des heiligen Franziskus eben nicht im als Glaubenszeugnis verstandenen Sterben für Gott, sondern in der Stigmatisation, die ihn über alle herkömmlichen Modelle der Heiligkeit erhebt. Insofern besetzt Bonaventura mit der Feuerprobe die „Narrativierung der Mission“ in „der Überschneidung von Heilsverkündung und Selbstheiligung“, wie sie Franziskus in der Mission von Anfang an verfolgt hatte: ${ }^{298}$

Mit dieser Narrativierung rückte Bonaventura zu einem Zeitpunkt, als die beiden Mendikantenorden miteinander um die Abfassung von Missionstraktaten wetteiferten, die Zeichenhaftigkeit des Bekenntnisses, ganz wie der Ordensgründer es gefordert hatte, in den Mittelpunkt der Mission. Der Heilige überbot die Macht der Argumente, weil in ihm das überwältigende Feuer des Glaubens brannte, das ihn furchtlos vor dem Feuer machte und unerschrocken für seinen Glauben Zeugnis ablegen ließ. ${ }^{299}$

Diese Erzählung findet ihre Funktion aber eben nicht im Sinne operationalisierbaren Wissens als Modell konkreter missionarischer Aufbrüche der Minoriten, sondern in der Legitimation des Ordens über das Bild des Ordensgründers nach außen wie in den internen Streitigkeiten. Die Bedeutung der Zeichenhaftigkeit des Bekenntnisses in diesem Rahmen wird an anderer Stelle bei Bonaventura noch deutlicher: In seiner zweiten Predigt über den heiligen Franziskus, lässt er diesen, als der Sultan über den Glauben disputieren und dazu seine Weisen herbeirufen lassen will, antworten: ,Fides nostra est super rationem, et ratio non est efficax nisi credenti, et non possum arguere per sacram Scripturam, quia ipsi non credunt sacrae Scripturae ‘ (2 Bon 15, 8). ${ }^{300}$

Weil der Glaube also weder über Vernunft vermittelbar ist, noch auf Grundlage der Heiligen Schrift, wenn diese nicht schon als solche anerkennt und an sie geglaubt wird, schlägt Franziskus dem muslimischen Herrscher hier die Feuerprobe vor. Wenn

297 In ganz ähnliche Richtung weisen die grundlegenden Beobachtungen von Gert Melville zum kirchlich-institutionellen Umgang mit dem Charisma des heiligen Franziskus, das letztlich gerade nicht in der Regel des Ordens weiterlebt, sondern im überzeitlichen Modell, auf das er reduziert beziehungsweise zu dem er erhoben wird. Der Erfolg der franziskanischen Bewegung gründe also ,in der Institutionalität des selbst nicht mehr einholbaren, des entrückten und zugleich stets wieder präsent zu machenden, als Mythos reaktivierbaren“ exorbitanten und völlig singulären Heiligen. Der geteilte Franziskus. Beobachtungen zum institutionellen Umgang mit Charisma. In: Kunst, Macht und Institution. Studien zur Philosophischen Anthropologie, soziologischen Theorie und Kultursoziologie der Moderne. Festschrift für Karl-Siegbert Rehberg. Hrsg. von Joachim Fischer, Hans Joas. Frankfurt/New York 2003, S. 347-363.

298 Münkler, Erfahrung des Fremden, S. 97.

299 Ebd., S. 96.

300 Lateinischer Text nach S. Bonaventurae Opera Omnia. 9. Quaracchi 1901. „,Unser Glaube übersteigt die Vernunft, und die Vernunft kann nur den wirklich führen, der glaubt. Ich kann aber nicht die Heilige Schrift zum Beweis heranziehen, da diese nicht an die Heilige Schrift glauben.““ 
die Szene damit also zeigt, dass der Glaube über jeder menschlichen Vernunft steht, schlagen sich darin die Auseinandersetzungen innerhalb des Franziskanerordens wie innerkirchlich mit dessen Rivalen um den Stellenwert intellektueller Fähigkeiten und rationaler Argumentation in Bezug auf die christlicher Wahrheit nieder. ${ }^{301}$ Auch die besagten Missionstraktate stehen nicht einfach nur im Spannungsfeld der miteinander konkurrierenden Orden: Der franziskanische Philosoph Roger Bacon stand wegen seiner Arbeiten in Konflikt mit seinem Orden und namentlich Bonaventura und widmet sein Opus maius von 1267, in dem er sich auch mit der Mission beschäftigt, ${ }^{302}$ seinem Gönner, Papst Clemens IV.

Die Missionsreise des heiligen Franziskus wird in der Folge immer spektakulärer ausgestaltet, sie erscheint als exklusives Unterfangen, und der Eindruck, den Franziskus beim Sultan erzeugt haben soll, wird konsequent umgesetzt. In der zitierten Predigt lässt Bonaventura den Sultan auf das Angebot der Feuerprobe antworten: ,Non auderem hoc facere, quia timeo, quod mei lapidarent me; sed credo, quod fides vestra bona sit et vera', und kommentiert dieses Bekenntnis: Et ex illa hora semper habuit fidem christianam impressam in corde suo. (2 Bon 15, 11) ${ }^{303}$ Diese vorsichtige Uminterpretation der Missionsreise des Heiligen auf einen zumindest verborgenen Erfolg hin lässt sich sicher mit der spezifischen Kommunikationssituation und zielorientiertpersuasiven Funktion der Gattung der Predigt erklären. ${ }^{304}$

Aber der zugrundeliegende Anspruch findet ebenso Eingang in die Legenden des Heiligen und wird dort gar noch konkreter umgesetzt: In den Ende des 14. Jahrhunderts entstandenen italienischen Fioretti, ${ }^{305}$ die zur beliebtesten ,volkstümlichen Legendensammlung über Franziskus werden, lässt sich der Sultan später von zwei Franziskanern sogar taufen: Zunächst erlaubt er Franziskus und seinen Gefährten, deren Zahl hier wie die der Apostel mit zwölf angegeben wird, unter seinem Schutz in seinem Herrschaftsgebiet zu predigen, bis dieser sieht, „dass er in diesem Land keine Frucht mehr bringen konnte“ und „durch göttliche Offenbarung [beschloss], mit seinen Gefährten zu den Gläubigen zurückzukehren“ (Fior 24, 15). ${ }^{306}$ Beim Abschied bekennt der Sultan, dass er sich gern zum christlichen Glauben bekehren würde, sich aber fürchte, dass seine Untergebenen dann ihn wie Franziskus, der noch viel Gutes zu

301 Vgl. Tolan, Saint Francis and the Sultan 2009, S. 131-134.

302 Vgl. oben in Kap. 2.3.2 Das Verhältnis von Kreuzzug und Mission, S. 83.

303 „Ich könnte nicht wagen, so etwas zu tun, denn ich fürchte, die Meinen steinigten mich; doch glaube ich, dass euer Glaube gut und wahr ist. Und von jener Zeit an blieb der christliche Glaube immer seinem Herzen eingeprägt.“

304 „Erinnert man sich an Bonaventuras frühere Bemerkung, im Herzen des Sultans habe der wahre Glaube keine Wurzel fassen können, so gewinnt man den Eindruck, daß sich Bonaventura in der Gattung Predigt vom Adressatenbezug und Ziel der Unterweisung leiten ließ und so der Begegnung mit dem Sultan einen gewissen Erfolg sichern mußte.“ Einhorn, Franziskus und der ,edle Heide‘, S. 643. 305 Eine Übertragung der lateinischen Actuum Beati Francisci, vgl. oben Anm. 243.

306 „Alla perfine, veggendosi santo Francesco non potere fare più frutto in quelle part, per divina rivelazione si dispuose con tutti i suoi compagni a ritornare tra i fedeli“. Zitiert nach: I Fioretti di San Francesco. Hrsg. von R. Pratesi, G. Sabatelli. Florenz 1982, S. 106. 
tun habe, und seine Gefährten umbringen würden. Franziskus verspricht ihm daraufhin, nach seinem Tod vom Himmel aus zwei seiner Brüder zu ihm schicken, von denen er die Taufe empfangen solle, bis dahin möge er sich ganz frei machen für die Gnade Gottes. Als der Sultan nach einigen Jahren krank wird, so heißt es weiter, erfüllt sich diese Verheißung: „Dann empfing er von jenen Brüdern die Unterweisung im Glauben an Christus und die heilige Taufe. Auf diese Weise in Christus wiedergeboren, starb er an jener Krankheit und seine Seele wurde durch die Verdienste und das Wirken des heiligen Franziskus gerettet.“ (Fior 24, 25)

Die Bekehrung des heidnischen Herrschers ist also nicht nur und gar nicht so sehr das Ergebnis einer besonderen Vorbildhaftigkeit des apostelgleichen Franziskus, sondern vor allem Ausdruck und Beglaubigung seiner göttlichen Begnadung und Wirksamkeit als Heiliger, der selbst wundersam aus der Transzendenz in die Immanenz hineinwirkt und für die Aufnahme des Sultans in die Gemeinschaft der Gläubigen sorgt. Aber schon zuvor vermag er den religiösen Gegensatz zum Heidentum ebenso wie die Grenze zur Transzendenz zu überwinden, wenn er ,den Glauben, der alle Vernunft übersteigt', allein durch sein Auftreten wirksam werden lässt. Damit schließlich eignet er sich nicht mehr zum konkreten Vorbild der missionarischen Sendung aller Gläubigen in die Welt: „Heiligkeit sogar kulturübergreifend darstellen zu können, war ein dem Charismatiker vorbehaltenes Privileg. “308 Die heimliche oder tatsächliche Konversion des Sultans bleibt in dieser Narrativierung der Mission fromme christliche Fiktion oder besser: narrative Funktion, die sich nicht als Ergebnis der missionarischen Wirksamkeit einer apostolischen Lebensweise verstehen lässt, sondern als Erweis des außergewöhnlichen Charismas des heiligen Ordensgründers.

307 „Ricevendo adunque informazione della fede di Cristo, e il santo battesimo da’ detti frat, così rigenerato in Cristo si morì in quella infermità, e fu salva l'anima sua pei meriti e operazione di santo Francesco.“ Ebd., S. 107.

308 Müller, Bettelmönche und Islam, S. 294. 